أثر حوكمة الثركات علي العلاقة بين الثقة الإدارية المفرطة والسلوك غير المتماثل للتكلفة (دراسة إختبارية )

د/ أحمد بغدادي أحمد بغدادي (**)

(*) محمد محمود سليمان محمد

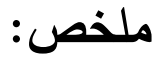

يهدف هذا البحث إلي دراسة العلاقة بين الثقة الإدارية المفرطة وعدم التماثل في سلوك

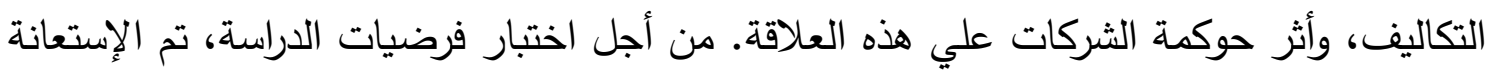
بعينة من الثركات غير المالية المدرجة بالسوق المصري للفترة من عام 2010 حتي عام 2018 بإجمالي مشاهدات 954، وتوصلت النتائج إلي وجود علاقة معنوية موجبة بين الثقة الإدارية

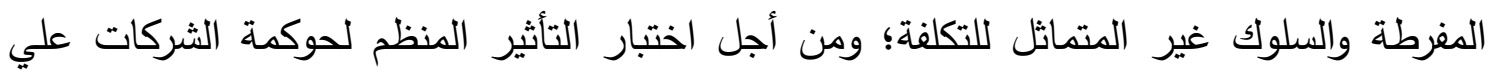

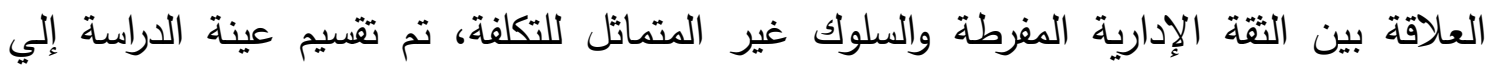

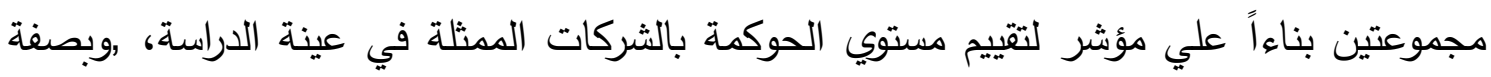
عامة فإن نتائج الدراسة تثير الي أن حوكمة الثركات تنظم العلاقة بين الثقة الإدارية المفرطة

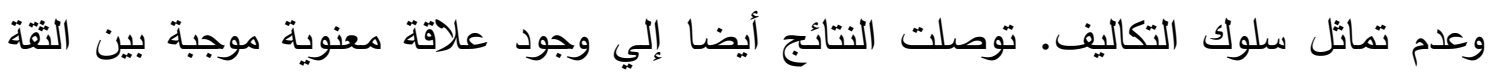
الإدارية المفرطة والسلوك غير المتماثل للتكاليف في الثركات ذات الحوكمة الضعيفة؛ بينما أثارت النتائج إلي عدم وجود علاقة بين الثقة الإدارية المفرطة والسلوك غير المتماثل للتكاليف في الثركات ذات الحوكمة القوية .

الكلمات الدالة: الثقة الإدراية الدفرطة، عدم التماثل في سلوك التكاليف، لزوجة التكلفة، حوكمة الشركات.

مدرس بقسم المحاسبة كلية التجارة - جامعة الزقازيق ،

Mohamed.m gh@zu.edu.eg

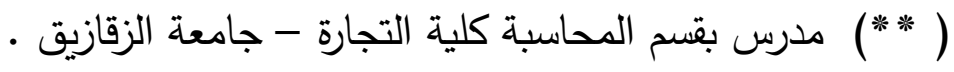

Baghdady 100@hotmail.com 


\title{
The impact of Corporate Governance on the Relationship
} between Managerial Overconfidence and Asymmetric Cost Behavior: "An Empirical Etudy" Mohamed M. Soliman

Lecturer, Department of Accounting Facullty of Commerce, Zagazig University, Egypt

Ahmed B. A. Baghdady

Lecturer, Department of Accounting

Facullty of Commerce, Zagazig University, egypt

\begin{abstract}
:
This study investigates the relationship between managerial overconfidence and asymmetric cost behavior and the effect of corporate governance on this relationship. Using a sample of non-financial companies listed on Egyptian stock exchange over the period from 2010 to 2018, with 954 firm-year observations.

The results show a significant positive relationship between managerial overconfidence and asymmetric cost behavior. In order to test the moderation effect of corporate governance on the relationship between asymmetric cost behavior and managerial overconfidence, the study sample was divided into two groups based on corporate governance index. In general, the results suggest that the corporate governance moderates the relationship between managerial overconfidence and asymmetric cost behavior.
\end{abstract}

The results also show a significant positive relationship between managerial overconfidence and asymmetric cost behavior in companies with weak corporate governance, while there is no relationship between managerial overconfidence and asymmetric cost behavior in companies with strong corporate governance.

Keywords: Managerial overconfidence; asymmetric cost behavior; cost stickiness, corporate governance 
يعتبر السلوك البشري محصلة لتفاعل العديد من العوامل والمؤثرات المحيطة بالثخص

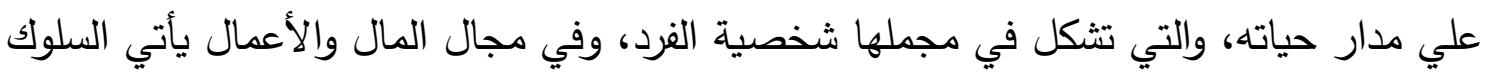

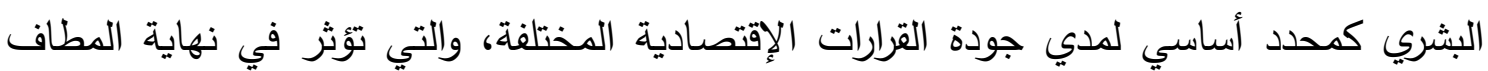

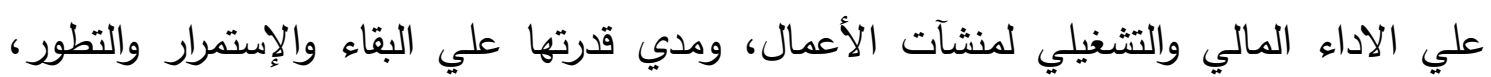

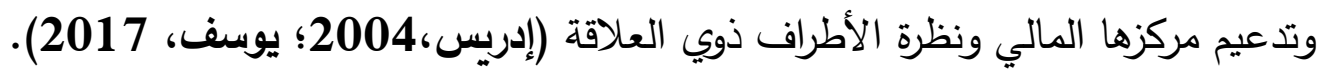

وتتتوع سلوكيات المديرين اتجاه نفس القرار الإقتصادي، ويرجع ذلك إلي إختلاف النشأة

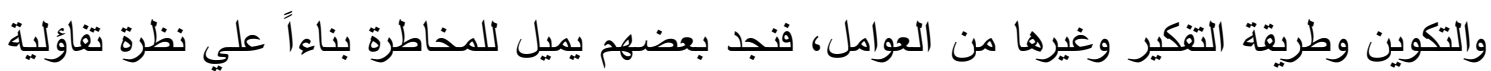
نابعة من طبيعته الثخصية في الأساس، وعلي النقيض نجد البعض الآخر يميل إلي التحفظ بناءاً

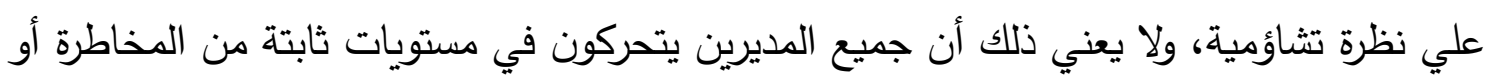

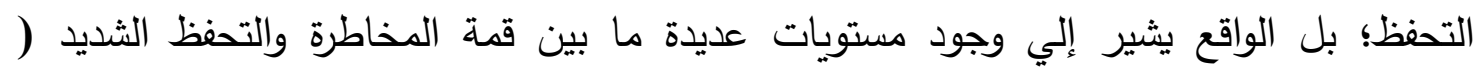

.(Ben-david et al., 2007 ؛Margolin, 2012

يقبل الددير المخاطر بشكل عام علي المواجهة والتحدي، وتنعكس آثار ذلك بالضرورة

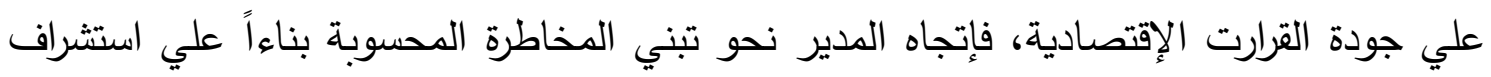

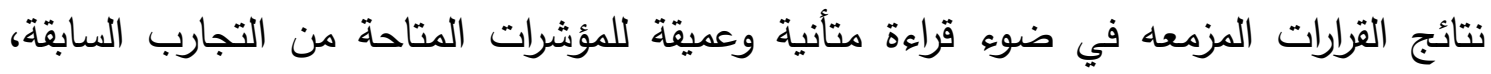

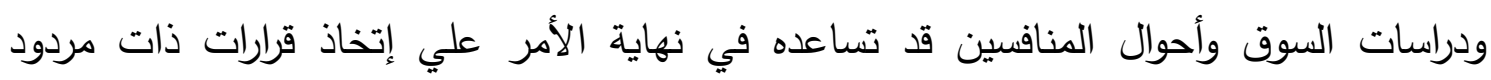

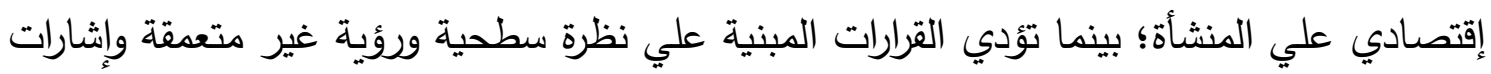
ضعيفة حول النجاح في المستقبل إلي نتائج كارثية قد تهدد قدرة المنشأة علي الإستمرار

والتطور (Felong et al., 1990؛ Goel and Thakor, 2008 ؛ (Fairchild, 2009 ( وتتبع النزعة نحو المخاطرة من تبني المدير لنظرة تفاؤلية حيال المستقبل، وإن كان ذلك إنكان

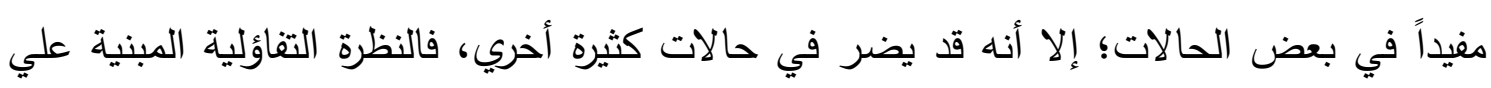

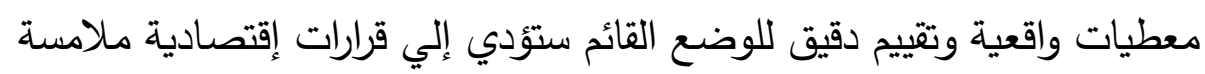
للواقع، وبالتالي تتحقق التوقعات حيال المستقبل، والتي بني علي أساسها القرار الإقتصادي؛ بينما تؤدي النظرة التفاؤلية المبنية علي تقديرات غير دقيقة حول حلئل الإمكانيات الحالية 
والقدرة علي مواجهة الأحداث المستقبلية أياً كانت طبيعتها إلي قرارات إقتصادية ذات مردود سلبي،

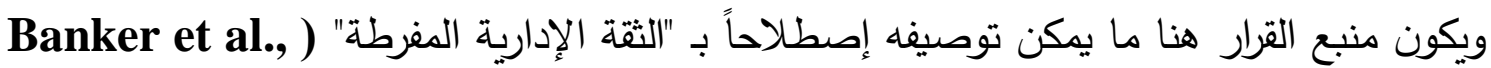
.Chen et al., 2018 2014 تعد الثقة الإدارية أحد العوامل السلوكية التي نالت الإهتمام في العديد من البحوث والدراسات في مجال الأعمال بشكل عام، فنجد تعدد وتتوع الكتابات في مجال التمويل السلوكي والإقتصاد السلوكي حول التأثيرات المتوقعة للعوامل السلوكية علي ألئ أداء منشآت الأعمال، ونظراً

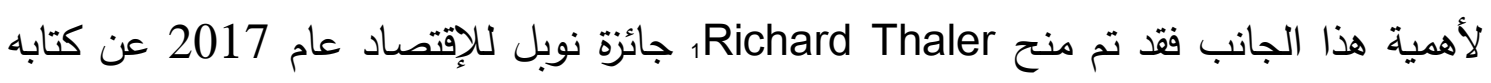
الإقتصاد السلوكي Behavior Economics (الجبوري، 2014).

وتقدم نظرية التمويل السلوكي تفسيراً للتصرفات غير العقلانية المتكررة التي يقوم بها المديرين عند إتخاذ القرارات الإستثمارية، عن طريق التشكيك في فرضيتي التصرف لتصني الرشيد، وكفاءة

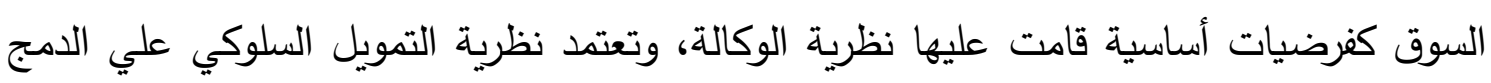

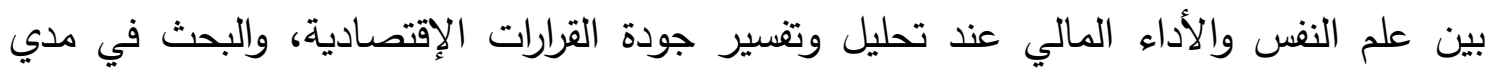

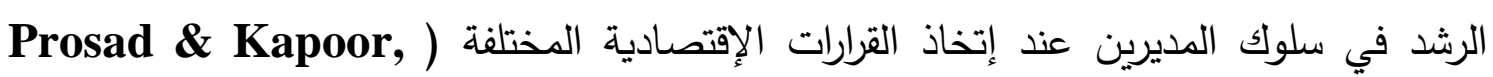
. (2015

ويقصد بالثقة الإدارية المفرطة ميل المديرين إلي المبالغة في تقدير ما يمتلكونه من قدرات

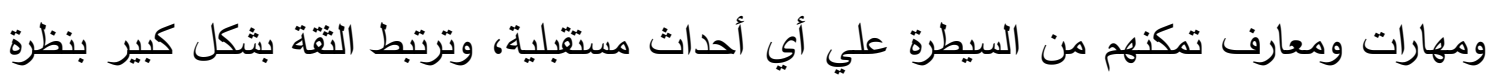

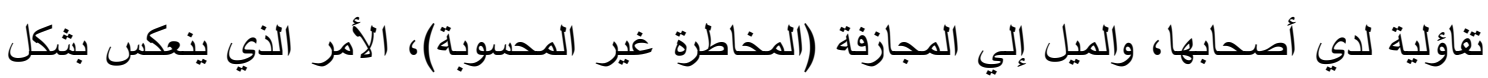
سلبي علي أداء المنثآت التي يديرونها (Barone-Adesi et al., 2012) ؛ .(Ma, 2008 ؛ Deaves, 2010

وتؤدي الثقة الإدارية المفرطة إلي تبني المديرين لوجهات نظر تفائلية حيال الأحداث

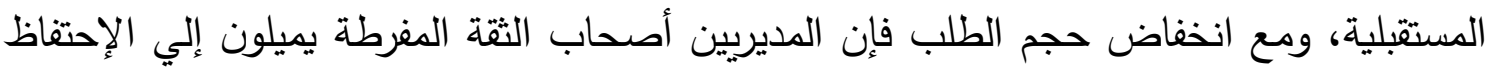

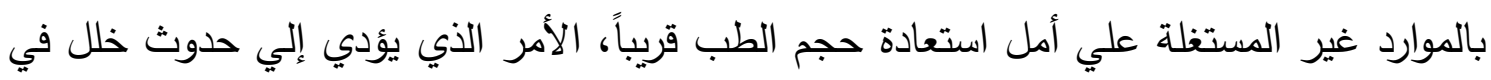

1 يعمل Richard Thaler أستاذ للأقتصاد في جامعة شيكاغو، بالولايات المتحدة الأمريكية. 
تماثيلية هيكل التكاليف، ويؤدي لظهور ما يعرف إصطلاحاً " بالسلوك غير المتماثل للتكلفة "2 .(Chen et al., 2013 !Banker et al., 2014)

ويقصد بالسلوك غير المتماثل للتكلفة أن الزيادة في التكاليف المرتبطة بزيادة معينة في مستوي النشاط لا تساوي الإنخفاض في التكاليف المرتبط بإنخفاض النشاط بنفس النسبة، وينتج السلوك

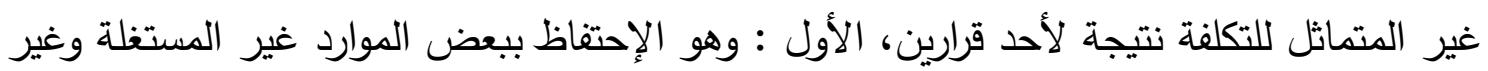

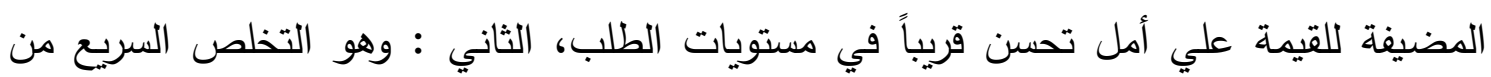

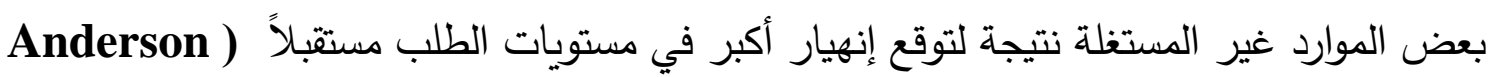
.(Bruggen et al., 2014 !et al., 2013 وتتشأ العلاقة بين الثقة الإدارية المفرطة والسلوك غير المتماثل للتكلفة نتيجة للقرارات

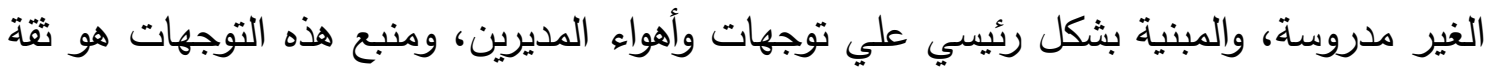

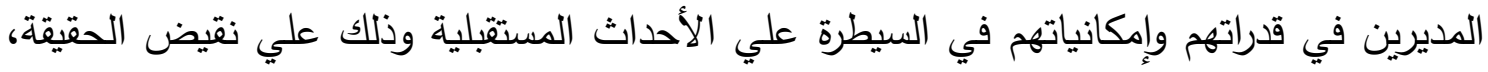

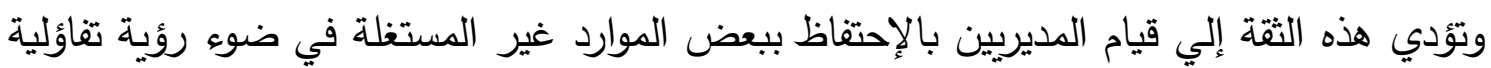

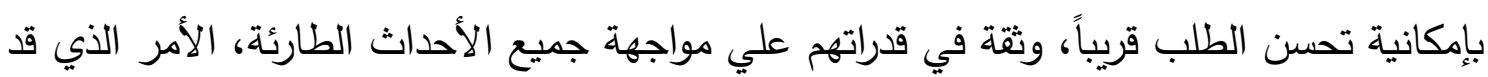

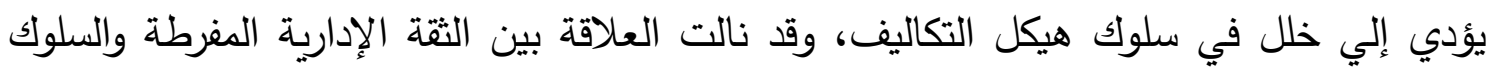

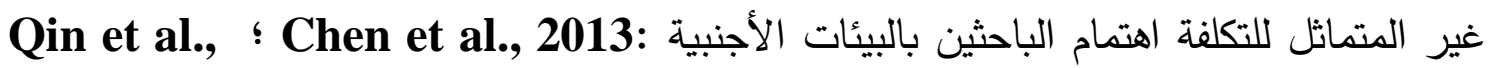
2015؛ Chen et al., 2018 ؛ Hur et al., 2019 ورغم ذلك لم يحظي هذا الموضوع بالإهتمام الكافي في البيئة الدصرية، وقد دفع ذلك الباحثين إلي الإهتمام به ودراسته وتحليله، وذلك لكأل

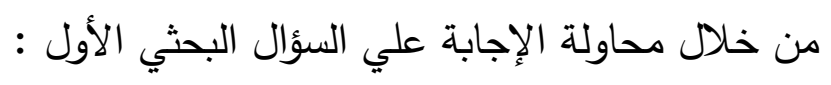

" هل تؤدي الثقة الإدارية المفرطة للمديرين بالثركات المدرجة بسوق الأوراق المالية المصري إلي عدم التماثل في سلوك التكلفة؟

تساهم قواعد حوكمة الثركات في وضع النظم والهياكل وآليات العمل التي تعمل علي مراقبة التصرفات الإدارية بمنشآت الأعمال بهدف تعظيم قيمة المنشأة واستمرارها في المدين الئين

2 تصنتخدم الأدبيات العربية مصلطحات مترادفة لمصطلح السلوك غير المتماثل للتكلفة مثل :التكاليف اللزجة، التكاليف ثنائية الإتجاه، 
القصير والطويل، بالإضافة إلي حماية حقوق جميع الأطراف ذوي العلاقة، وحتي لا تتوغل الإدارة التتفيذية التي تمتلك السلطة والمعلومة الكاملة علي حقوق باقي الأطراف. وتساهم حوكمة الثركات في تعزيز المساءلة والثفافية من خلال وضع أطر للسلوك الجيد عند الممارسات الإدارية المختلفة، كما تساهم الحوكمة الجيدة في تقوية نظم الرقابة الداخلية من خلال الإثارة إلي أهمية اللجان الرقابية في الحد من الممارسات الخاطئة والعمل علي تصويها لهابها بشكل فوري وفعال ( عفيفي، 2008؛ أبو سالم، 2017).

وبالتالي قد تساهم حوكمة الثركات القوية علي تقويم التصرفات المختلفة للمدير التتفيذي والحد من القرارات الإستثمارية التي لم تنطوي علي دراسة كافية بخصوص الآثار والنتائج المترتبة عليها؛ كما قد تساهم الحوكمة القوية في إعادة تفكير المدير التنفيذي في القرارات الإستثمارية لفترة

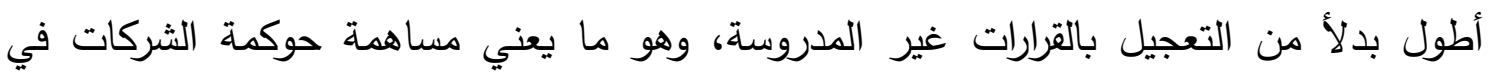

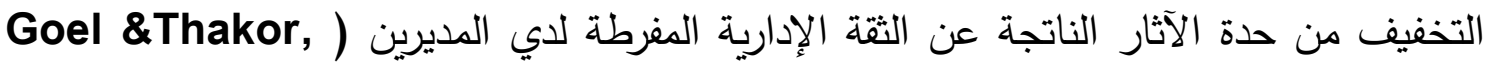
. ( Chang\& Hsu, 2017 2008 وقد يؤدي الحد من آثار الثقة الإدارية الهفرطة الناتج عن مساهمة حوكمة الثركات القوية

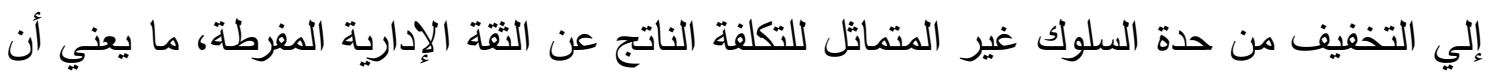

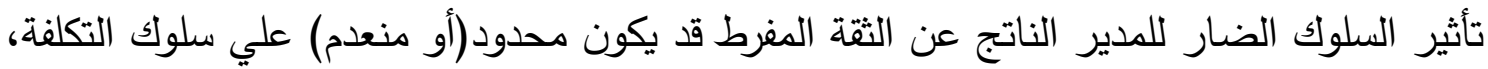
وفي ضوء ما سبق يمكن صياغة السؤال البحث الثاني علي النحو التالي :

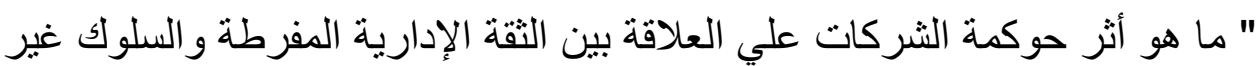
المتماتل للتكلفة بالثركات المدرجة بسوق الأوراق المالية المصري؟

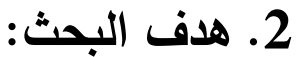

$$
\text { في ضوء مشكلة البحث، تتمثل الأهداف الرئيسية للبحث في: }
$$

• التعرف علي طبيعة العلاقة بين الثقة الدفرطة للمديرين بالثركات المدرجة بسوق الأوراق المالية المصري وعدم التماثل في سلوك التكاليف. التعرف علي التأثير المتوقع لحوكمة الثركات علي العلاقة بين الثقة الإدارية المفرطة للمديرين والسلوك غير المتماثل للتكلفة. 


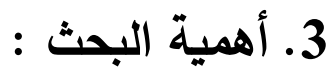 \\ ترجع أهمية البحث الحالي إلي عدة اعتبارات لعل أهما ما يلي :}

يلقي الضوء علي الجانب السلوكي في تصرفات المديرين بالسوق المصري، ولما لها من

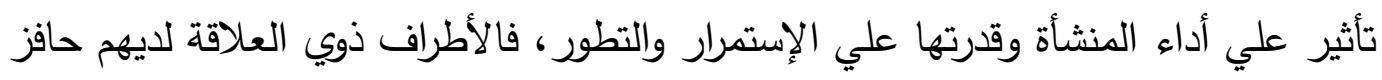
دائم نحو الحصول علي تطمينات حول المنشأة وتطورها، وبالتالي فإن تقييم الإدارة بشكل

عام يجب أن يتضمن في أحد جوانبه العوامل السلوكية المحركة لتصرفات المديريين.

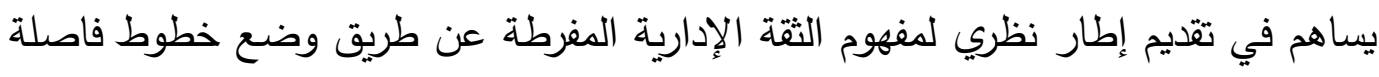
بين الثقة بشكل عام، والثقة المفرطة المضرة بالأداء المالي وقيمة الثركة. يسعي إلي تقديم دليل إمبريقي عن أثر الثقة الإدارية المفرطة علي السلوك غير الثيل المتماثل للتكلفة، ومن ثم إبراز أهمية الإهتمام بالثقة الإدارية المفرطة كأحد العوامل السلوكية المؤثرة في أداء المنشأة وتطورها. هيعي لإستكثاف الدور التأثيري لقواعد حوكمة الثركات المطبقة بسوق الأوراق المالية

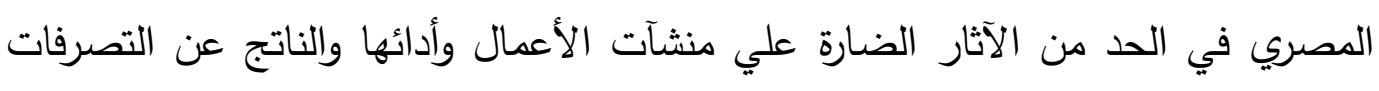

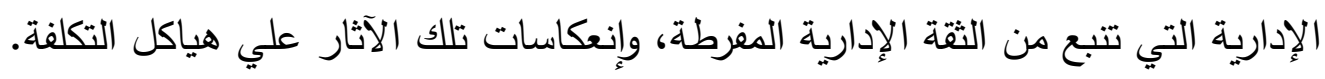
يعد البحث الحالي إحدي الدراسات المتعلقة بربط العوامل السلوكية في تصرفات التبات المديرين مع السلوك غير المتماثل للتكلفة وهي إحدي المجالات البحثية الحديثة التي لإني

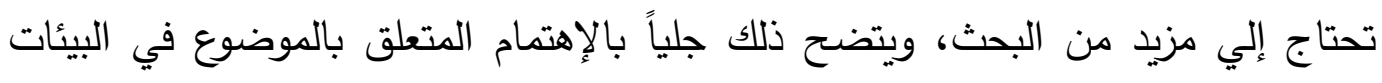
الأجنبية.

في حدود علم الباحثين فإن العلاقة بين الثقة الإدارية الدفرطة والسلوك غير المتماثل للتكاليف لم يتم اختباره من قبل في البيئة المحلية. في حدود علم الباحثين فإن تأثير حوكمة الثركات علي طبيعة العلاقة بين الثئة الإدارية

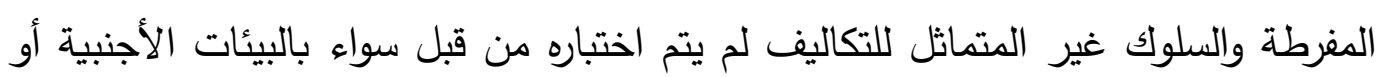
بالبيئة المحلية.

4. الإطار النظري للثقة الإداربـة المفرطة

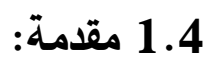


أشار تقارير عن Jeffrey skilling الرئيس السابق لشركة "أنرون" العملاقة التي انهارت عقب أزمة مالية طاحنة مرت بها إلي إعتقاده بامكانية التلاعب بالمعلومات المالية دون القدرة علي كثف ذلك من قبل المراجعين، وأستند في ذلك بناء هذا الإعتقاد علي ثقته المفرطة في القدرة علي لداني

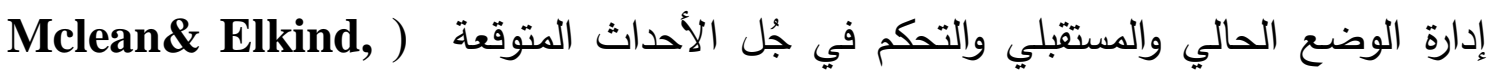

تعتبر الثقة الإدارية المفرطة أحد السمات التي يتصف بها بعض البشر خلال تعاملاتهم

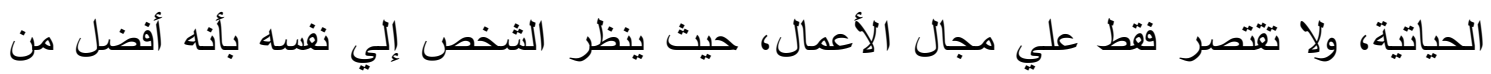

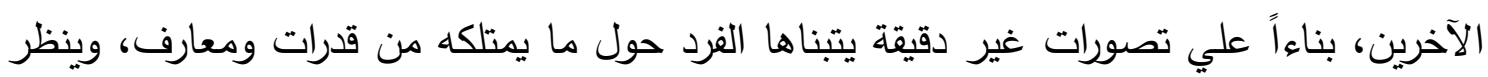

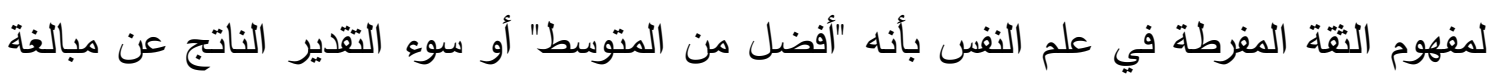
الأفراد في توقعاتهم (Chen et al., 2013).

وينظر إلي المديرين مفرطي الثقة في الأدبيات المحاسبية بإعتبارهم مفرطي التفاؤل للدرجة

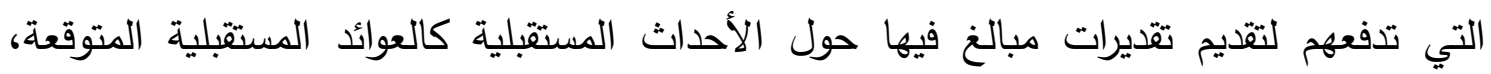
والتدفقات النقدية المتوقعة، وغيرهم، بالإضافة إلي التقليل بثكل منهجي من تأثير النتائج السلبية.

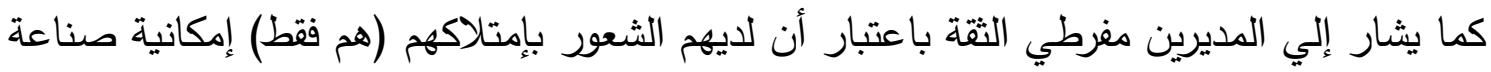

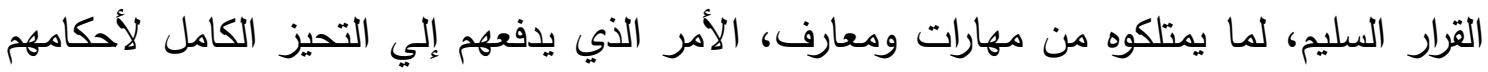

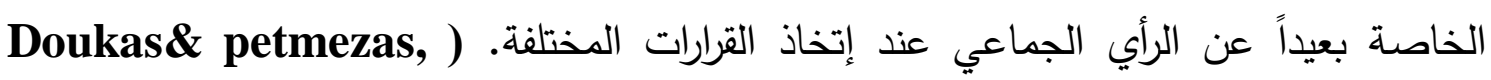
.2007

وعطفاً علي ماسبق فإن الثقة المفرطة تؤثر في طرق إعداد التقارير المالية حيث يكون

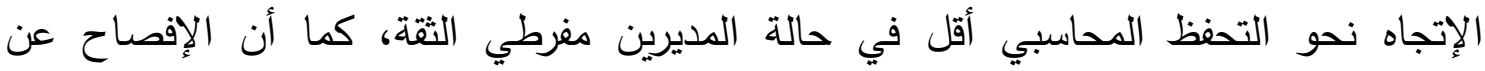

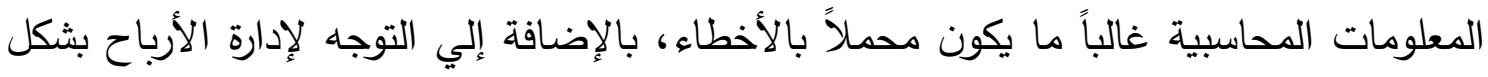

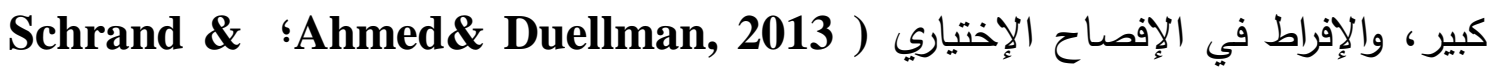
.( Hribar \& Yang, 2016 ! Zechman, 2012 وتدفع الثقة الإدارية الدفرطة الديرين نحو نشر التنبؤات والتثديرات بخصوص المستثبل،

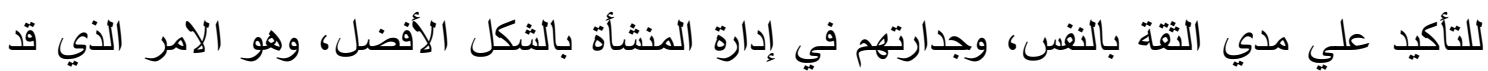

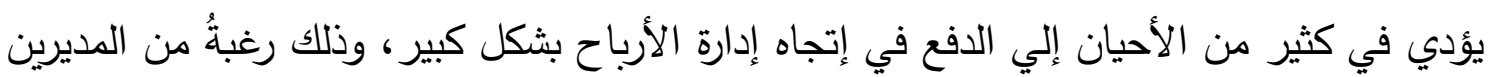


في الوصول إلي التتبؤات المعلنة مسبقاً في تقاريرهم التخطيطية ، وحتي لا تهتز الصورة التي

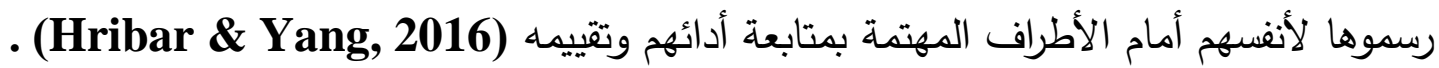
2.4 التمييز بين الثقة والتفاؤل المتحيز

تُميز الدراسات السابقة بين تأثير كلاً من التفاؤل المتحيز والثقة المفرطة عند تقييم السلوك المالي للشركات، فالتفاؤل المتحيز يعبر عن المبالغة في تقييم التقديرات الذاتية حول الأحداث

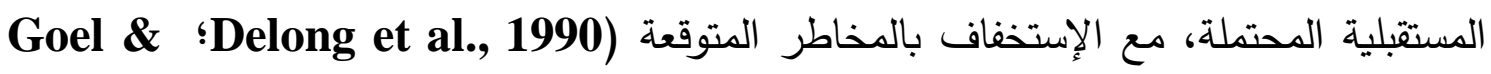
Thajor, 2008 (Fairchild, 2009 بينما يشير مفهوم الثقة المفرطة إلي المديريين المبالغين

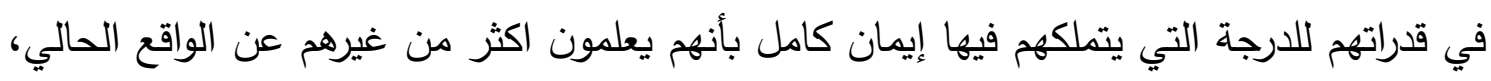

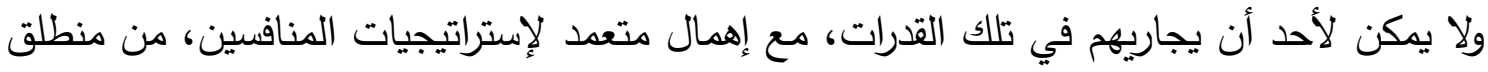
العلم الكامل والسيطرة التامة ( pardes, 2005 ) . وبالتالي يمكن النظر إلي التفاؤل المتحيز بإعتباره أحد الصور الناتجة عن تبني المديرين

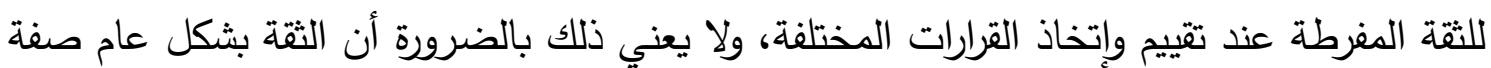

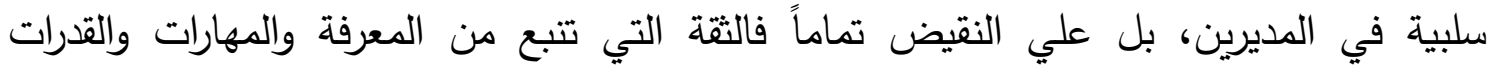

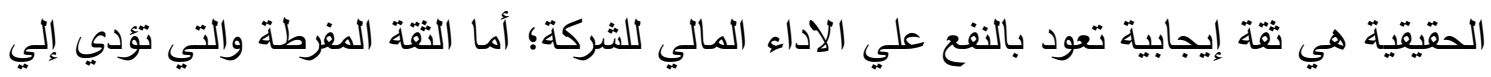
تفاؤل متحيز هي التي تسعي الدراسة الحالية للتأصيل النظري لها، والتأكيد علي الآثار السلبية الناتجة عنها علي أداء وقيمة منشآت الأعمال. 


\section{4 مفهوم الثقة الإدارية المفرطة}

تثير الثقة الإدارية بثكل عام إلي خليط من الظواهر النفسية التي تتفاعل معاً لتساهم في خلق ما يسمي الشعور (Ferreria, 2012)، كما تشير الثقة إلي الأفراد الذين يميلون للتفاؤل في

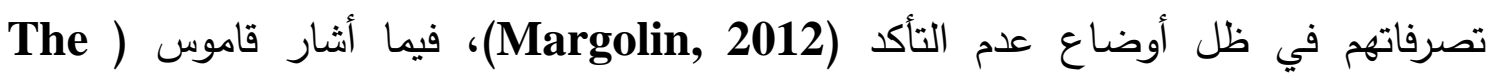
(Oxford English

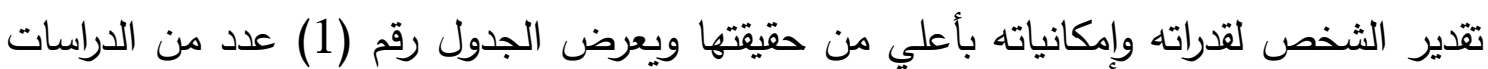
التي تتاولت مفهوم الثقة الإدارية المفرطة.

جدول رقم (1) : مفهوم الثقة الإدارية الدفرطة

\begin{tabular}{|c|c|}
\hline تعريف الثقة الإدارية المفرطة & 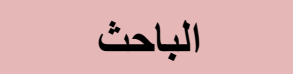 \\
\hline 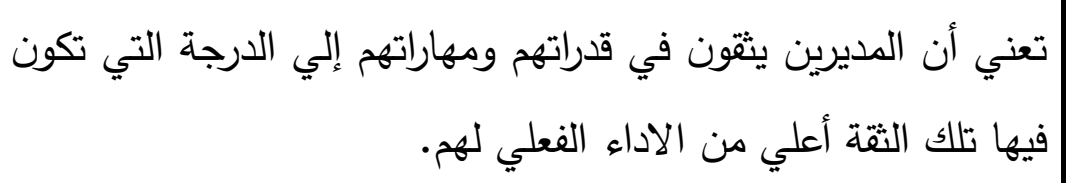 & $\begin{array}{c}\text { Pallier et al., } \\
2002\end{array}$ \\
\hline 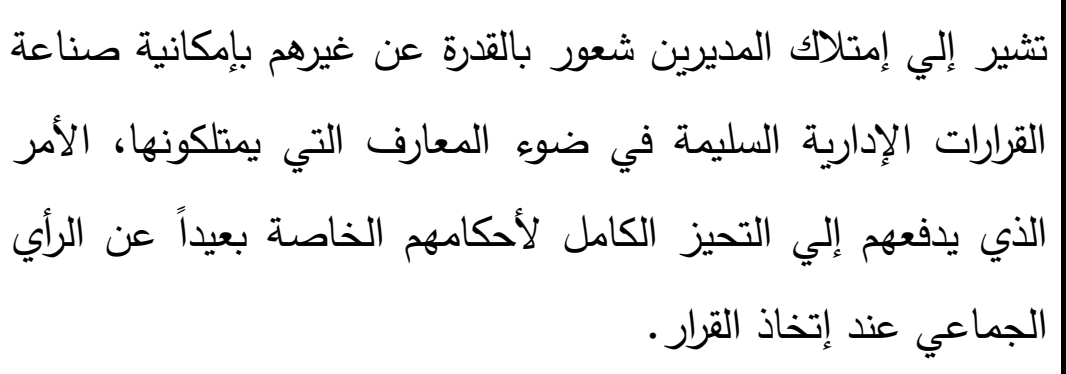 & $\begin{array}{l}\text { Doukas \& } \\
\text { petmesas, } \\
2007\end{array}$ \\
\hline 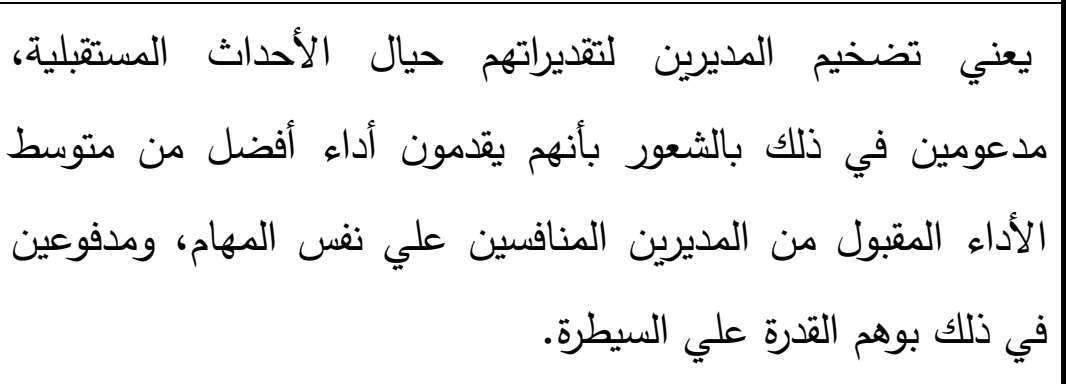 & Ma, 2008 \\
\hline عليثير إلي ميل المديرين للمبالغة في تقدير معارفهم وقداتهم ودقة & $\begin{array}{c}\text { Ackert\& } \\
\text { Deaves, } 2010\end{array}$ \\
\hline
\end{tabular}




\begin{tabular}{|c|c|}
\hline إحتمال حدوث أحداث إيجابية، والتقليل من إلتيز إلي التفاؤل، وبمعن الميل إلي المبالغة في تقدير & Sharot, 2011 \\
\hline تعتبر مظلة لمجموعة متتوعة من الظواهر تعبر في مجملها عن & $\begin{array}{c}\text { Margolin, } \\
2012\end{array}$ \\
\hline إليثير إلي تفاعل العوامل النفسية مع العوامل المعرفية؛ وبما يؤدي & Zaher, 2018 \\
\hline
\end{tabular}

1- تمثل الثقة المفرطة أحد الصفات البشرية التي يتطبع بها الأنسان وترتبط به خلال حياته،

$$
\text { وتؤثر علي جميع قراراته. }
$$

2- ترتبط الثقة بالشعور النفسي للمديريين بالسمو والإرتقاء عن بقية الأفراد بالبيئة المحيطة. 3- تؤدي الثقة إلي دفع المديرين إلي تضخيم تقديراته حول المستقبل إلي المستوي الذي تبعد

$$
\text { فيه هذه التقديرات عن الواقع • لمن }
$$

4- يتولد الثعور بالثقة لدي المديرين نتيجة لعدة عوامل أهمها إمتلاك بعض الخبرات السابقة أو المهارات والمعارف، أو بعض النجاحات في التجارب التاريخية .

5- ترتبط الثقة المفرطة بميل المديرين إلي التحيز في التفاؤل حيال بعض الأحداث المستقبلية

$$
\text { المتوقعة }
$$

6- تدفع الثقة المفرطة المديرين نحو تفضيل المخاطرة، مع التقليل من شأن الآثار السلبية المترتبة عليها. 


\section{وفي ضوء ما سبق يمكن تعريف الثقة الإدارية الدفرطة بأنها :}

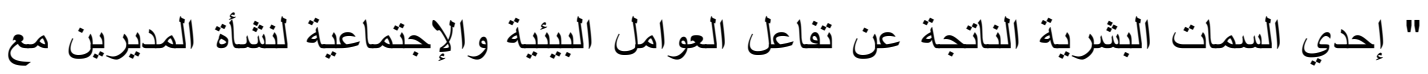

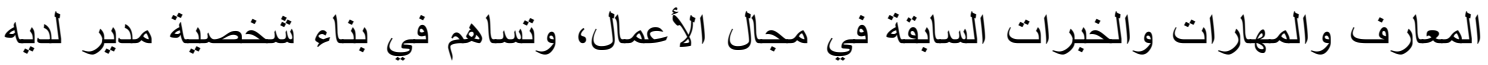

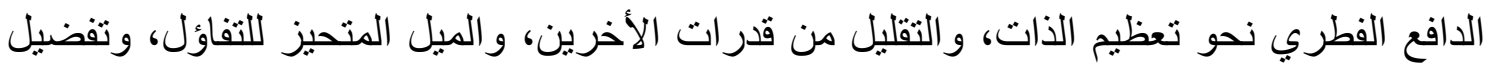

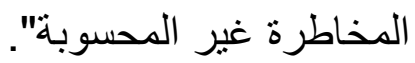

\section{4}

تتعدد الصور التي يمكن من خلالها التعرف علي الثقة الإدارية المفرطة، فقد تأتي في صورة

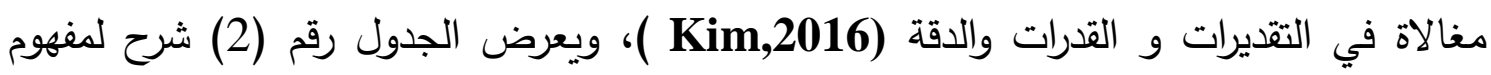
صور وأشكال الثقة الإدارية المفرطة.

جدول رقم (2): صور و أثنكال الثقة الإدارية المفرطة

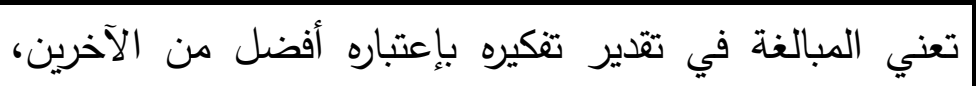

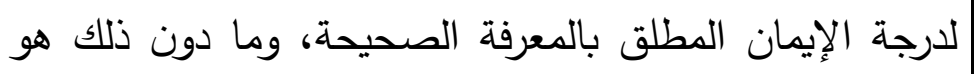
المغالاة في التقديرات Overestimation الخطأ، وتظهر المغالاة في التقديرات عندما يكون الأداء الفعلي

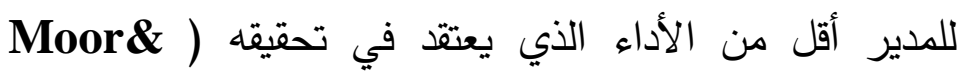
. (Olsson, 2014 ؛Schatz, 2017

تعرف أيضا بأسم "التأثير فوق المتوسط"، وتعني المبالغة في

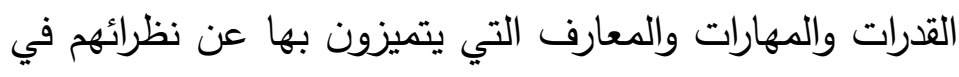
المغالاة في القدرات نفس المستوي الوظيفي(Moor\& Schatz, 2017) Overplacement .(David et al., 2013 تعرف أيضاً بأسم "وهم السيطرة"، وتعني ميل الأفراد إلي

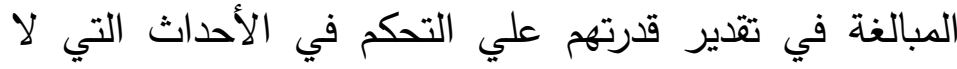
المغالاة في الدقة يمتلكون تأثيراً عليها أو يمتلكون تأثير محدود عليها، ويصحبها التقليل من أهمية التقلبات العشوائية (Langer, 1975؛ overprecision (Ben-David et al., 2013 

هناك العديد من الأسباب التي تؤدي لبلورة سلوك إداري مائل بشكل تلقائي نحو الإفراط في

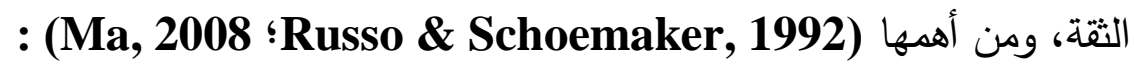
" توافر التحيز Bias Availability: تعني استناد الديرين إلي عدد قليل من الدسارات بثأن الثقديرات المستقبلية، في ظل صعوبات تواجههم في تخيل المسارات الأخري المككنة

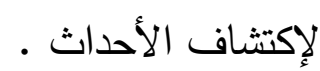
ترسيخ النحيز Bias Anchoring: تعني توجه المدير إلي التأكيد علي قيمة أو فكرة معينة علي الرغم من عدم التكيف معها بالشكل الكافي.

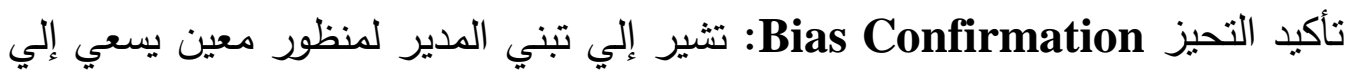
التأكيد عليه دون امتلاك الأدلة والبراهين التي تؤكد صحته. الإدراك المتأخر Hindsight : يشير إلي وهم امتلاك الددير للعلم والمعرفة الكافية التي تمكنه من تقديم تقديرات عالية الدقة، وأفضل مما هو قائم الآن. الإهتمامات التفاضيلية Differential interests: تعني أن المديرين يميلون بطبيعة الحال إلي الحقائق التي تتناسب مع تفضيلاتهم ورغباتهم، وبالتالي فإن استدعاء التحيز سيكون بهدف تدعيم تلك التفضيلات والرغبات.

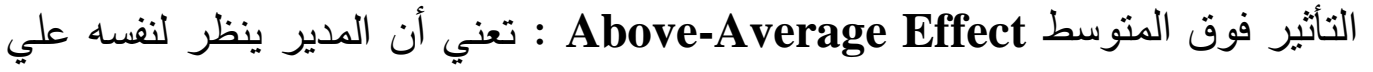

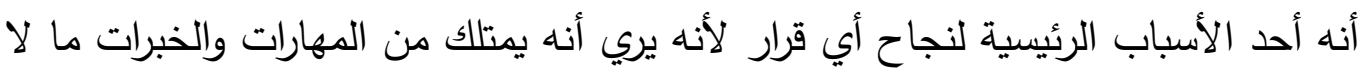

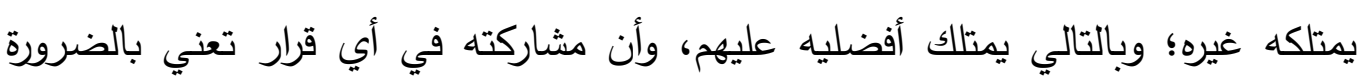
نجاحه. أو هام السيطرة Illusions of Control : وتشير إلي اعتقاد الدير بإمتلاك كل أدوات القوة والهيمنه التي تمكنه من السيطرة علي أي موقف. 6.4 إنعاسات الثقة الإدارية المفرطة علي نظريتي المحاسبة والمراجعة: تؤدي الثقة الإدارية الدفرطة إلي توجه الديرين لإتخاذ قرارات تنعكس بطبيعتها علي عمل النظام الدحاسبي، ونناقش في الجانب التالي جزء من هذه التأثيرات : 
• الإفصاح الإختياري: يسعي المدير إلي تبني استراتجيات تؤدي إلي الإفصاح عن

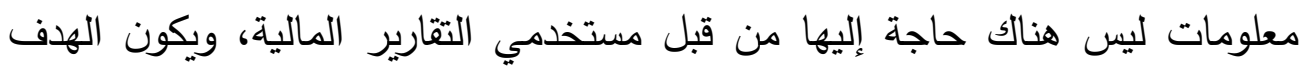
الرئيسي من وراء ذلك هو تحسين الإنطباع العام والصورة الذهنية عن كفائته وقدراته، لهنه بل والعمل علي التضخيم من تلك القدرات بخلاف الواقع الحقيقي، الأمر الذي يؤدي الأني

إلي تثويه ( أو علي الأقل تثويش) التقارير المالية (Rawson, 2019؛ Schand\& !Hwang et al., 2015 ؛Andriosopoulos et al., 2013 .(Zechman, 2012 إدارة الأرباح: تفع التقديرات التي أعدت من قبل المديرين مفرطي الثقة إلي دفعهم التهاه

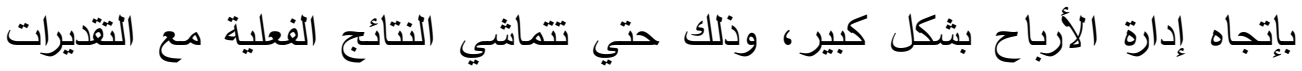

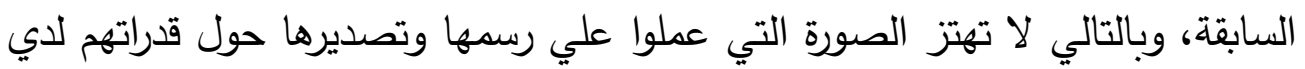
الأطراف المتمه بأدائهم (Chae\& Ryu, 2016 (Berry-stolzle, 2018؛ Hsieh et al., !Habib et al., 2012 ؛Goel, 2008 ؛chang et al., 2018 .(xu, 2015 ؛2014

• التحفظ المحاسبي: تدفع التقديرات المتفائلة بخصوص النتائج المستقبلية من قبل المديرين مفرطي الثقة إلي المبالغة في تقدير الأصول، بالإضافة إلي تأخير الإعتراف بالخسائر الحالية علي إعتبار أن النتائج المتوقعة قادرة علي تغطية الخلل الحالي في الإني

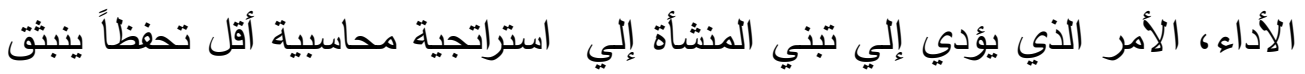

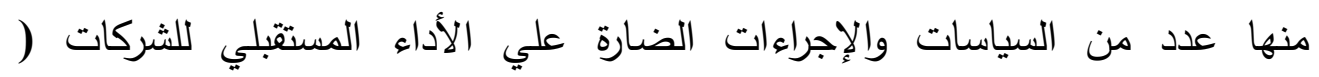
Hasanikolavani\& Mahfoozi, ‘Ramsheh\& Molanzari, 2014 .(Hsu et al., 2017 ؛Ahmed\& Duellman, 2013 2015 • هيكل التكلفة: تؤثر النزعة التفاؤلية المتحيزة من قبل المديرين مفرطي الثقة علي

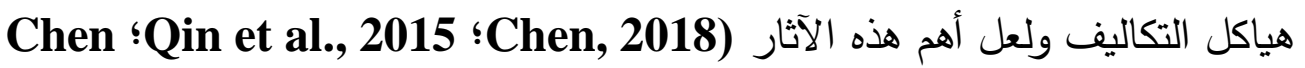
: (et al., 2017

- - التمسك ببعض الأسس غير الملائمة عند توزيع التكاليف الصناعية غير المباشرة.

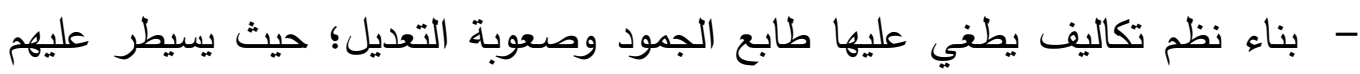
قناعات كبيرة بصلاحية النظام للعمل لفترات طويلة قادة وعدم الحاجة للتعديل مستقبلاً. 
- التمسك ببعض عناصر التكاليف غير المستغلة لفترات طويلة، وعدم التخلص منها رغم أنها تمثل عبء علي إيرادات المنشأة ونتيجة نثاطها. •• الموازنات التخطيطية وتقديرات الأرباح: تؤدي النزعة التفاؤلية لدي الدديريين إلي تبني

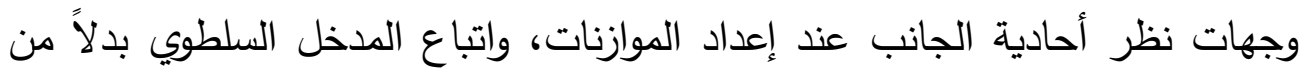
إتباع مدخل المشاركة في إعداد الموازنة وبالتالي عدم الإستفادة من الكفاءات التي تعمل بالنظام المحاسبي بشكل كبير، بالإضافة إلي الميل للنتائج الإيجابية في معظم توجهات الموازنة، الأمر الذي يؤدي إلي إعداد موازنات بعيدة بشكل كبير عن الواقع بإئ الفعلي (Hervais et al., 2011 .(2016 • نظم الضبط والرقابة الداخلية: تؤدي الثقة الإدارية المفرطة إلي تبني استراتيجيات رقابية ضعيفة من قبل المديرين، نظراً لضعف الحاجة إليها، ولإعتقادهم الكامل بأن دولاب العمل سيتحرك بشكل كبير في ضوء التوجيهات والتعليمات الصادرة من خلاله،

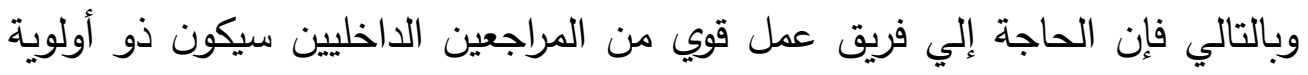
ضعيفة في إهتمامات المديرين مغرطي الثقة (Lee, 2016 (Chen et al., 2014). •• ارتفاع تكلفة المراجعة الخارجة : تحتاج منشآت الأعمال التي يدير العمل بها مديرين

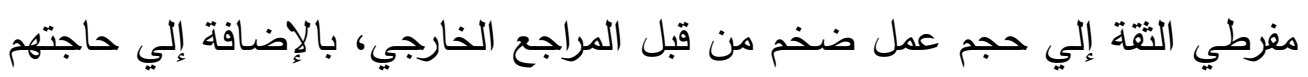

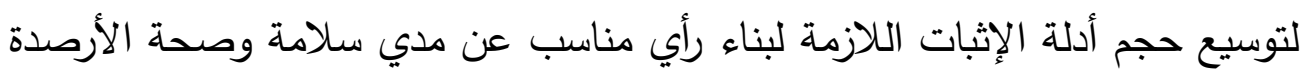

$$
\text { والسجلات، ويرجع ذلك إلي أن طبيعة العمليات التي أقبل علي }
$$

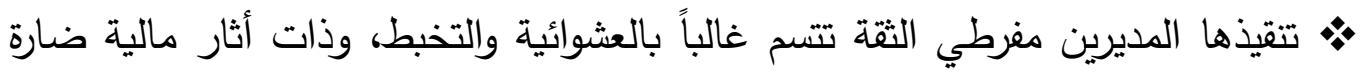

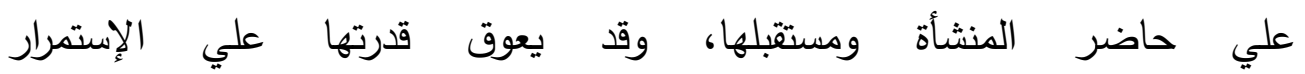

. (Mitra et al., 2019 !Duellman,2015) 


\section{4 مقاييس الثقة الإدارية المفرطة}

تعددت المقاييس التي استخدمت في الدراسات السابقة للثقة الإدارية المفرطة، ونستعرض

في الجانب التالي جزء من هذه المقاييس:

(1)(مقاييس تعتمد علي نشر صورة زهنية معينة عن المدير التنفيذي

(أ) عبر التقارير السنوية تعنية

استخدمت دراسة (Qin, 2015) مقياس مدي بروز صورة المدير التنفيذي في التقارير السنوية للشركة، حيث يسعي المدير التنفيذي مفرط الثقة لإظهار نفسه بشكل أوضح عند عن المسئولين التتفيذيين الآخرين، ولبناء صورة ذهنية عن أداءه متضمنه مدي قوته وأهميته ومهارته وإلمامه بكل

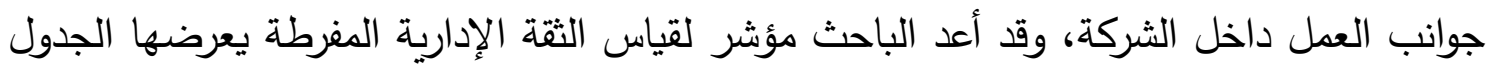

جدول رقم (3): مقياس دراسة (Qin, 2015) للثقة الإدارية المفرطة

\begin{tabular}{|c|c|}
\hline قليمة المؤشر المقابلة & مستوي الوصف و المعلومات عن المدير مفرط الثقة \\
\hline 4 & - أكثر من نصف صفحة بالتقرير السنوي عن المدير \\
\hline 3 & - أقل من نصف صفحة بالتقرير السنوي عن المدير \\
\hline 2 & - - تقرير مشترك عن المدير التتفيذي مع أطراف أخري \\
\hline 1 & - عدم وجود أي وصف متعلق بالمدير التنفيذي \\
\hline
\end{tabular}

وبطبيعة الحال فإن وصف المدير "بأكثر من نصف صفحة" بالتقرير السنوي عن المدير

التتفيذي دون الإثارة لأطراف أخري يعد مؤشراً علي مستوي ثقة إدارية مفرطة. كما أن عدم وجود أي وصف متعلق بالمدير التتفيذي يعد مؤشراً علي انخفاض مستوي الثقة الإدارية المفرطة. (ب) عبر التقارير الصحفية المنشورة 


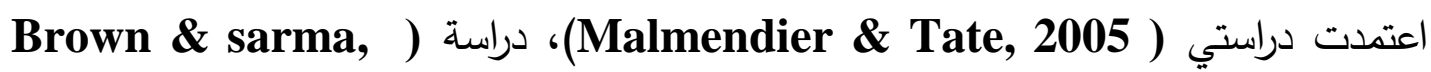
2007) في قياس الثقة الإدارية المغرطة علي تصور الصحافة المهتمة بالجانب المالي والإقتصادي للمديرين التنفيذيين وعلي وجه الخصوص الصحف الرائدة في هذا المجال مثل ل نيورك تايميز، يزنس ويك، فاينشل تايم، الايكونومست، وول استريت جرنل" عن طريق تتبع ما يتم

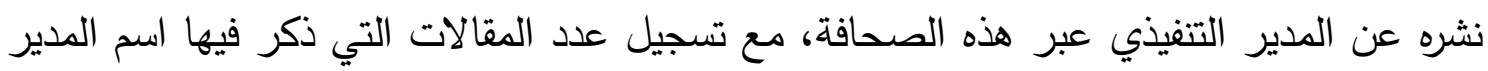
التنفيذي متضمنة عبارات " واثث، ثقة، متفائل، تفائل، موثوق به" كمؤشرات للثقة الإدارية المفرطة،

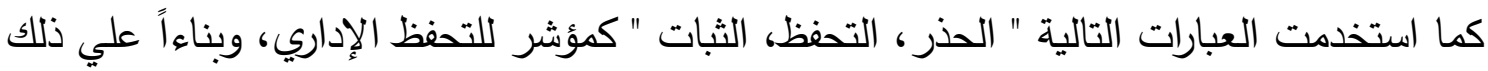

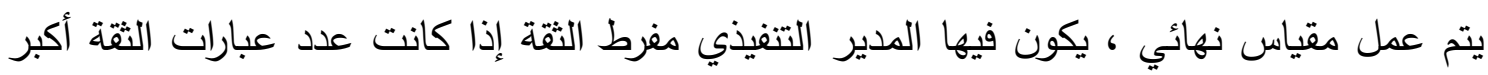

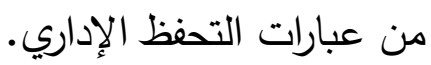
(ج) مؤشر الإسناد للذات (Self Attribution) اعتمدت دراسة (Hirshleifer et al., 2012) في قياس الثقة الإدارية المفرطة علي التحليل اللغوي لأسلوب المدير، علي أن يتم تقسيم النتائج في مجموعات إلي: متفائل وغير متفائل،

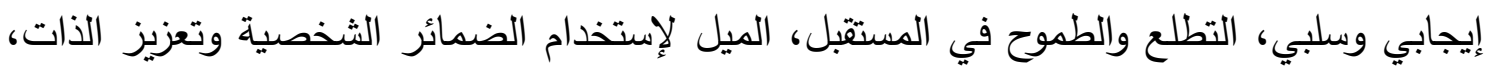
وبناءأ علي نتائج هذه المجموعات يمكن تصنيف المدير علي أنه مفرط الثقة من عدمه.

(2)(Option Based Measurs) مقياس خيارات الأسهم)

تساهم نظم الحوافز المعدة علي أساس ربط حافز الإدارة بأداء المنشأة في تثجيع المدير لتنبي وجهات نظر الملاك والعمل علي تحقيق مصالحهم، وتعتبر خيارات الأسهم أحد طرق الحوافز التي

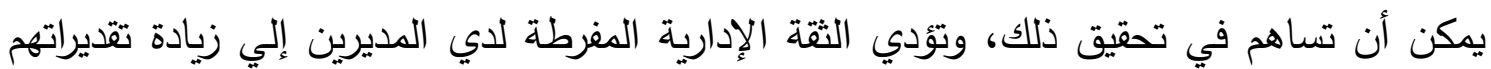

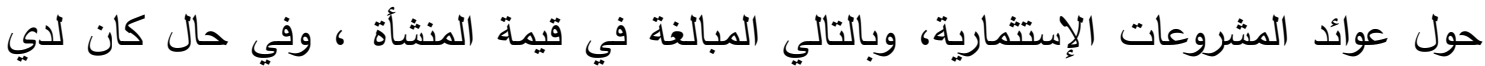

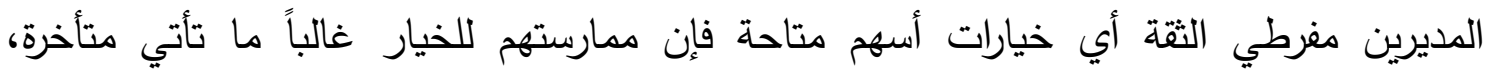
بالإضافة إلي التوجه نحو شراء أسهم إضافية للإحتفاظ الثخصي بها، والإستفادة من العوائد المستقبلية المتوقعة .

واستخدمت دراسة (Malmendier \& Tate, 2005) مقياس خيارات الأسهم لقياس الثقة

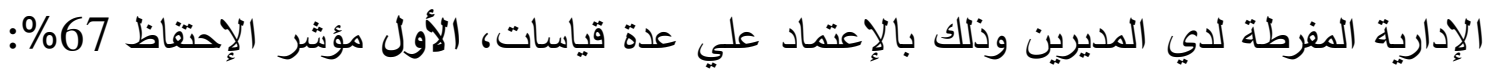

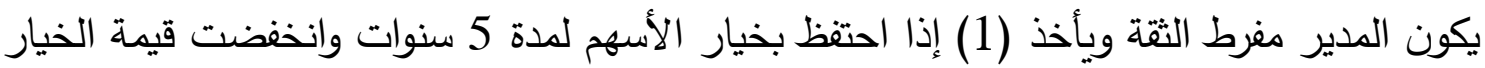


بمعدل 67\% ولم يقم بتتفيذ الخيار، و(صفر) بخلاف ذلك، الثاني مؤشر الإحتفاظ المتد : يكون المدير مفرط الثقة ويأخذ (1) إذا احتفظ بخيار الأسهم حتي أخر سنة في مدة الخيار علي الرغم من إنخفاض قيمته بمعدل 67\%، و (صفر) بخلاف ذلك، الثالث: يكون المدير مفرط الثقة ويأخذ (1) إذا كانت صافي مشتريات الأسهم من قبل المدير التنفيذي -لأسهم الثركة التي يديرونها-

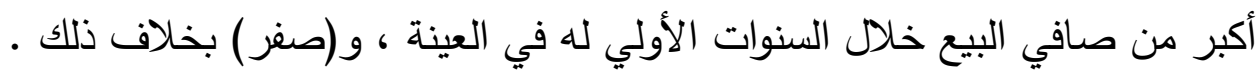

Return Distribution Forecast Based ) مقياس عوائد التوزيعات المتوقعة (3) (Measure

استخذمت دراسة (Lin et al., 2005) توقعات المدير بالعوائد كمقياس للثقة الإدارية

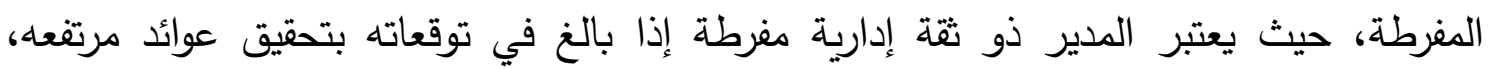

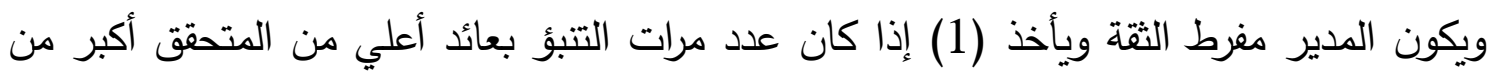
عدد مرات التتبؤ بعائد أقل من المتحقق، و(صفر) بخلاف ذلك.

وكذلك استخدمت دراسة (Ben-David et al., 2007 ) توقعات المدير بعوائد التوزيعات كمقياس للثقة الإدارية المفرطة، من خلال الإجابة علي سؤالين، الأول (قصير الأجل): يتعلق

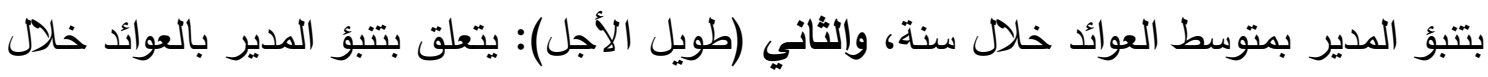

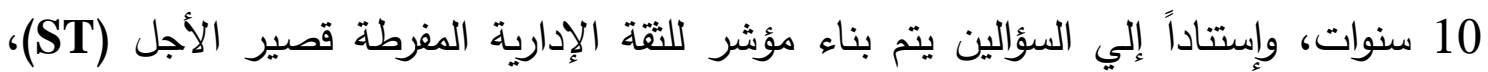

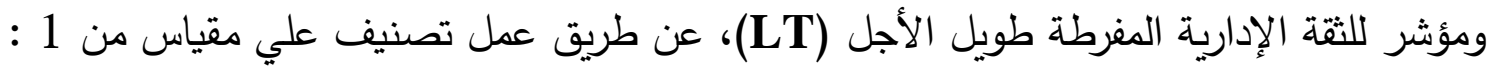
10، ويلي ذلك فرز المديرين تنازلياً، بحيث يأخذ (صفر) المديرين الأقل ثقة، و و(1) بخلاف ذلإنك. (4)مقياس الأجر النسبي

Chatterjee \& Hambrick, ؛ Hayward\& Hambrick, 1997) استخدمت دراسة

2007) الأجر النسبي كمؤشر لنرجسية المدير التنفيذي، حيث تدفع النرجسية المدير إلي الإفراط في ثقته بذاته، ويتم حساب الأجر النسبي بقسمة أجر الددير إلي ثاني أعلي أجر .

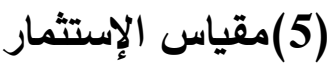


استخدمت دراسة (Schrand\& Zechman, 2012) الإنفاق الاستثماري كمقياس للثقة

الإدارية الدفرطة، حيث يعتبر المدير مفرط الثقة ويأخذ (1) إذا كان نسبة "الإنفاق الرأسمالي

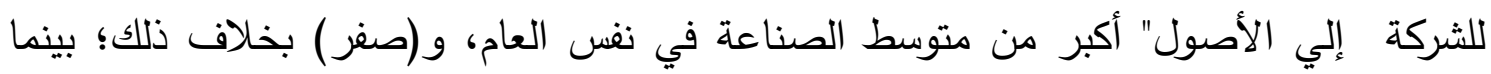

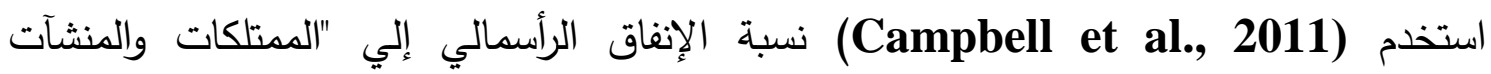

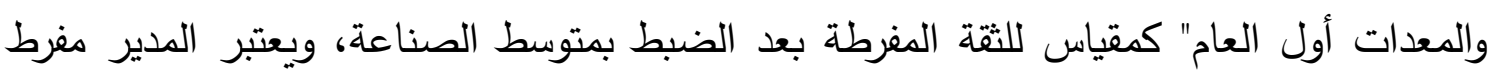

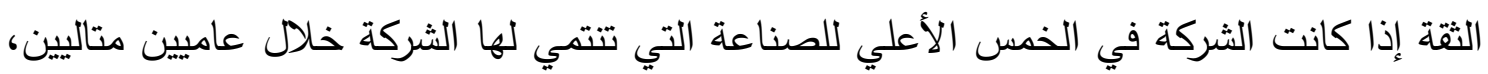
و(صفر) بخلاف ذلك

\section{التعليق علي قياسات الثقة المفرطة للمديرين:}

في ضوء ما تم استعراضه من مقاييس في الجزء السابق يمكن للباحثين تقديم عدد من الملاحظات أهمها :

•• مقياس "الصورة الذهنية ": يصعب تطبيقه في البيئة المصرية، حيث تخلو معظم

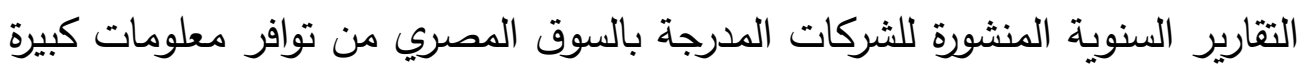

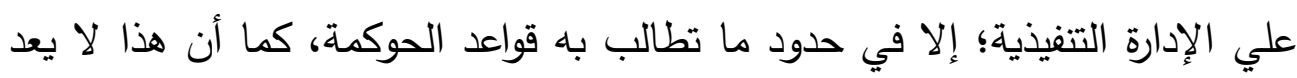

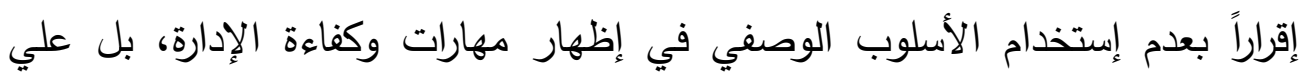

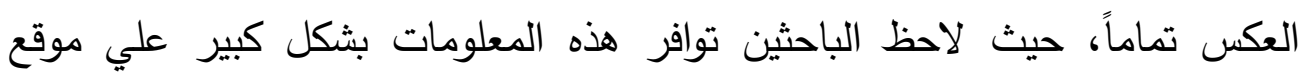

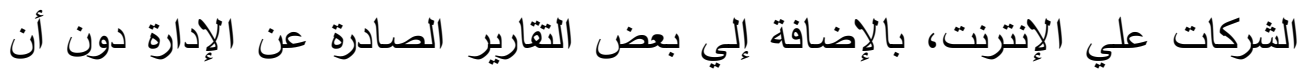

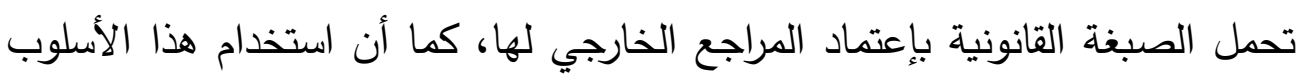

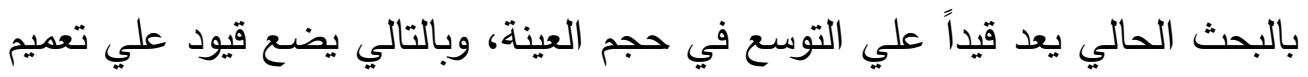
نتائج البحث.

•. مقياس "خيارات الأسهر" :لا يتضمن هيكل رأس المال المصري أي إفصاحات متعلقة بخيارات الأسهم ، ورغم أن هذا القياس يعد من المقاييس الهامة والثائعة الإستخدام

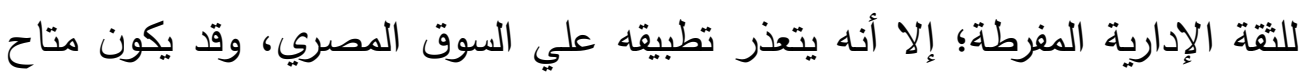
ذلك مستقبلاً مع تطور حال سوق الأوراق المالية المصري خلال الفترات القادمة. 
• مقياس عوائد التوزيعات المتوقعة: تتسم البيئة المصرية بإنخفاض حجم التتبؤات

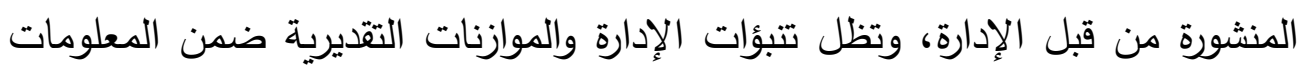

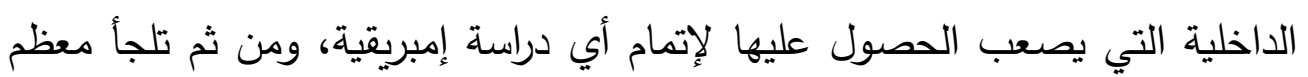

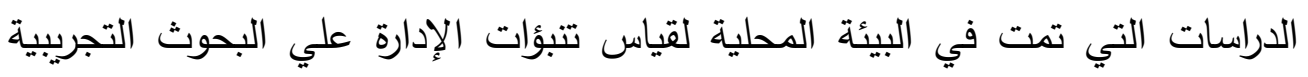

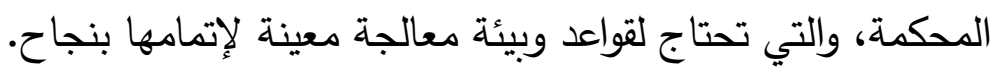

•• مقياس الأجور النسبية : تتسم التقارير المالية المنشورة بشكل عام في البيئة المصرية

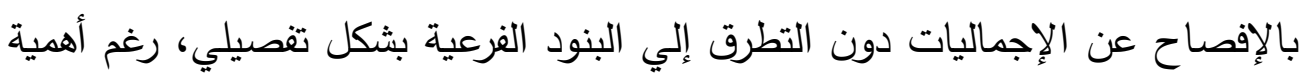
بعض البنود وتفصيلاتها، ولذلك فإن استخدام مقياس الأجور

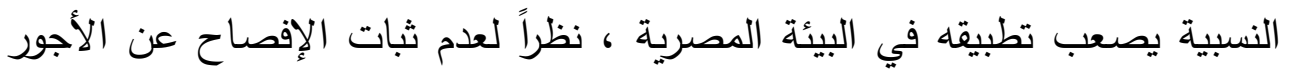
التفصيلية للإدارة بالتقارير المنشورة.

•. مقياس الإستثمار : يعتبر هذا المقياس أكثر المقاييس ملائمة للبيئة المصرية، حيث

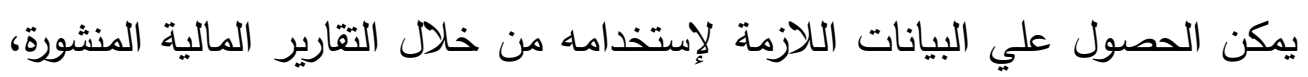
وبالتالي إتمام الدراسة الإمبريقية.

\section{5 5راجعة الدراسات السابقة}

تعددت الدراسة التي اهتمت بإختبار العلاقة بين الثقة الإدارية المفرطة وعدم التماثل في سلوك التكاليف، ونستعرض في الجزء التالي عدد من هذه الدراسات :

(Chen et al., 2013) دراسة

اختبرت الدراسة العلاقة بين الثقة الإدارية المفرطة للديرين وسلوك التكاليف البيعية والإدارية غير المتماثل، بالإعتماد علي عينة من 1500 شركة إجمالي مشاهدات 14568 للفترة

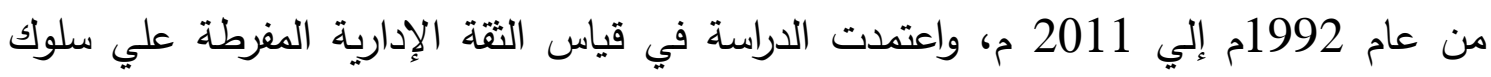
المدير إتجاه خيارات الأسهم، وتتضمن نموذج الدراسة عدد من المتغيرات الضابطة التي تم تصنيفها في مجموعتين وهما: 
" متغيرات اقتصادية وتتمثل في متغيرات : كثافة الأصول، وكثافة العمالة، وعائد السهح الدفتري للفترة السابقة . متفيرات متغيرات الوكالة وتتمثل في متغيرات : التدفقات النقدية الحرة، والمدفوعات الثابتة للمديرين. وتقوم الدراسة علي تصنيف توقعات الإدارة في إتجاهين وهما: توقعات الإدارة الدتحيزة،

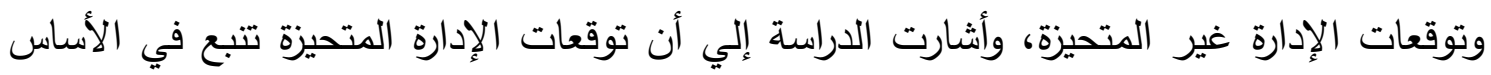

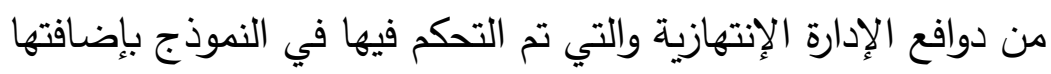
كمتغيرات ضابطة (متغيرات الوكالة)؛ بينما تصنف الثقة الإدارية المفرطة ضمن توقعات

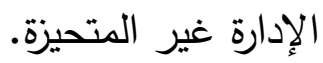
وتوصلت الدراسة إلي وجود علاقة معنوية وموجبة بين الثقة الإدارية المفرطة للمديريين

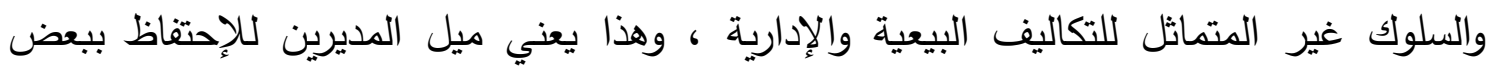
الموارد غير المستغلة لفترات زمنية معينة، كنتيجة للثقة في أنفسهم علي تحسين الوضع الإنع القائم

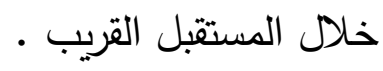

(Qin et al., 2015 ) دراسة

اختبرت الدراسة العلاقة بين الثقة الإدارية المفرطة للمدير والسلوك غير المتماثل للتكاليف البيعية والإدارية، وأنصب الإهتمام بالدراسة علي الجانب السلوكي للمديرين كأحد محددات السلوك الإدئ غير المتماثل للتكلفة، وأجريت الدراسة بإستخدام عينة من 257 شركة مدرجة بسوق الإندام الأوراق المالية

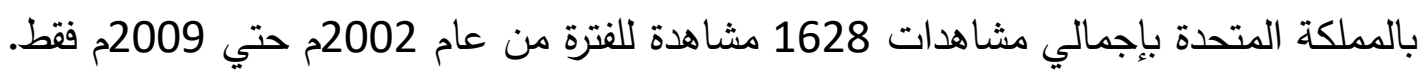
واعتمدت الدراسة في قياس الثقة الإدارية المفرطة لدي المديرين علي مقياس بروز صورة

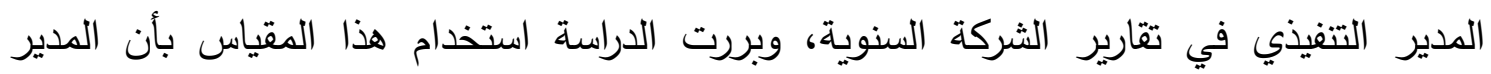
التنفيذي مفرط الثقة يسعي بشكل دؤوب لإظهار أنفسه بثكل أكثر وضوحاً من المسئولين التتفيذيين الآخرين، وذلك كإعلان قوي منهم بمدي أهميتهم ومهارتهم ودرايتهم وسيطرتهم . 
وتتضمن نموذج الدراسة مجموعة المتغيرات الضابطة الإقتصادية متمثلة في كثافة الأصول، وكثافة العمالة ، بالإضافة إلي استخدام متغير التدفقات النقدية الحرة لتحييد آثار مشكلات الوكالة علي نتائج العلاقة الرئيسية للدراسة. وتوصلت الدراسة إلي وجود علاقة طردية قوية بين ثقة المدير التنفيذي المفرطة والسلوك

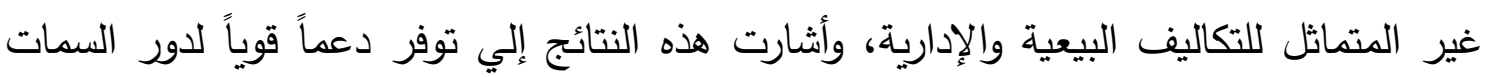
الثخصية للمديرين عند إتخاذ القرارات المختلفة .

\section{دراسة ( Chen et al., 2017 )}

اختبرت الدراسة العلاقة بين لهجة الإدارة في التقارير المالية المنشورة والسلوك غير المتماثل للتكاليف البيعية والإدارية علي عينة من الثركات المدرجة بسوق الأوراق المالية بالولايات

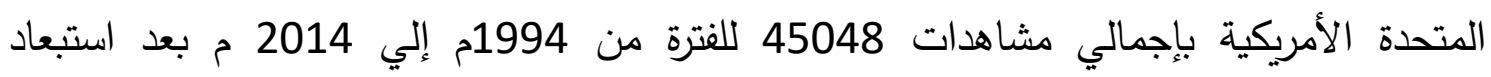

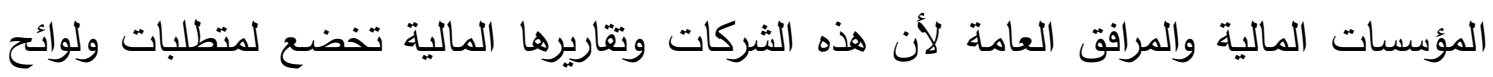
خاصة، بالإضافة إلي تعديل جميع الأرقام بمعدلات التضخم الصادرة عن وزارة الخزانة الأمريكية. واعتمدت الدراسة علي مقياس (Loughran \& Mcdonald, 2011) في قياس لهجة الإدارة و الذي تم حسابه كما يلي :

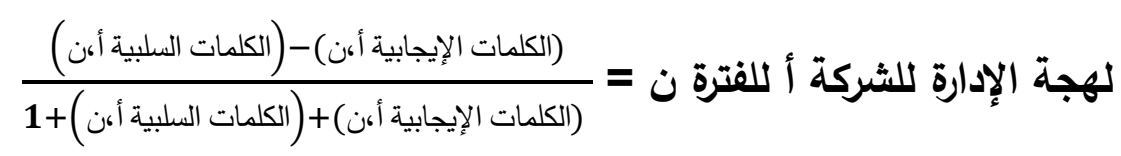

وأجريت الإختبارات اللازمة لإتمام الدراسة بعد ضبط أهم العوامل المرتبطة بتكاليف التعديل

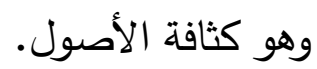

وتثير نتائج الدراسة إلي وجود علاقة طردية ومعنوية بين لهجة الإدارة والسلوك غير

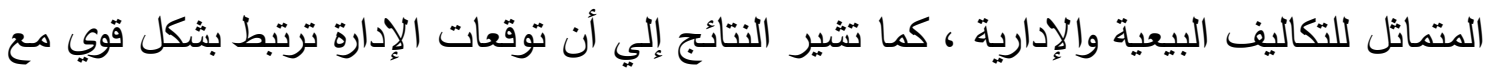

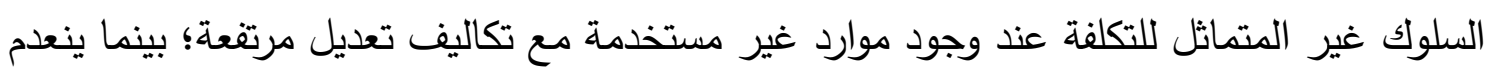
التأثير علي سلوك التكاليف مع انخفاض حجم موارد غير مستغل، وتكاليف التعديل.

\section{دراسة (Liang \& Mo, 2017)}


اختبرت الدراسة العلاقة بين الثقة الإدارية المفرطة للمديرين والسلوك غير المتماثل لتكاليف

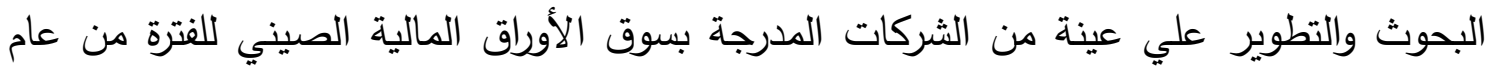

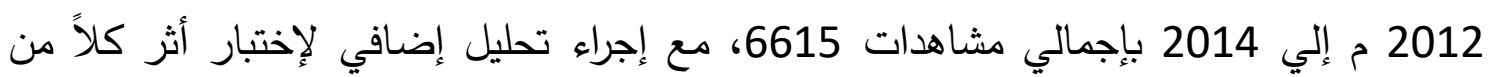
الملكية الحكومية علي العلاقة بين الثقة الإدارية المفرطة للمدير والسلوك غير المتماثل لتكاليف البحوث والتطوير •

واعتمدت الدراسة في قياس الثقة الإدارية المفرطة للمديرين علي مقدار التغير في عدد

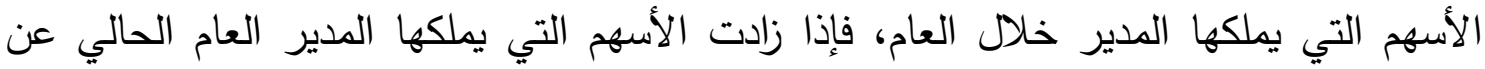

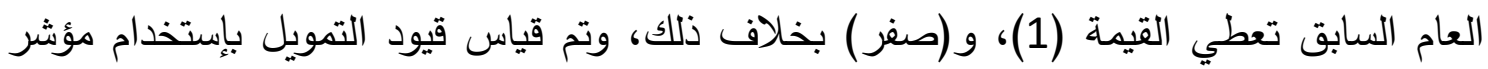
والذي تعتمد منهجيته في الأساس علي حجم الثركة، وعمر الثركة، بالإضافة إلي إدراج عدد من المتغيرات الضابطة وتتمثل في متغيرات التالية: حجم الثركة، والرفع المالي، وتركز الملكية، والفصل بين المدير التتفيذي ورئيس مجلس الإداره من عدمه.

وتوصلت الدراسة إلي وجود علاقة طردية ومعنوية بين الثقة الإدارية المفرطة للمديرين

والسلوك غير المتماثل لتكاليف البحوث والتطوير في الثركات التي تعاني من قيود علي عمليات

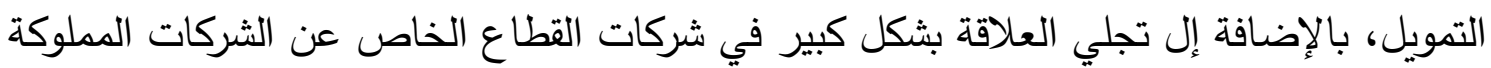
للدولة في ظل ضبط النموذج بقيود التمويل، وتوصلت لنتيجة أساسية مفادها أن قيود التمويل التي

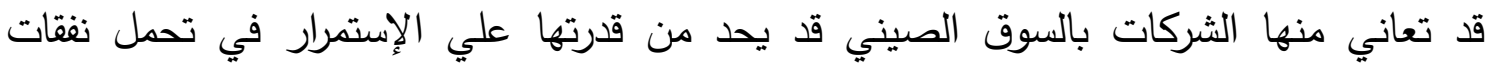
البحوث والتطوير ، الأمر الذي ينعكس بالضرورة علي سلوك التكلفة لديها.

(Chen et al., 2018 (راسة

اختبرت الدراسة علاقة الثقة الإدارية المفرطة لدي كلاً من المدير التنفيذي والمدير المالي علي السلوك غير المتماثل للتكاليف البيعية والإدارية، واجريت الدراسة علي عينة كبيرة من الداريه

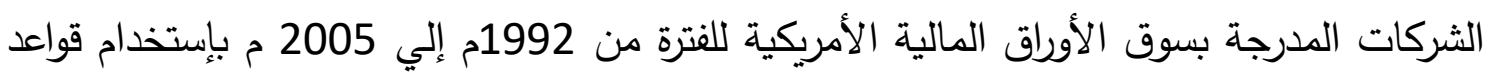
بيانات CRSP Execucomp، وبإجمالي مشاهدات 20280. 
واعتمدت الدراسة في قياس الثقة الإدارية المفرطة علي سلوك المديرين أمام خيارات الأسهر

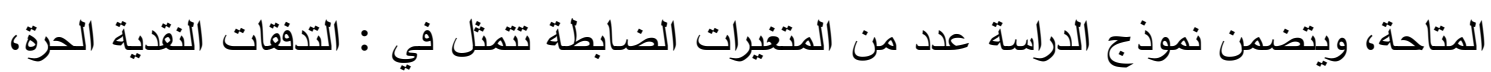
والمدفوعات الثابتة للمديرين، وكثافة العمالة ، وكثافة الأصول، وأداء الأسهر. وتثير نتائج الاراسة إلي عدد من النتائج أهمها : الثقة الإدارية المفرطة لدي كلاً من المدير التتفيذي والمدير المالي ترتبط بعلاقة طردية ومعنوية مع السلوك غير المتماثل للتكاليف البيعية والإدارية

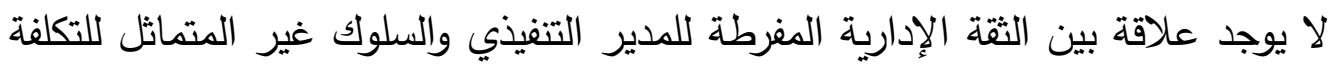
بعد ضبط الثقة الإدارية المفرطة للمدير المالي

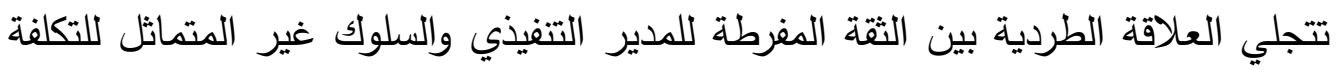

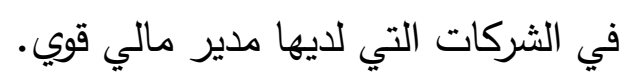

دراسة ( Hur et al., 2019 (

اختبرت الدراسة العلاقة بين الثقة الإدارية المفرطة للمدير والسلوك غير المتماثل لتكاليف البحوث والتطوير، وأشارت الدراسة أن تكاليف البحوث والتطوير تعد جزءاً مهماً من استراتجية

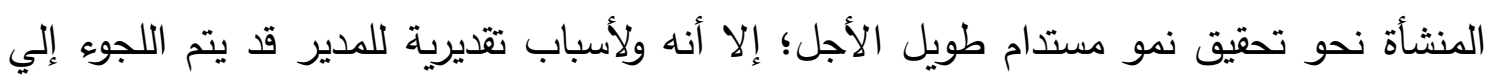
تخفيض تكاليف البحوث والتطوير خلال المدي القصير ، وبالتالي فإن سلوك المدير وخصائصه قد الدابل تلعب دوراً مؤثراً في تماثيلية سلوك تكاليف البحوث والتطوير .

واعتمدت الدراسة علي عينة من الثركات المدرجة بسوق الأوراق المالية الكوري بعد

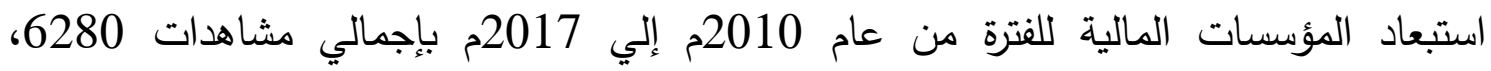
ويتضمن نموذج الدراسة عدد من المتغيرات الضابطة، والتي تتمثل في المتغيرات التالية : كثافة الأصول، والناتج المحلي الإجمالي GDP، ونوع الصناعة، ونجاح المنشأة في زيادة المبيعات

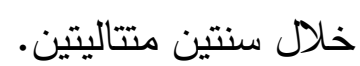

وتوصلت الدراسة إلي أن المديرين التنفيذيين مفرطي الثقة لا يميلون إلي اتخاذ إجراءات لتخفيض تكاليف البحوث والتطوير عند انخفاض حجم المبيعات لأن لديهم الثقة الكاملة بقدراته 
علي استعادة مستويات المبيعات السابقة، وبالتالي ترتبط الثقة الإدارية المفرطة بعلاقة طردية ومعنوية بالسلوك غير المتماثل لتكاليف البحوث والتطوير .

\section{التعليق علي الدراسات السابقة}

• نال موضوع العوامل السلوكية للمدير وتأثيره علي القرارات الإقتصادية المختلفة

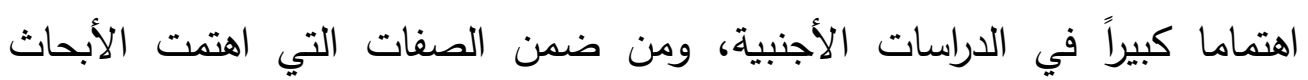

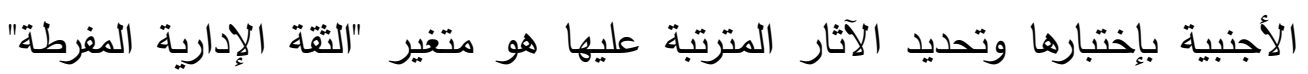
ويظهر ذلك من الأبحاث الحديثة التي تتاولته. • • تعدد وتتوع مقاييس الثقة الإدارية المفرطة، فبعض الدراسات استخدمت خيارات الأسهم

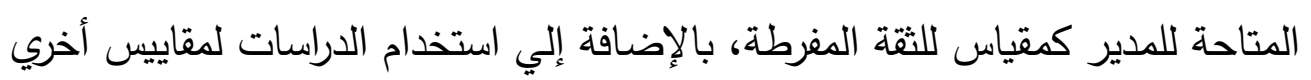

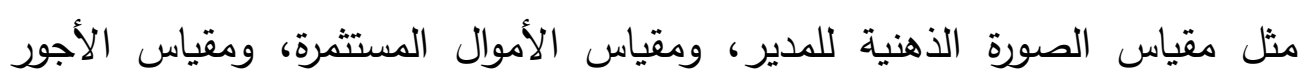
النسبية .. وغيرها. ويرجع ذلك الإختلاف في القياس إلي اختلاف بيئة التطبيق والتي

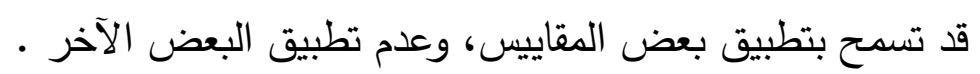

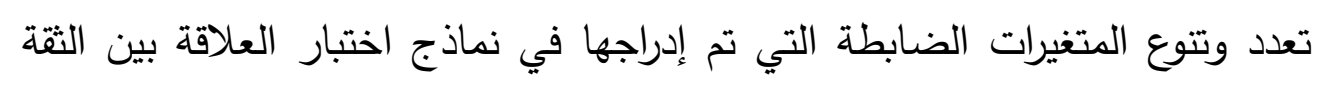

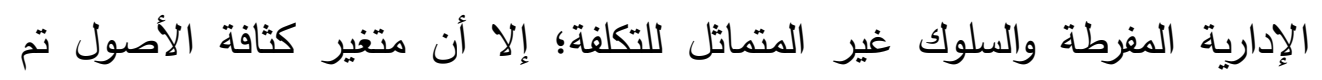

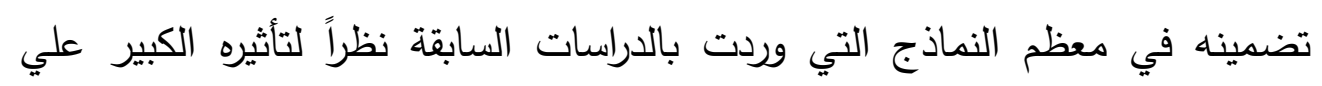
سلوك التكاليف.

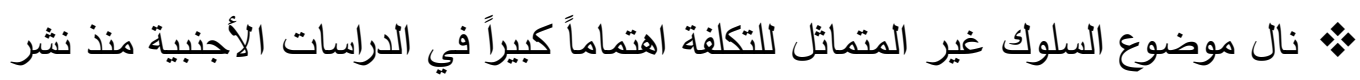
دراسة Banker et al., 2003 وتلي ذلك تيار ضخم من الدراسات والبحوث التي لتئي اهتمت بتدعيم نظرية الدحاسبة بأبعاد وتأثيرات السلوك غير فيار المتماثل، كما ظهر

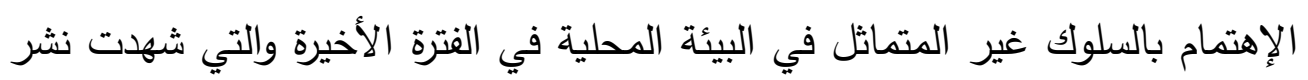
العديد من الدراسات حول السلوك غير المتماثل للتكلفة. • نالت العلاقة بين الثقة الإدارية المفرطة والسلوك غير المتماثل للتكاليف إهتمام العديد

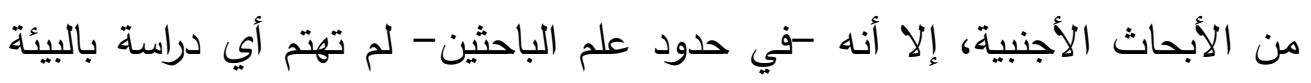

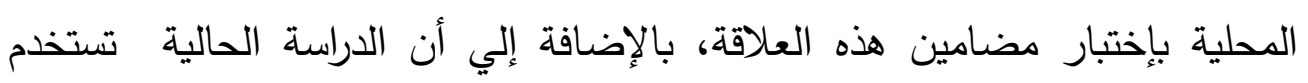


مقياس الإستثمار المعدل بالصناعة كمقياس للثقة الإدارية المفرطة، وبالتالي إتمام الدراسة بشكل إمبريقي.

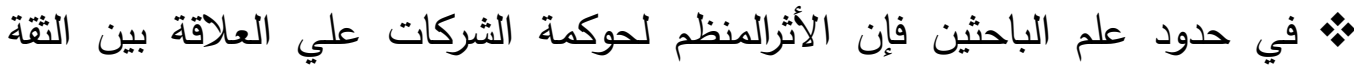

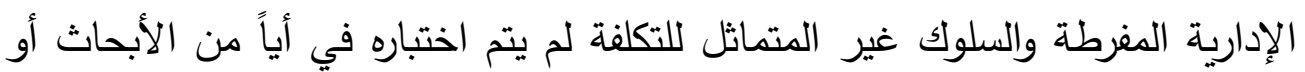
الاراسات سواء بالبيئة الأجنبية أو المحلية.

\section{6. الدراسة الإختبارية}

يهدف هذا الجزء من البحث إلي عرض المنهجية المتبعة في تحقيق أهداف البحث، وفي

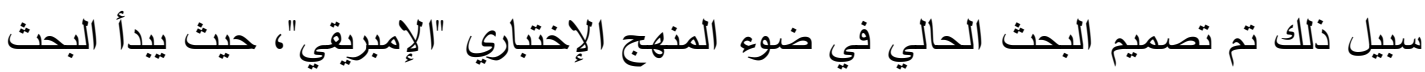

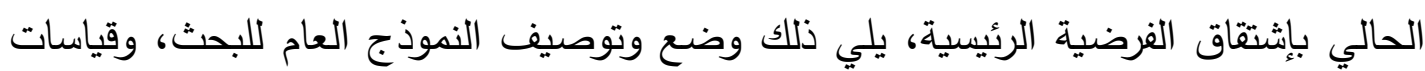

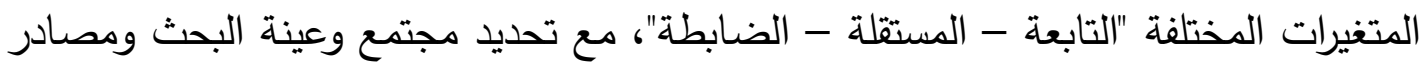

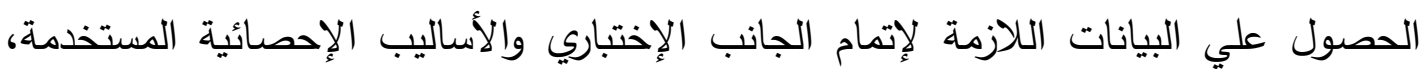

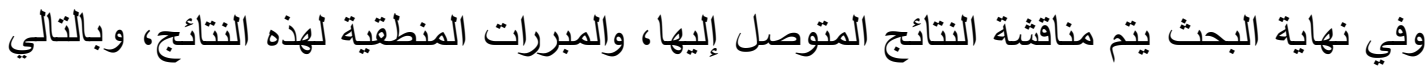
يمكن تقسيم هذا الجزء إلي : 1.6 التصميم الإختباري للبحث . 2.6 اختبار الفرضية الرئيسية للبحث. 3.6 مناقشة النتائج وتفسيرها. وسيتم تناول النقاط السابقة علي النحو التالي : 1.6 ويتضمن هذا القسم تطوير الفرضيات الرئيسية للبحث في ضوء ما توصلت إليه مراجعة

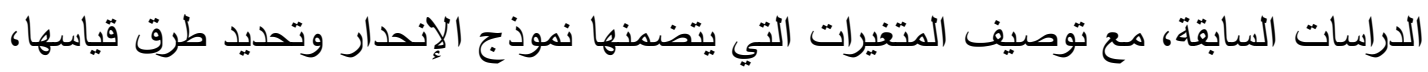
ومصادر البيانات اللازمة لعملية القياس وذلك من خلال النقاط التالية :

1.1.6 تطوير فرضيات البحث :

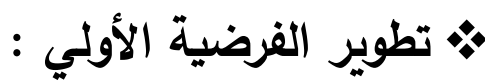


اهتمت الأبحاث الحديثة التي تناولت إدارة التكلفة بظاهرة عدم التماثل في سلوك التكاليف كأحد

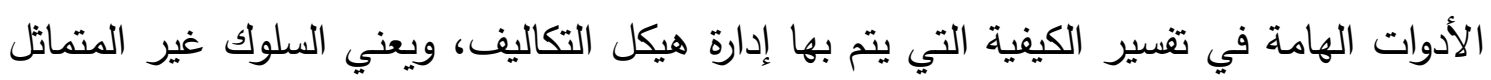

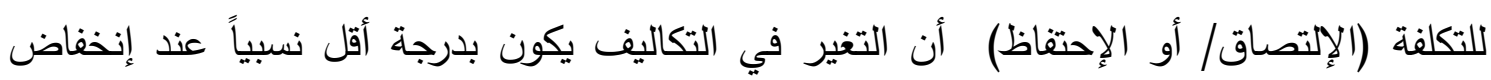

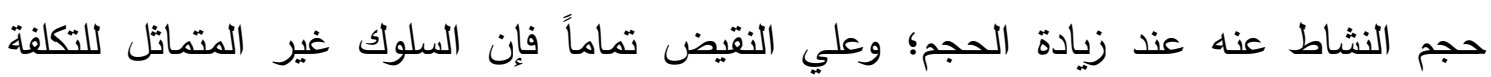
(التخلص) يعني أن التغير في التكاليف يكون بدرجة أعلي نسبياً عند إنخفاض حجم النمان النشاط عنده

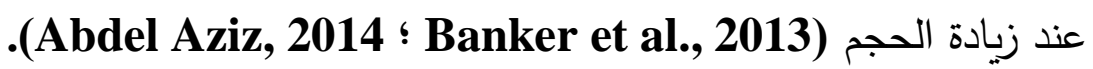
وتثير العديد من الدراسات السابقة إلي أن التباين في سلوك التكاليف يرجع في الأساس إلي

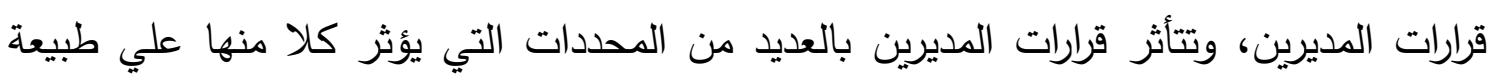

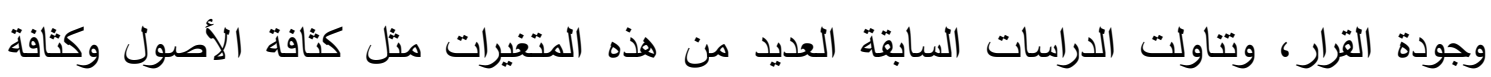

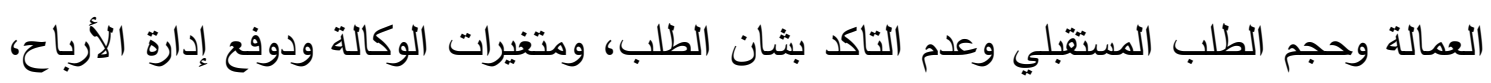

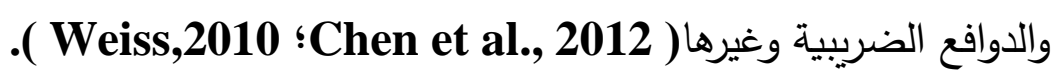
والثقة الإدارية المفرطة هي احدي السمات البشرية الناتجة عن تفاعل العوامل البيئة والإجتماعية

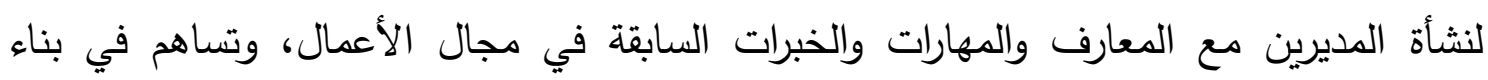

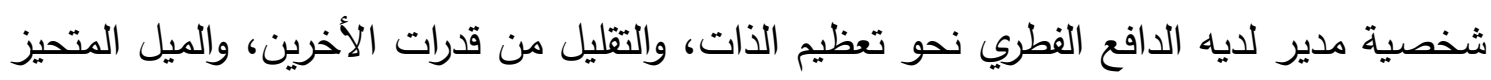
للتفاؤل ، وتفضيل المخاطرة غير المحسوبة. وتدفع الثقة الإدارية المفرطة المدير إلي المبالغة في توقعات حجم الطلب المستقبلي، والقدرة

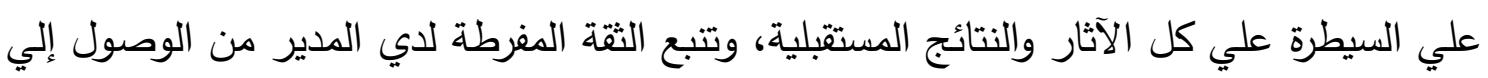

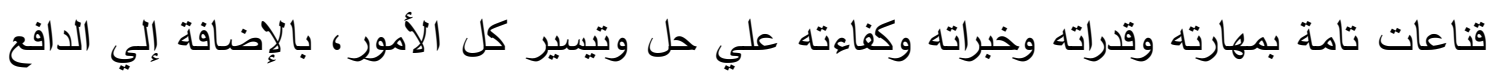
الفطري لديه نحو الميل المتحيز للتفاؤل.

وتؤدي الثقة الإدارية الدفرطة بالددير إلي الإحتفاظ بموارد غير مستغلة لفترات زمنية معينة

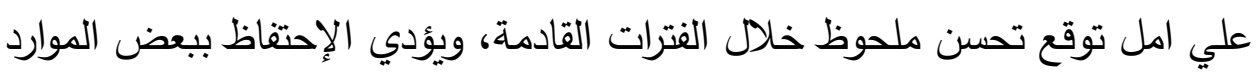

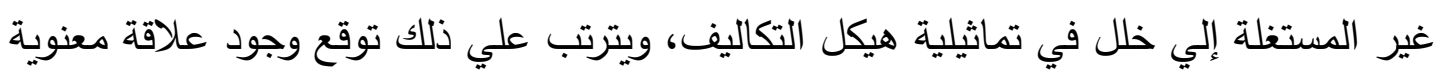

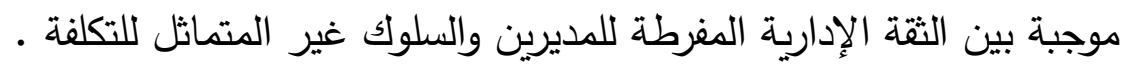
وفي ضوء ما سبق يمكن صياغة الفرضية الأولي للدراسة علي النحو التالي:

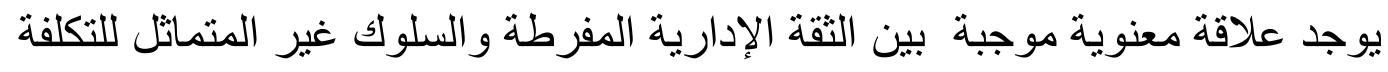




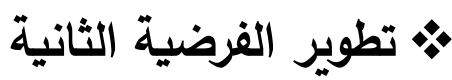

تساهم قواعد حوكمة الثركات في وضع النظم والهياكل وآليات العمل التي تعمل علي مراقبة التصرفات الإدارية بمنشآت الأعمال بهدف تعظيم قيمة المنشأة واستمرارها في المديد المديين القصير والطويل، بالإضافة إلي حماية حقوق جميع الأطراف ذوي العلاقة، وحتي لا تتوغل الإدارة

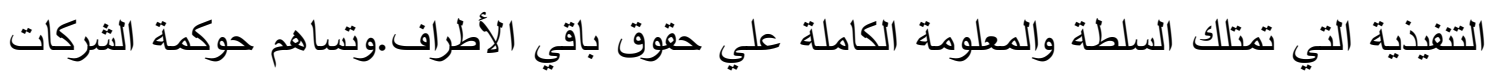

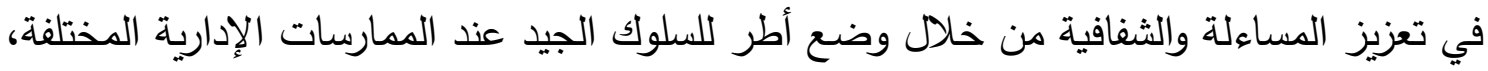

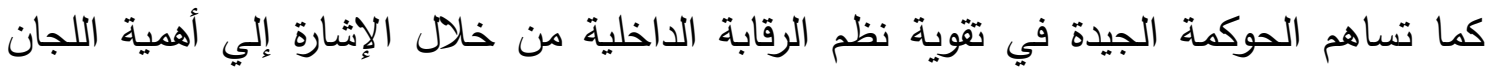

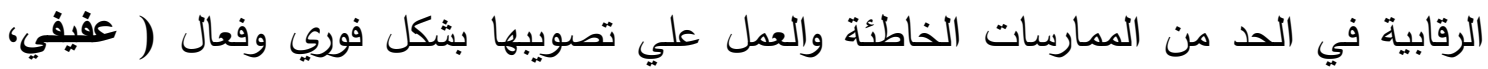

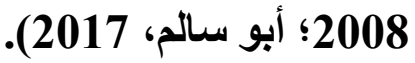

وبالتالي قد تساهم حوكمة الثركات القوية علي تقويم التصرفات المختلفة للمدير التنفيذي والحد من القرارات الإستثمارية التي لم تنطوي علي دراسة كافية بخصوص الآثار والنتائج المترتبة عليها(Malekvar\& Abdoli, 2015)؛ كما قد تساهم الحوكمة القوية في إعادة تفكير المدير

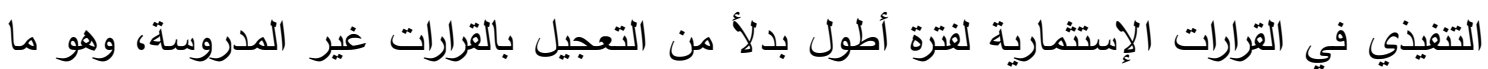

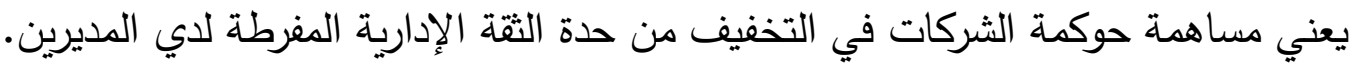
وقد يؤدي الحد من آثار الثقة الإدارية المفرطة الناتج عن مساهمة حوكمة لشركات القوية إلي التخفيف من حدة السلوك غير المتماثل للتكلفة الناتج عن الثقة الإدارية المفرطة، ما يعني أن الندان مساهمة السلوك المفرط للمدير في سلوك التكلفة سيصبح محدود وفي ضوء ما سبق يمكن صياغة الفرضية الثانية الدراسة علي النحو التالي: تعتدد العلاقة بين الثقة الإدارية الدفرطة والسلوك غير المتداثل للتكاليف علي درجة

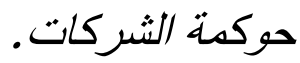


$3 \beta+\log \left(\frac{(O P R i, t)}{(O P R i, t-1)}=\beta o+\beta 1 \quad \log \left(\frac{\text { Salesi }, t}{\text { Salesi,t-1 }}\right)+\beta 2\right.$ DecDummy DecDummy. $\log \left(\frac{\text { Salesi,t }}{\text { Salesi, }-1}\right)+\beta 4 \log \left(\frac{\text { Salesi }, t}{\text { Salesi },-1}\right) *$ OVERCON $_{i t}+$ $\beta 5 \log \left(\frac{\text { Salesi,t }}{\text { Salesi,t-1 }}\right) *$ FCF $_{i t}+\beta 6 \log \left(\frac{\text { Salesi }, t}{\text { Salesi }, t-1}\right) *$ SUCCE $_{i t}+\beta 7$ $\log \left(\frac{\text { Salesi }, t_{\text {Salesi } t-1}-1}{\text { Sa }^{2}}\right) *$ ASINT $_{i t}+\beta 8$ DecDummy. Log $\left(\frac{\text { Salesi }, t}{\text { Salesi }, t-1}\right) * \operatorname{OVERCON}_{i t}$ $+\beta 9$ DecDummy. $\log \left(\frac{\text { Salesi,t }}{\text { Salesi,t }-1}\right) *$ FCF $_{i t}+\beta 10$ DecDummy. $\log \left(\frac{\text { Salesi }, t}{\text { Salesi }, t-1}\right) *$ SUCCE $_{i t}+\beta 11$ DecDummy. Log $\left(\frac{\text { Salesi }, t}{\text { Salesi }, t-1}\right) *$ ASINT $_{i t}+$ $\varepsilon_{\mathrm{i}, \mathrm{t}}+\mathrm{ASINT}_{i t}+\beta 15$ SUCCE $_{i t} \beta 13$ FCF $_{i t}+\beta 14 \beta 12$ OVERCON $_{i t}+$ جدول رقم (4): توضيح للرموز الواردة بنماذج الانحدار

\begin{tabular}{|c|c|}
\hline | المصروفات التشغيلية للشركة i للفترة t & ${ }_{i} \mathbf{O P R}_{i}$ \\
\hline | المصروفات التشغيلية للشركة i للفترة 1-t & ${ }_{t-1} \mathbf{O P R}_{i}$ \\
\hline | اللوغاريتم الطبيعي & $\log$ \\
\hline 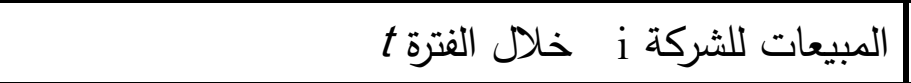 & ${ }_{t}$ Sales $i$ \\
\hline | المبيعات للشركة i خلال الفترة 1-t & Sales $i t-1$ \\
\hline متغير وهمي لفترة انخفاض المبيعات & DecDummy \\
\hline الثقة الإدارية المفرطة للمدير بالثركة i خلال الفترة t & OVERCON $_{i t}$ \\
\hline | النجابقة في زيادة المبيعات للشركة i خلال الفترة t ، والفترة & SUCCE $_{i t}$ \\
\hline التدفقات النقدية الحرة للشركة i خلال الفترة t & FCF $i t$ \\
\hline t خثافة الأصول للشركة i خلا الفترة t & ASINT $_{i t}$ \\
\hline المتبقي الإحصائي من تقدير النموذج (الخطأ العشوائي) & $\varepsilon_{\mathrm{i}, \mathrm{t}}$ \\
\hline
\end{tabular}




\subsection{6 التعريف الإجرائي لمتغيرات الدراسة}

> المتغير التابع : السلوك غير المتماثل للتكاليف التثغيلية : واعتمدت الدراسة في تقدير قياس السلوك غير المتماثل للتكاليف التثغيلية علي المنهجية المتبعة في دراسة Anderson et al., 2003 وذلك كما يلي :

$$
+\log \left(\frac{(\text { OPRi,t })}{(\text { OPR }, t-1)}=\beta 0+\beta 1 \log \left(\frac{\text { Salesi,t }}{\text { Salesi,t-1 }}\right)+\beta 2\right. \text { DecDummy }
$$

DecDummy. $\log \left(\frac{\text { Salesi,t }}{\text { Salesi,t-1 }}\right)+\varepsilon \mathrm{i}, \mathbf{3 \beta}$

ويظهر عدم التماتل في سلوك التكاليف إذا كان : 3 م أقل من صفر.

التعريف الإجرائي للمتغير المستقل:

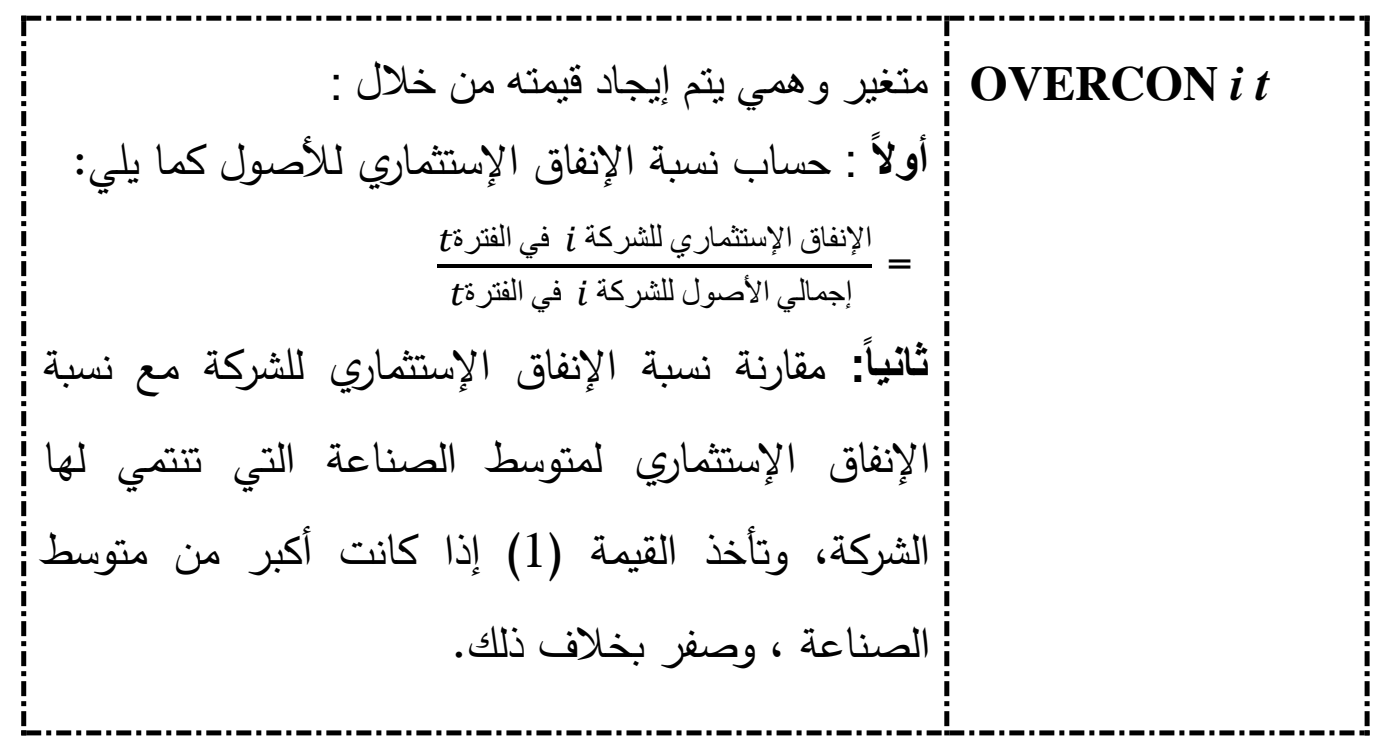

التعريف الإجرائي للمتغير المنظ :

يتم بناء مؤشر لمدي قوة حوكمة الثركات بعينة الدراسة ، ويتكون المؤشر من 7 متغيرات، ويعرض الجدول رقم (5) المتغيرات التي ينظوي عليها المؤشر مع التعريف الإجرائي لها:

جدول رقم (5): المتغيرات التي يتضمنها مؤشر الحوكمة والقياس الإجرائي لها 


\begin{tabular}{|c|c|}
\hline القياس الإجرائي & المتغير \\
\hline 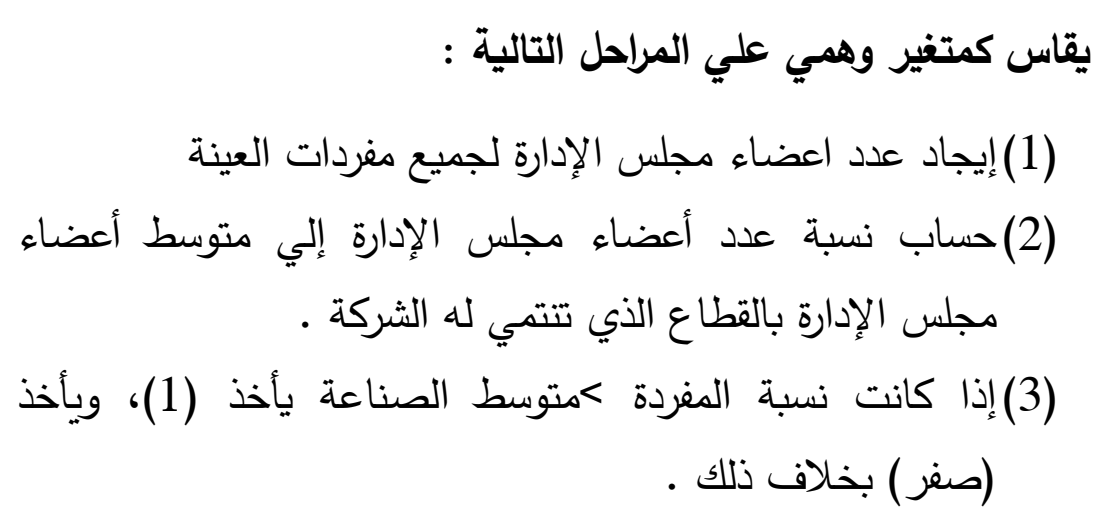 & حجم مجلس الإدارة \\
\hline 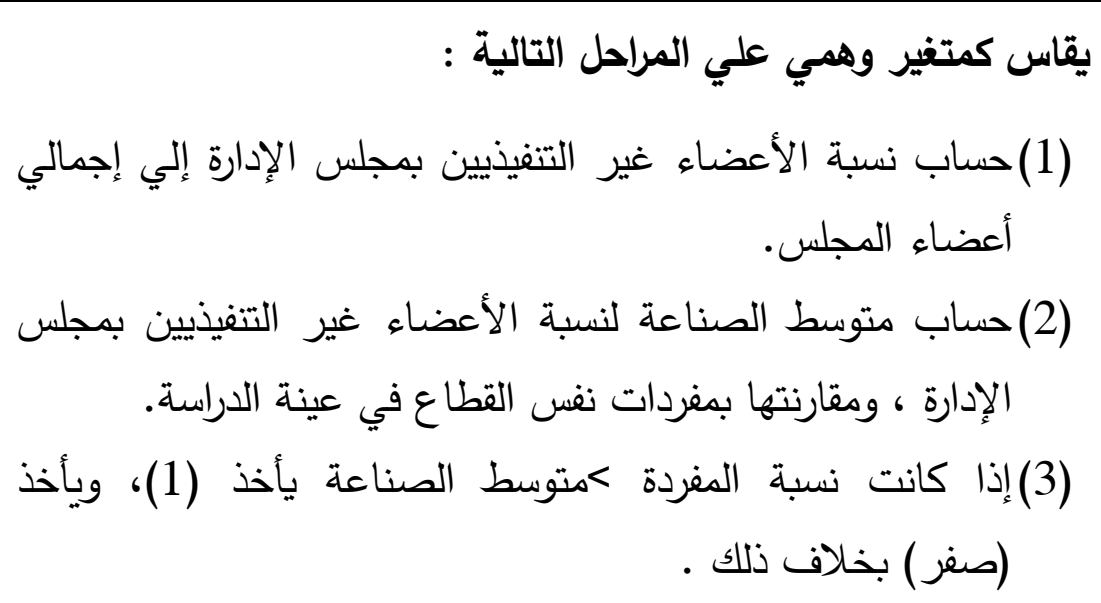 & مجلس الإدارة \\
\hline نقاس كمتغير وهمي يأخذ (صفر) إذا كان المدير التنفيذي الأول هو & إزدو اجية دور التنفيذي \\
\hline 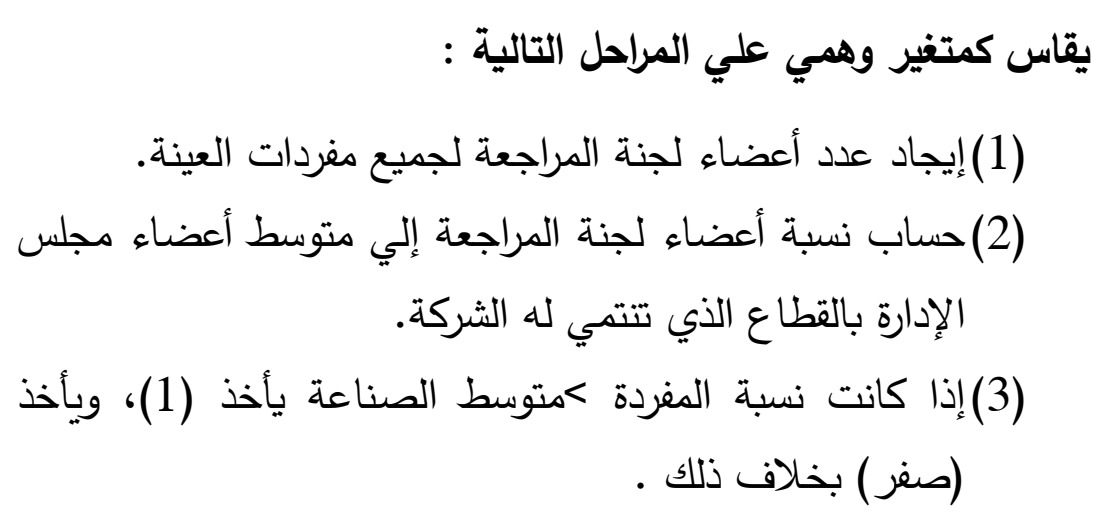 & حجم لجنة \\
\hline يقاس كمتغير وهمي علي المراحل التالية : & استقلالية لجنة المر اجعة \\
\hline
\end{tabular}




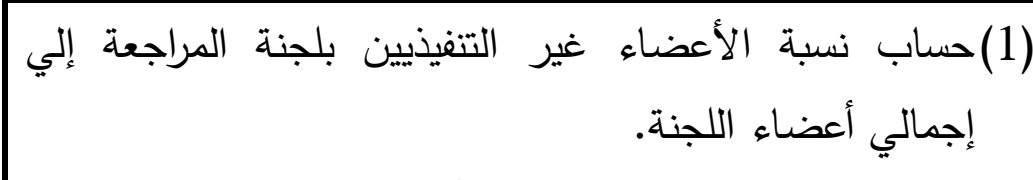

(2) حساب متوسط الصناعة لنسبة الأعضاء غير التنفيذيين بلجنة

المراجعة ، ومقارنته بمفردات نفس القطاع في عينة الدراسة.

(3) إذا كانت نسبة المفردة >متوسط الصناعة يأخذ (1)، ويأخذ

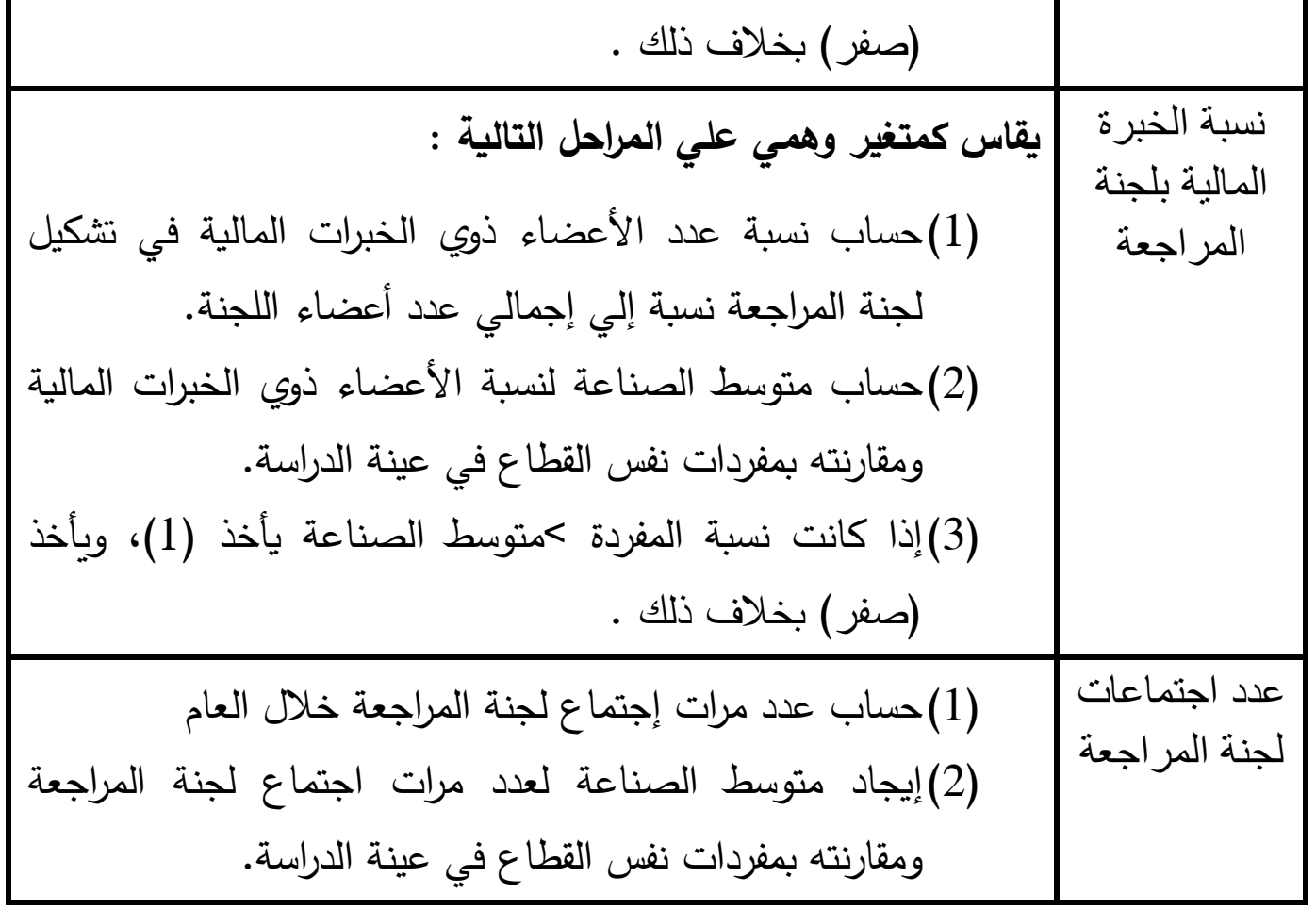

بعد إدر اج قيمة لكل متغير من المتغيرات السابقة لكل مفردات العينة يتم ما يلي :

• عمل مؤشر مركب سنوي لكل شركة من الشركات الممثلة في عينة الدراسة ، حيث

$$
\text { تأخذ كل شركة علي قيمة سنوية من (7). }
$$

• يتم مقارنة القيمة السنوية لكل شركة مع متوسط الصناعة، وتأخذ الشركة (1) إذا

$$
\text { كانت أكبر من متوسط الصناعة، وتأخذ (صفر) بخلاف ذلك . }
$$

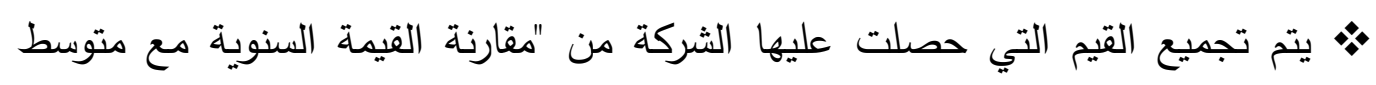

الصناعة"، لتأخذ كل شركة تقييم للحوكمة من 9 (يسمي لاحقاً مقياس 9) وهو عدد سنوات التي تجري عليها الإختبارات الإحصائية بالبحث الحالي، ويتم هذا الإجراء نظراً لإعتماد الدراسة علي سلسة متتالية لكل شركة، وبالتالي لا يمكن الفصل لنفس الشركة لإلت 
خلال مدة الدراسة، وبمعني أن الثركة ستدرج بثكل كامل تحت عينة بمواصفات حوكمة قوية أو العكس. • يتم حساب متوسط للقيم التي حصلت عليها كل شركة علي مقياس (9)، فإذا كانت القيم التي حصلت عليها الثركة أكبر من متوسط العينة يتم إدراج الشركة بالعينة ذات خصائص حوكمة قوية ، وأما إذا حصلت الثركة علي قيمة أقل من متوسط العينة العينة

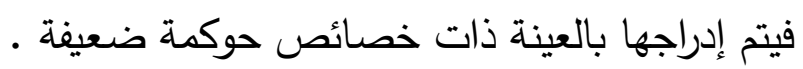
> التعريف الإجرائي للمتغيرات الضابطة: يعرض الجدول رقم (6) التعريف الإجرائي للمتغيرات الضابطة للبحث الحالي. جدول رقم (6):التعريف الإجرائي للمتغيرات الضابطة لنموذج الإندار المتعدد للبحث

\begin{tabular}{|c|c|}
\hline القياس & المتغير \\
\hline اللوغارتيم الطبيعي لإجمالي الأصول إلي إجمالي المبيعات & كثافة $\quad \begin{array}{r}\text { ASINT } \\
\quad \text { الأصول }\end{array}$ \\
\hline 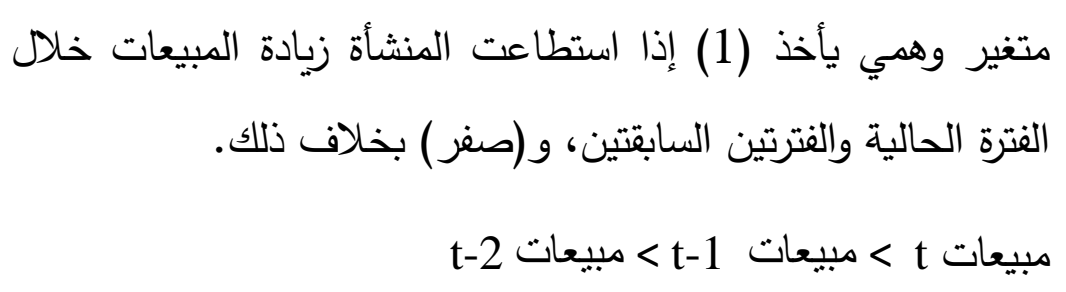 & المبيعات المنشأة في زيادة \\
\hline 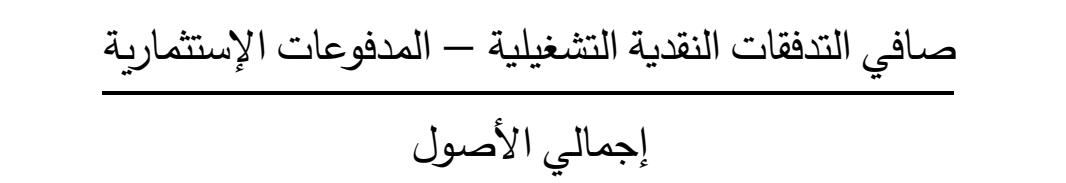 & $\begin{aligned} & \text { التقفقية الحرة } \\
& \text { FCFit }\end{aligned}$ \\
\hline
\end{tabular}




\section{مبررات إدراج المتغيرات الضابطة}

ASINT

يعبر متغير كثافة الأصول علي مدي أهمية أصول المنشأة في تحقيق المبيعات، بمعني أن

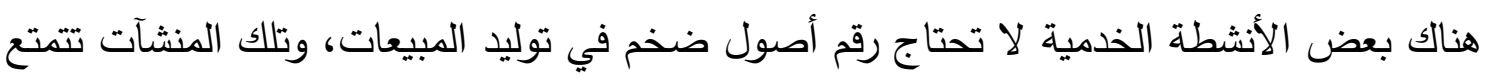

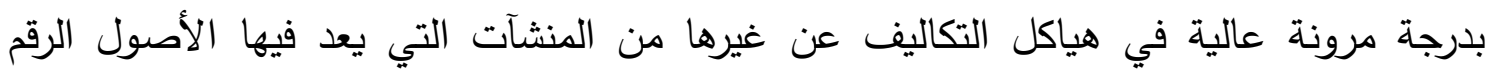

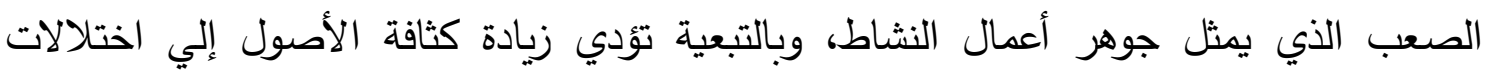

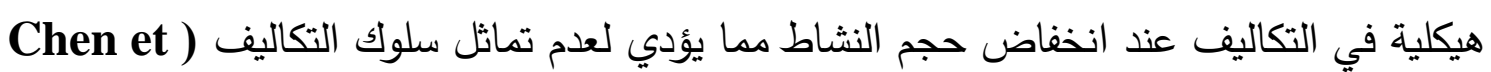
.(Chen et al., 2014 ؛ Bruggen et al.,2014 ؛al., 2012 FCF التدفقات النقدية الحرة

يستخدم متغير التدفقات النقدية الحرة كمقياس للتعبير عن ظاهرة الميل لبناء الإمبراطورية وتعظيم الدوافع الإنتهازية لدي المدير وهي احدي مشكلات الوكالة المتعارف عليها، وتتفاقم آثار

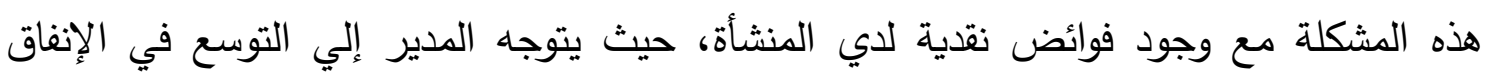
الترفي غير المضيف للقيمة، كتعيين عدد كبير من المساعدين، وتغيير المكاتب والسيارات، وتعيين

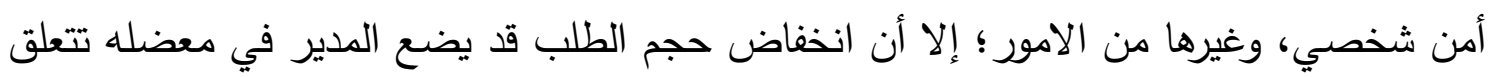

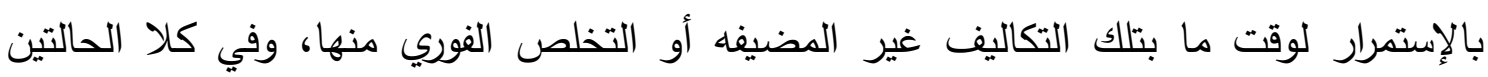
سيؤدي إلي اختلالات في تماثيلية هيكل التكاليف ، مما يؤدي إلي ظاهرة عدم التماثل في سلوك Dey, ؛Jensen, 1986 (Richardson, 2006, TiTman et al., 2004 ) (التكاليف .2008

\section{SUCCEit نجاح المنثأة في زيادة المبيعات}

يستخدم مقياس النجاح في زيادة المبيعات للتعبير عن استقرار الوضع بالمنشأة خلال الفترات السابقة، وبالتالي فإن أي خلل في أحجام الطلب خلال الفترة الحالية هو خلل آني غير مستمر ، وبالتالي إحتمالية استعادة مستويات الطلب لأرقامها المعهودة خلال فترة قصيرة، مما يدفع إدارة

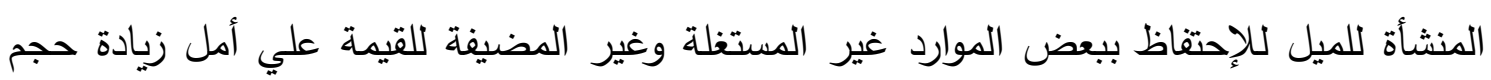
النشاط، الأمر الذي يؤدي لحدوث ما يعرف بظاهرة عدم التماثل في سلوك التكاليف. 


\section{1 .6 مجتمع وعينة البحث:}

يعتمد البحث علي عينة من الثركات المقيدة بسوق المال المصري (المجتمع)، وبالتالي تخضع لكل التعليمات والتوجيهات من هيئة الرقابة المالية، من أجل استمرار القيد، وتتوزع العينة علي القطاعات الإقتصادية المختلفة خلال الفترة من عام 2010م إلي عام 2018 م، مع الإعتماد علي بيانات عام 2009 كسنة أساس لحساب التغير لعدد من متغيرات الدراسة خلال عام 2010، وتتكون العينة الميسرة للبحث الحالي من عدد 106 شركة (أنظر : ملحق 1) بعد استبعاد الثركات التي تتنمي لقطاع الخدمات المالية نظراً لإختلاف طبيعة عملها وطبيعة القواعد الدحاسبية الحاكمة لإعداد التقارير المالية، ويوضح الجدول رقم ( 7 ) التوزيع القطاعي لعينة البحث. جدول رقم (7): التوزيع القطاعي لعينة البحث

\begin{tabular}{|c|c|c|c|}
\hline النسبة المئوية & عدد الثركات & القطاع & b \\
\hline 15.09 & 16 & التشييد و مواد البناء & $\mathbf{1}$ \\
\hline 13.21 & 14 & 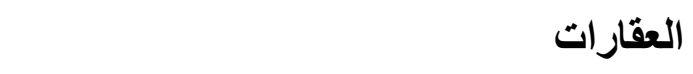 & 2 \\
\hline 7.55 & 8 & السياحة و الترفيه & 3 \\
\hline 6.60 & 7 & الكيماويات & 4 \\
\hline 14.15 & 15 & الأغذية و المشروبات & 5 \\
\hline 8.49 & 9 & المنتجات المنزلية و الثخصية & 6 \\
\hline 11.32 & 12 & الذدمات و المنتجات الصناعية و السيارات & 7 \\
\hline 9.43 & 10 & الموارد الأساسية والمرافق & 8 \\
\hline 3.77 & 4 & الاعلام والاتصالات والبترول & 9 \\
\hline 10.38 & 11 & الرعاية الصحية و الأدوية & 10 \\
\hline 100 & 106 & الإجمالي & \\
\hline
\end{tabular}




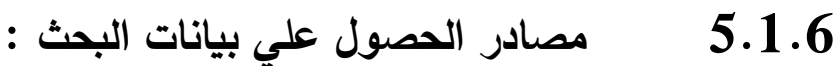

اعتمد البحث علي مصادر متتوعة للحصول علي البيانات اللازمة لإتمام الدراسة الإمبريقية

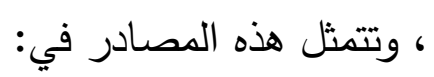

> الهيئة العامة للرقابة المالية

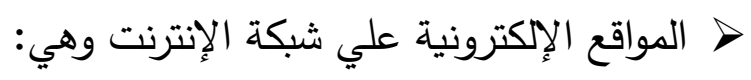

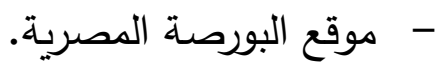
- - مواقع شركات عينة الدراسة.

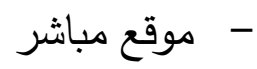

2.6

يساهم الجزء التالي في عرض الإحصاءات الوصفية وتحليلها بهدف التعرف علي السمات التي تنطوي عليها عينة البحث، بالإضافة إلي عرض الأساليب الإحصائية المستخدمة في اختبار فرضيات البحث، وعرض وتحليل نتائج تحليل الإنحدارمن خلال مناقثة النقاط التالية:

1.2.6 الإحصاء الوصفي والتعليق عليه 2.2.6 الأساليب الإحصائية والتحقق من شروطها. 3.2.6 عرض نتائج تحليل الإنحدار والتعليق عليها. 4.2.6 عرض ومناقثة نتائج فرضيات الدراسة 
وفيما يلي مناقشة للنقاط السابقة : 1.2.6 الإحصاءات الوصفية لمتفيرات البحث. جدول رقم (8): الإحصاءات الوصفية لمتغيرات البحث

\begin{tabular}{|c|c|c|c|c|c|}
\hline المعياري & الأقصي & الأدني & الوسبط & الوسط & المتفير \\
\hline 184 & 3140 & 0.7595 & 205 & 688 & التكاليف التثغيلية (مليون جنيه) \\
\hline 64 & 309 & 7 & 33 & 50 & كثافة الأصول (\%) \\
\hline 13.87 & 280 & صفر & 2.29 & 5.85 & الإنفاق الإستثماري (\%) \\
\hline 2.8 & 17 & 1 & 7 & 7.8 & حجم مجلس الإدارة (عضو) \\
\hline 24 & 1 & صفر & 72.8 & 65.9 & استقلالية مجلس الإدارة (\%) \\
\hline 0.99 & 8 & صفر & 3 & 3.4 & حجم لجنة المراجعة (عضو) \\
\hline 3.52 & 40 & صفر & 4 & 5 & عدد اجتماعات لجنة المراجعة (مرة) \\
\hline 30.8 & 100 & صغر & 33.3 & 46.9 & الخبرات المالية بفريق لجنة المراجعة(\%) \\
\hline 22.1 & 100 & صفر & 100 & 88.7 & استقلالية لجنة المراجعة (\%) \\
\hline 25 & 462 & $120-$ & 33 & 6 & التدفقات النقدية الحرة (\%) \\
\hline 209 & 3600 & 0.180 & 223 & 777 & ايراد المبيعات (مليون جنيه) \\
\hline
\end{tabular}

وبإمعان النظر في الأرقام التي تضمنها الجدول السابق يمكن إبراز عدد من الملاحظات : تتراوح قيم متغير التكاليف التشغيلية في عينة البحث من 759.5 الف جنيه إلي 3140 مليون جنيه وهو ما يعد مؤشر لتقاوت كبير بين مفردات عينة متغير التكاليف التثغيلية؛ 
في حين بلغ متوسط قيم المتغير وقيمة الوسيط له 688 مليون جنيه، 205 مليون جنيه علي الترتيب، وبلغ الإنحراف المعياري للمتغير 184 مليون جنيه.

يعد متغير كثافة الأصول أحد المتغيرات الهامة للتعبير عن مدي إعتمادية المنشآت في توليد

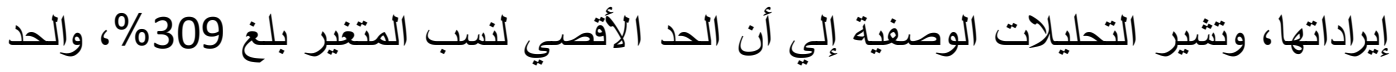

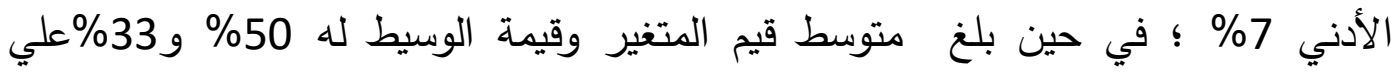
الترتيب، وبلغ الإنحراف المعياري للمتغير 64\% المبن يعبر متغير التدفقات النقدية الحرة عن مدي تجذر مشكلات الوكالة في الثركات الممثلة لعينة الدراسة، حيث تدفع الفوائض النقدية إلي قيام إدارة المنشأة بتوجيه الفوائض إلي أنشطة لئنة

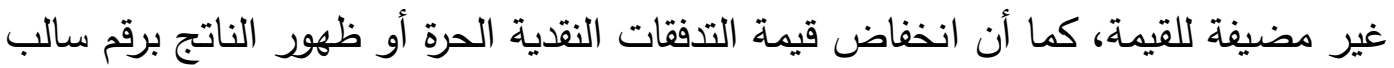
قد يعد مؤشراً لإنخفاض الفوائض النقدية المتاحة للإدارة استخدامها في أنثطة غير مضيفة للقيمة، وتتطوي التحليلات الوصفية لمتغير التدفقات النقدية الحرة علي فجوة كبيرة بين

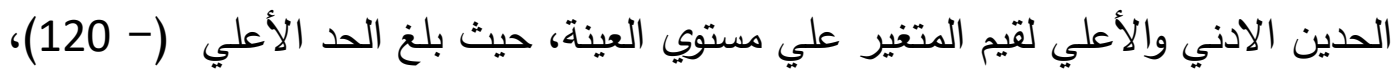

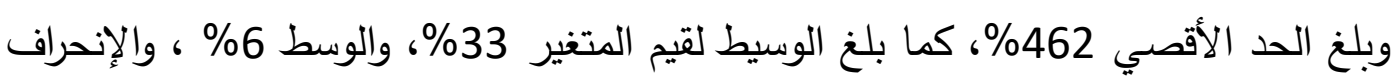

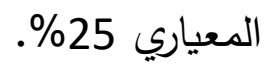

تستخدم نسبة الإنفاق الإستثماري كمقياس لظاهرة الثقة الإدارية المفطرة لاي الدديرين، وبالتحديد عند زيادتها عن متوسط القيمة للقطاع الذي تتمي له الثركة، وتثير التحليلات

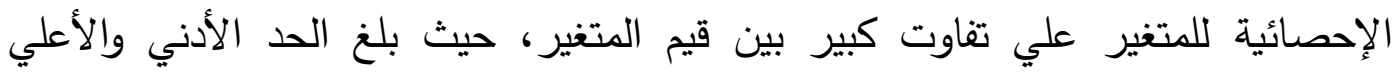

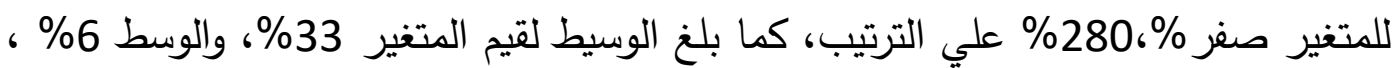
والإنحراف المعياري 25\%. وجود مدي واسع لقيم المبيعات في مفردات العينة ، حيث تشير التحليلات الإحصائية إلي

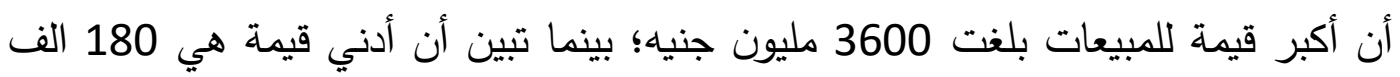
جنيه وهو يعني وجود تفاوت كبير بين مفردات العينة، وبلغ الوسيط لقيم المتغير 233 مليون جنيه والوسط 777 مليون جنيه، والإنحراف المعياري 209 مليون جنيه. اعتمد البحث الحالي علي مؤشر لقياس حوكمة الشركات، وبناء عليه يتم تقسيم العينة إلي مجموعتين أحداهم بخصائص حوكمة قوية، والأخري بخصائص حوكمة ضعيفة، ويتضمن ولئركن 
البناء الهيكلي للمؤشر علي عدد من المتغيرات، وفيما يلي مناقثة وتحليل الإحصائيات الوصفية لبعض قيم متغيرات المؤشر:

م تتضارب أعداد أعضاء مجلس الإدارة من شركة لأخري في شركات العينة، حيث وصل

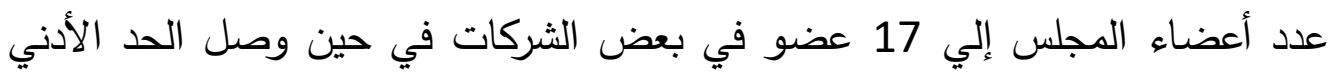

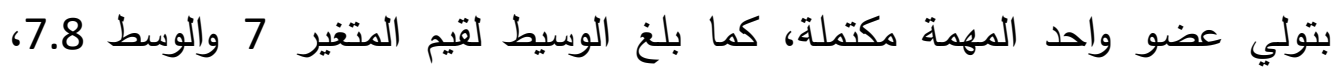
والإنحراف المعياري 2.8.

م تتفاوت أحجام لجان المراجعة من شركة لأخري من الشركات المكونة لمفردات العينة،

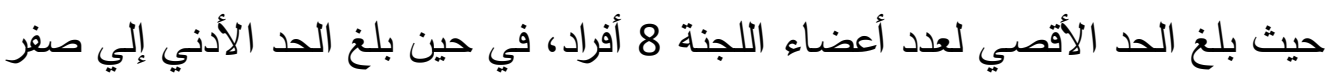

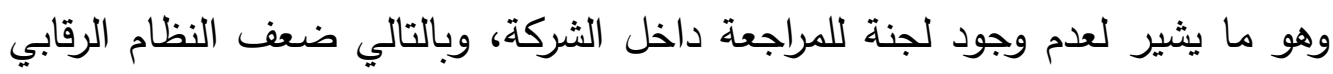

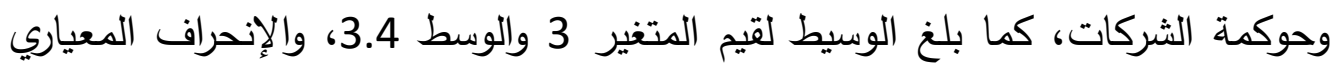

0.99

م يشير متغير استقلالية مجلس الإدارة إلي عدد الأعضاء غير التتفيذيين إلي الأعضاء

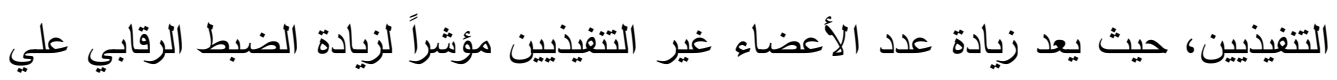

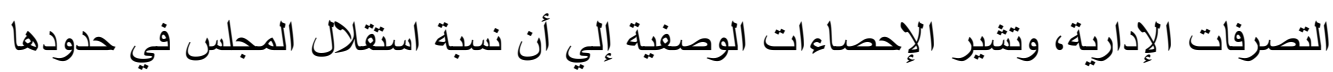

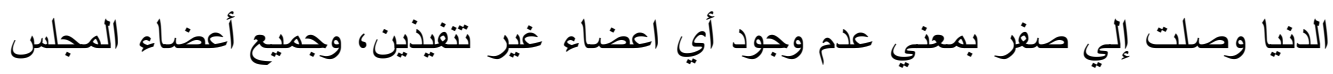

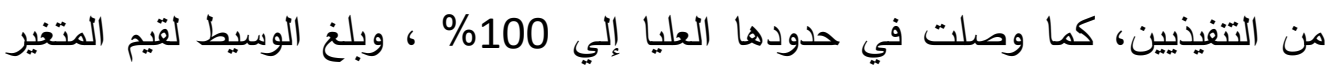
72.8 والوسط 65.9،والإنحراف المعياري 24. م تلعب لجان المراجعة الداخلية دوراً هاماً في ضبط النظم الداخلية، والحد من حالات الهدر والتلاعب، عن طريق المتابعة والمناقثة الدورية لكل المستجدات التي تطرأ علي لـاني

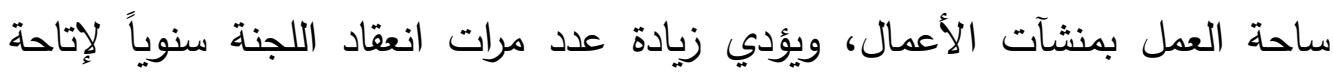
الفرصة لتناول ومتابعة حركة العمل بثكل اكثر ديمومة، وتثير نتائج التحليل التماديل الإحصائي إلي أن عدد مرات انعقاد لجان المراجعة في حدوده القصوي 8 مرات سنوياً

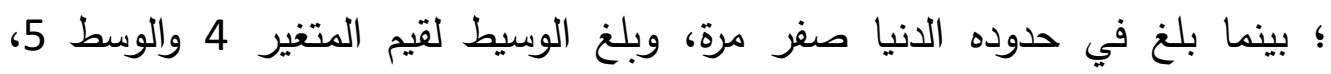
والإنحراف المعياري 0.99. 
م تتكون لجان المراجعة من تخصصات مختلفة لمتابعة حركة العمل بالمنثأة، إلا أن توافر

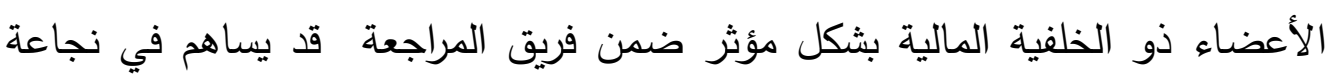

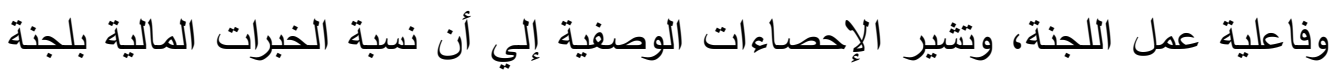

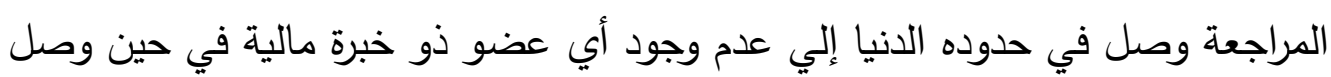

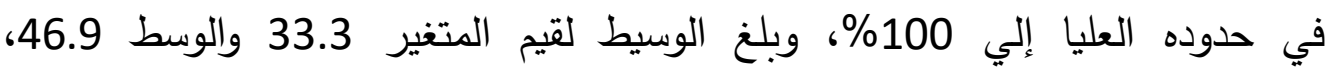
والإنحراف المعياري 24.

م يشير متغير استقلالية لجنة المراجعة إلي عدد الأعضاء غير التنفيذيين إلي إجمالي

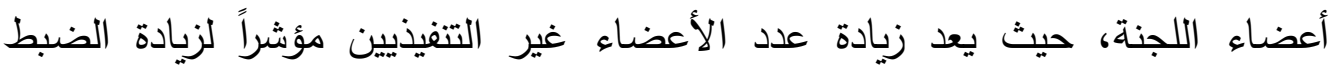

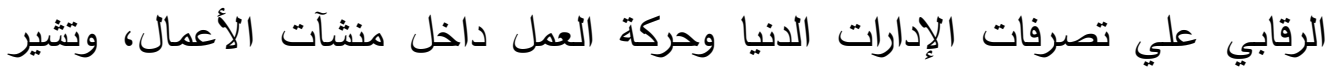

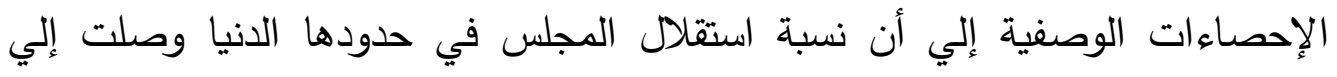

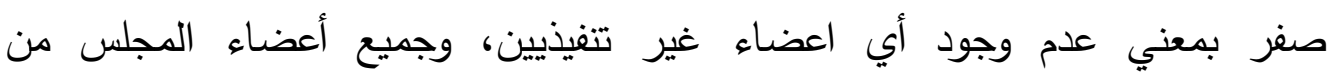

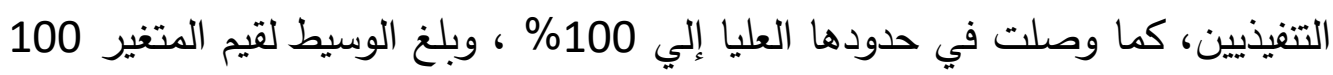
والوسط 88.7، والإنحراف المعياري 22.1.

2.2.6 الأساليب الإحصائية والتحقق من شروطها.

اعتمد البحث علي عدد من البرامج والحزم الإحصائية المتنوعة في سبيل إتمام التحليلات

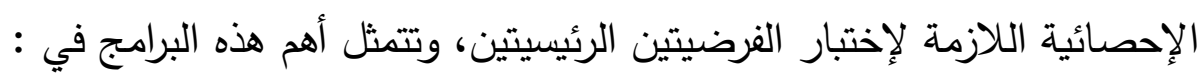

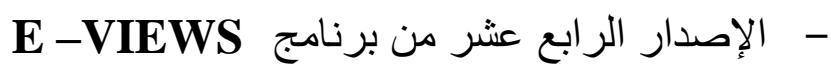

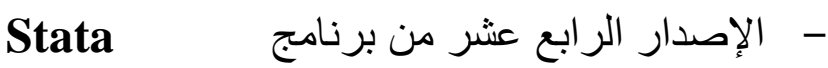

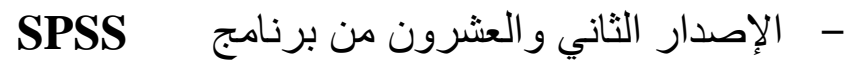
1.2.2.6 مصفوفة بيرسون للإرتباطات الثنائية تساهم مصفوفة إرتباط بيرسون في توضيح طبيعة واتجاه العلاقة بين المتغيرات التي

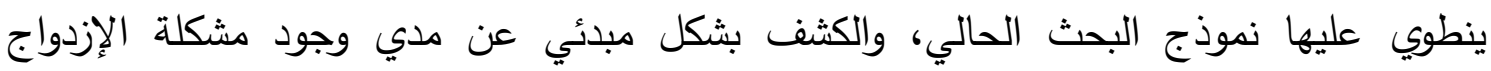

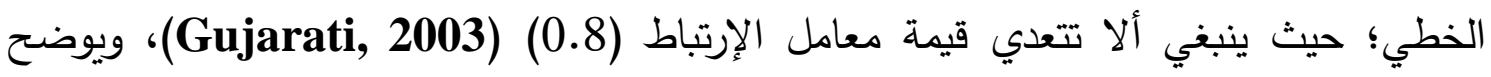
الجدول رقم(9) مصفوفة ارتباط بيرسون بين متغيرات البحث الحالي. 
الثقة الإدارية والسلوك غير المتماثل

د. محمد سليمان ، د. أحمد بغدادى

جدول رقم (9): مصفوفة ارتباط بيرسون

\begin{tabular}{|c|c|c|c|c|c|c|c|c|c|c|c|c|c|c|c|c|}
\hline LCS"CONF & LCS"SUC & LCS"FCF & LCS*ASINT & DLCS*CONF & DLCS*SUC & DLCS"FCF & DLCS ASI & ASI & FCF & suc & CONF & DLCS & DUM & LCS & LCOP & الهتغيرات \\
\hline & & & & & & & & & & & & & & & 1 & LOP \\
\hline & & & & & & & & & & & & & & 1 & $\begin{array}{c}0.7170 \\
\cdot 0.000\end{array}$ & LCS \\
\hline & & & & & & & & & & & & & 1 & \begin{tabular}{|l|l}
$0.435-$ \\
$\bullet 0.000$
\end{tabular} & $\begin{array}{c}0.575- \\
\cdot 0.000\end{array}$ & DUM \\
\hline & & & & & & & & & & & & 1 & \begin{tabular}{|l|}
$0.420-$ \\
0.000
\end{tabular} & \begin{tabular}{|l|l|}
0.6393 \\
& 0.000
\end{tabular} & $\begin{array}{l}0.563- \\
-0.000\end{array}$ & DLCS \\
\hline & & & & & & & & & & & 1 & $\begin{array}{l}0.0445 \\
0.1337\end{array}$ & \begin{tabular}{|l|}
$0.085-$ \\
0.003
\end{tabular} & \begin{tabular}{|l}
0.0245 \\
0.4098
\end{tabular} & $\begin{array}{l}0.0388 \\
0.1914\end{array}$ & CONF \\
\hline & & & & & & & & & & 1 & $\begin{array}{c}0.0326 \\
0.272\end{array}$ & $\begin{array}{l}0.1300 \\
\cdot 0.000\end{array}$ & $\begin{array}{l}0.230- \\
0.000\end{array}$ & \begin{tabular}{|l|l|l|l|l}
$\cdot 0.000$ \\
0.00
\end{tabular} & $\begin{array}{l}0.142 \\
\cdot 0.000\end{array}$ & suc \\
\hline & & & & & & & & & 1 & $0.034-$ & 0.2724 & 0.087 & $0.103-$ & 0.022 & 0.022 & FCF \\
\hline
\end{tabular}




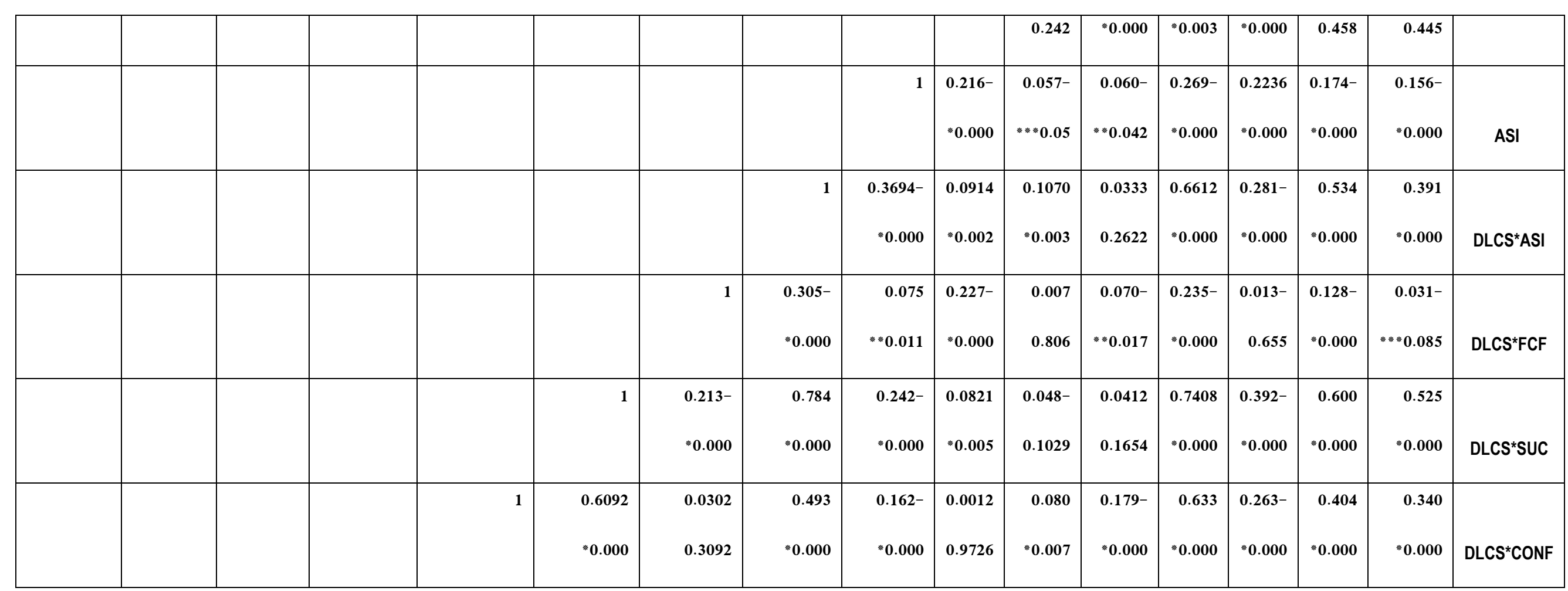




\section{تابع جدول رقم (9): مصفوفة ارتباط بيرسون}

\begin{tabular}{|c|c|c|c|c|c|c|c|c|c|c|c|c|c|c|c|c|}
\hline LCS*CONF & LCS*SUC & LCS*FCF & LCS*ASINT & DLCS*CONF & DLCS*SUC & DLCS*FCF & DLCS*ASI & ASI & FCF & SUC & CONF & DLCS & DUM & LCS & LCOP & 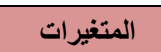 \\
\hline & & & 1 & $\begin{array}{l}0.3438 \\
=0.000\end{array}$ & $\begin{array}{l}0.5452 \\
0.000\end{array}$ & $\begin{array}{l}0.201- \\
=0.000\end{array}$ & $\begin{array}{l}0.6811 \\
0.000\end{array}$ & $\begin{array}{l}0.157- \\
" 0.000\end{array}$ & $\begin{array}{l}0.0293 \\
0.3239\end{array}$ & $\begin{array}{l}0.0926 \\
" 0.001\end{array}$ & $\begin{array}{l}0.004 \\
0.891\end{array}$ & $\begin{array}{l}0.597 \\
" 0.000\end{array}$ & $\begin{array}{l}0.248- \\
" 0.000\end{array}$ & $\begin{array}{l}0.750 \\
=0.000\end{array}$ & $\begin{array}{l}0.454 \\
" 0.000\end{array}$ & LCS*ASINT \\
\hline & & 1 & $\begin{array}{r}0.1525- \\
\quad 0.000\end{array}$ & $\begin{array}{l}0.0324 \\
0.2753\end{array}$ & $\begin{array}{r}0.1047- \\
\quad 0.000\end{array}$ & $\begin{array}{l}0.5937 \\
* 0.000\end{array}$ & $\begin{array}{r}0.1657- \\
\quad 0.000\end{array}$ & $\begin{array}{r}0.0149- \\
0.6150\end{array}$ & $\begin{array}{l}0.0188 \\
0.5256\end{array}$ & $\begin{array}{l}0.0219 \\
0.4608\end{array}$ & $\begin{array}{l}0.0252 \\
0.3951\end{array}$ & $\begin{array}{l}0.116^{-} \\
{ }^{*} 0.000\end{array}$ & $\begin{array}{l}0.062- \\
{ }^{* *} 0.03\end{array}$ & $\begin{array}{l}0.068- \\
* * 0.02\end{array}$ & $\begin{array}{l}0.0471 \\
0.1128\end{array}$ & LCS*FCF \\
\hline & 1 & $\begin{array}{l}0.060- \\
* 0.041\end{array}$ & $\begin{array}{l}0.7234 \\
0.000\end{array}$ & $\begin{array}{l}0.3821 \\
0.000\end{array}$ & $\begin{array}{l}0.6189 \\
0.000\end{array}$ & $\begin{array}{l}0.111- \\
* 0.000\end{array}$ & $\begin{array}{l}0.7403 \\
0.000\end{array}$ & $\begin{array}{l}0.154- \\
" 0.000\end{array}$ & $\begin{array}{l}0.0173 \\
0.5607\end{array}$ & $\begin{array}{l}0.0304 \\
0.3062\end{array}$ & $\begin{array}{l}0.0212 \\
0.4755\end{array}$ & $\begin{array}{l}0.5930 \\
\\
* 0.000\end{array}$ & $\begin{array}{l}0.417- \\
* 0.000\end{array}$ & $\begin{array}{l}0.6819 \\
\quad 0.000\end{array}$ & $\begin{array}{l}0.6960 \\
" 0.000\end{array}$ & LCS*SUC \\
\hline 1 & $\begin{array}{l}0.6567 \\
{ }^{*} 0.000\end{array}$ & $\begin{array}{l}0.0936 \\
* 0.001\end{array}$ & $\begin{array}{l}0.5405 \\
{ }^{*} 0.000\end{array}$ & $\begin{array}{l}0.5869 \\
{ }^{*} 0.000\end{array}$ & $\begin{array}{l}0.3920 \\
* 0.000\end{array}$ & $\begin{array}{l}0.0185 \\
0.5331\end{array}$ & $\begin{array}{l}0.3121 \\
* 0.000\end{array}$ & $\begin{array}{l}0.135- \\
{ }^{*} 0.000\end{array}$ & $\begin{array}{l}0.0274 \\
0.3561\end{array}$ & $\begin{array}{l}0.0850 \\
* 0.004\end{array}$ & $\begin{array}{l}0.1251 \\
{ }^{*} 0.000\end{array}$ & $\begin{array}{l}0.4097 \\
* 0.000\end{array}$ & $\begin{array}{l}0.292- \\
* 0.000\end{array}$ & $\begin{array}{l}0.6638 \\
* 0.000\end{array}$ & $\begin{array}{l}0.4249 \\
* 0.000\end{array}$ & LCS*CONF \\
\hline & & & & & & & & & & & & & & & & 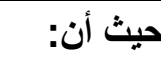 \\
\hline \multicolumn{7}{|c|}{ تفاعل كثافة الأصول مع التغير في المبيعات مضروباً في المتغير الوهمي } & \multicolumn{2}{|c|}{ DLCS*ASI } & & & & \multicolumn{4}{|c|}{ اللوغارتيم الطبيعي للتكاليف التشغيلية } & LOP \\
\hline \multicolumn{7}{|c|}{ تفاعل التدفقات النقدية الحرة مع التغير في المبيعات مضروباً في المتغير الوهمي } & \multicolumn{2}{|c|}{ DLCS*FCF } & & & & \multicolumn{4}{|c|}{ اللوغارتيم الطبيعي لإيراد المبيعات } & LCS \\
\hline
\end{tabular}




\begin{tabular}{|c|c|c|c|}
\hline ت تفاعل النجاح في زيادة المبيعات مع التغير في المبيعات مضروباً في المتغير الوهمي & DLCS*SUC & | متغير وهمي " يأخذ(1) في حال انخفاض المبيعات ، وصفر بخلاف ذلك" & DUM \\
\hline تفاعل الثقة الإدارية المفرطة مع التغير في المبيعات مضروباً في المتغير الوهمي & DLCS*CONF & تفاعل اللوغارتيم الطبيعي لإيراد المبيعات مع المتنير الوهمي & DLCS \\
\hline تفاعل كثافة الأصول مع التغير في المبيعات & LCS*ASINT & | الثقة الغذارية المفرطة للمديرين & CONF \\
\hline تفاعل التدفقات النقدية الحرة مع التغير في المبيعات & LCS*FCF & | نجاح المنثأة في زيادة المبيعات & SUC \\
\hline تفاعل النجاح في زيادة المبيعات مع التنير في المبيعات & LCS*SUC & 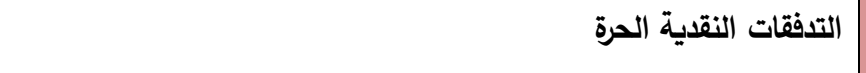 & FCF \\
\hline تفاعل الثقة الإدارية المفرطة مع التغير في المبيعات & LCS*CONF & كثافة الأصول الثابتة & ASI \\
\hline | الإرتباط معنوي عند مستوي مغنوية 5\% & $(* *)$ & | الإرتباط منوي عند مستوي مغوية 1\% & $\left({ }^{*}\right)$ \\
\hline & & | الإتباط معنوي عذ مستوي مغنوية 10\% & $\left({ }^{* * *}\right)$ \\
\hline
\end{tabular}




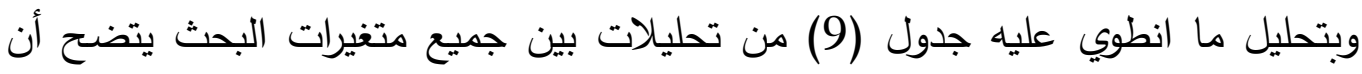

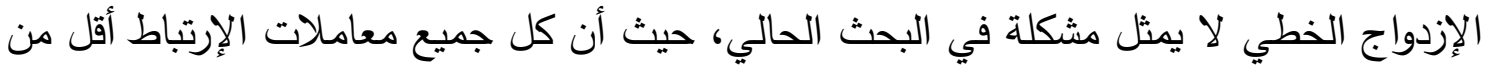
(0.8)، كذلك وبالنظر إلي عمود المتغير التابع بالدراسة الحالية " التغير في التكاليف التشغئيلية

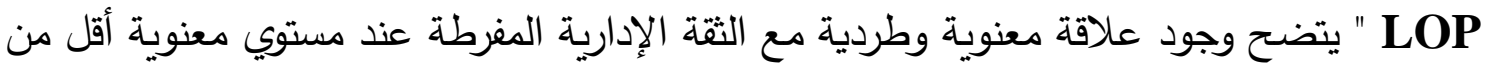

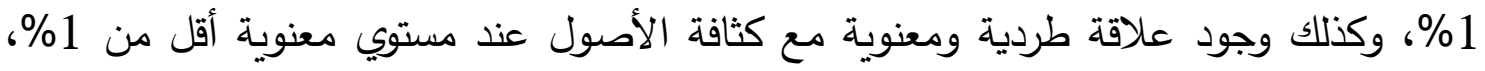
وكذلك وجود علاقة معنوية طردية مع متغير نجاح المنشأة في زيادة المبيعات عند مستوي معنوية

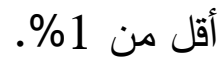

3.2.6

يعتبر نموذج التأثيرات الثابتة Fixed Effect Model من النماذج الهامة التي يمكن

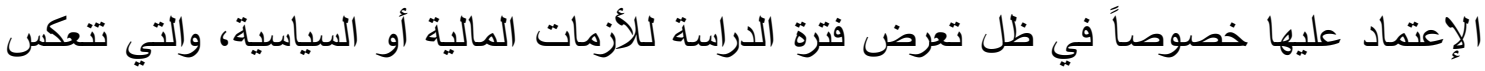
بثكل أو آخر علي الأرقام والبيانات المالية ,وبالتالي التاثير علي مدي قبول فئل أو رفض فرضات فرضيات البحث الحالي.

وللتأكد من ملائمة نموذج التأثيرات الثابتة Fixed Effect Model لبيانات البحث الحالي، تم إجراء مقارنة إحصائية للمفاضلة بينه وبين النماذج الأخري الممكن استخدامها " نموذج الماتج

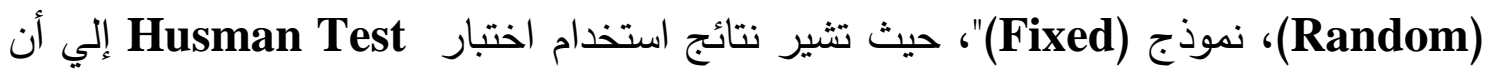
قيمة (P Value> 0.0000) وهو ما يعني أفضلية نموذج التأثيرات الثابتة للبيانات الحالية (

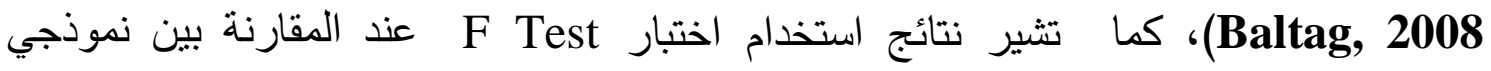
(Fixed) و (Pool) ) إلي أن قيمة (P Value > 0.0000) وهو ما يعني أفضلية نموذج التأثيرات الثابتة للبيانات الحالية (Baltag,2008) ( 1.3.2.6 التحليلات الإحصائية للفرضية البحثية الأولي

Fixed Effect Model نتائج تحليل الإنحدار باستخدام نموذج التأثيرات الثابتة

Multiple Linear Regression Model يستخدم نموذج الانحدار الخطي المتعدد لاختبار العلاقة بين المتغير التابع (السلوك غير المتماثل للتكاليف التثغيلية) والمتغير المستقل

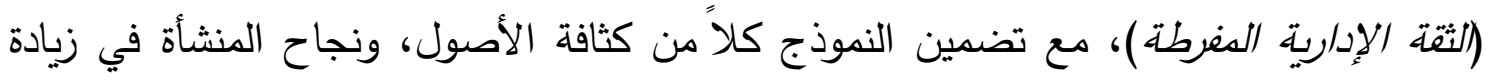


المبيعات والتدفقات النقدية الحرة كمتغيرات ضابطة للعلاقة، ولزيادة القدرة التنبؤية لنموذج الدراسة

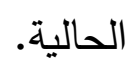

ويستخدم اختبار (Robust Standard Errors) للحصول علي أفضل نتائج ممكنة

حتي مع ظهور مشكلتي عدم ثبات التباينات، والإرتباط الذاتي من للأخطاء (Hoechle, 2007) The (Holzhacker et al., 2015

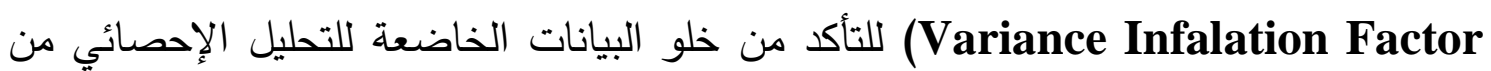
مشكلة الإزدواج.

ويقيس معامل تضخم التباين (VIF) الزيادة في تباين تقديرات معالم نموذج الإنحدار

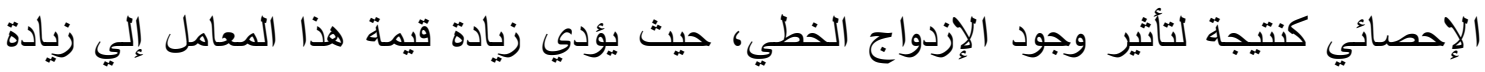

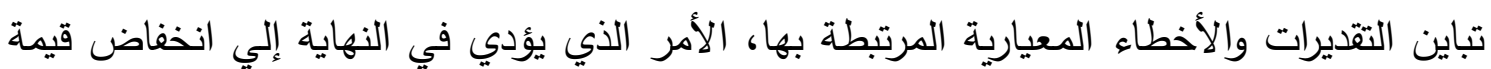
(t) المحسوبة المستخدمة في اختبارات المعنوية الإحصائية.

ويظل مقبولاً عدم وجود مشكلة الإزدواج الخطي بين المتغيرات مادام قيمة (VIF) لم تتعدي (10) لأي متغير من متغيرات النموذج التقسيرية، وتوصلت النتائج إلي أن الإزدواج الخطي

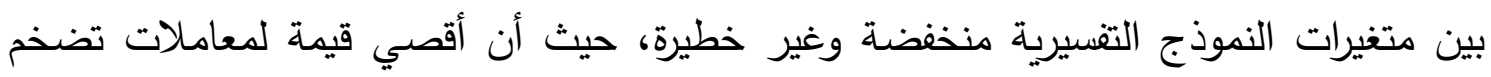
التباين تم الحصول عليها في النموذج الحالي كانت لمتغير تفاعل التغير في المبيعات مع المتغير التيري الوهمي حيث بلغت القيمة (6.25)، ويكن توضيح نلك من خلال الجدول رقم (10). 
جدول رقم (10): جدول معاملات تضخم التباين لمتغيرات الاراية (VIF)

\begin{tabular}{|c|c|c|c|}
\hline$\overline{\text { VIF }}$ & المتغيرات المستقلة & VIF & المتغيرات المستقلة \\
\hline 4.25 & DLCS*ASI & 6.25 & LCS \\
\hline 1.18 & DLCS*FCF & 5.77 & DUM \\
\hline 5.31 & DLCS*SUC & 5.62 & DLCS \\
\hline 3.97 & DLCS*CONF & 1.36 & CONF \\
\hline 4.23 & LCS*ASINT & 1.60 & SUC \\
\hline 1.48 & LCS*FCF & 1.10 & FCF \\
\hline \multirow[t]{2}{*}{6.02} & LCS*SUC & 1.89 & ASI \\
\hline & & 4.82 & LCS*CONF \\
\hline
\end{tabular}

ويتم تقدير معالم نموذج السلوك غير المتماثل المبدئية قبل تثغيل النموذج الرئيسي بما

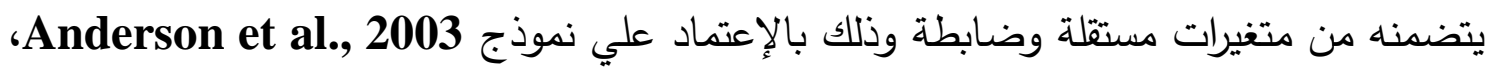

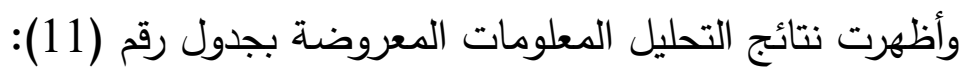


الثقة الإدارية والسلوك غير المتماثل

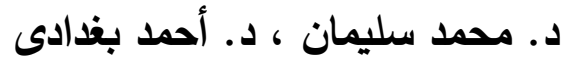

جدول رقم (11): نتائج تحليل الانحدار لنموذج قياس السلوك غير المتماثل للتكاليف التثغيلية

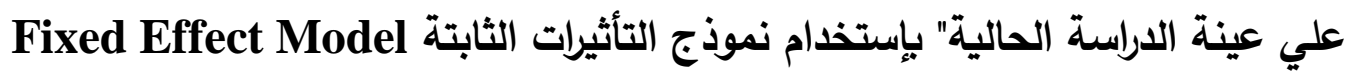

\begin{tabular}{|c|c|c|c|c|c|}
\hline \multicolumn{2}{|c|}{ معنوية معاملات الإندار } & \multirow{2}{*}{$\begin{array}{c}\text { المعياري } \\
\text { Robust } \\
\text { المطأ Std.Error }\end{array}$} & \multicolumn{2}{|c|}{ معاملات الإنحدارß } & \multirow[t]{2}{*}{ 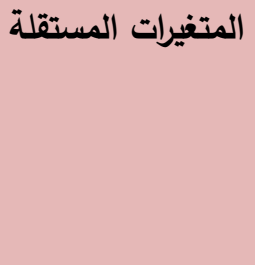 } \\
\hline مستوي الدلالة (Sig) & قيمة(T) & & & & \\
\hline$* * * 0.000$ & 5.43 & 0.00256 & 0.01389 & $\beta 0$ & ثابت الإنحدار \\
\hline ****0.000 & 17.57 & 0.10413 & 1.82957 & $\beta 1$ & LCS \\
\hline ****0.000 & 8.47 & 0.0366 & $0.31053-$ & $\beta 2$ & DUM \\
\hline ****0.000 & 7.04 & 0.04680 & $0.32949-$ & B3 & DLCS \\
\hline \multicolumn{6}{|c|}{ 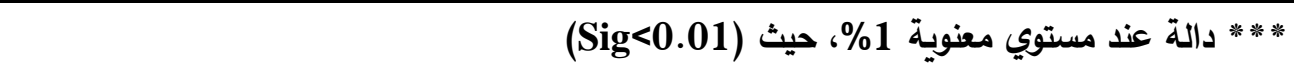 } \\
\hline$* * * 0.000$ & 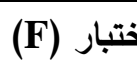 & & & $=$ & عدد الششا \\
\hline
\end{tabular}

ويتم تقدير معالم نموذج البحث الرئيسي من خلال التثشيل الإحصائي لبيانات العينة

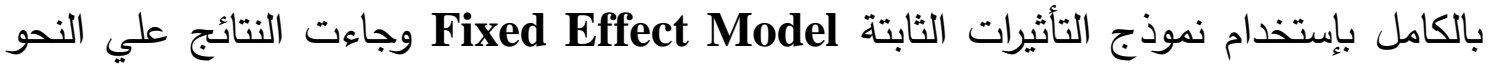
المعروض في جدول رقم (12). 
جدول رقم (12): نتائج تحليل الإنحدار بإستخدام نموذج Fixed Effect Model بين المتغير المستقل "الثقة الإدارية المفرطة " والمتغير التابع "عدم التماثل في سلوك التكاليف" التالئ

\begin{tabular}{|c|c|c|c|c|c|}
\hline \multicolumn{2}{|c|}{ معنوية معاملات الإندار } & \multirow{2}{*}{$\begin{array}{c}\text { الخطأ } \\
\text { Robust } \\
\text { المعيارئ } \\
\text { Std.Error }\end{array}$} & \multicolumn{2}{|c|}{ معاملات الإندارار } & \multirow[t]{2}{*}{ المتغيرات المستقلة } \\
\hline مستوي الدلالة (Sig) & قيمة(T) & & & \\
\hline$* * * 0.0008$ & 3.3659 & 0.021785 & \multicolumn{2}{|l|}{0.073327} & ثابت الإندار \\
\hline$* * * 0.0021$ & 14.40 & 0.086177 & 1.240952 & $\overline{\beta 1}$ & $\overline{L C S}$ \\
\hline$* * * 0.0000$ & $5.11-$ & 0.042492 & 0.215600 - & $\beta 2$ & $\overline{\text { DUM }}$ \\
\hline$* * * 0.0000$ & $5.80-$ & 0.170125 & 0.986724 - & $B 3$ & DLCS \\
\hline 0.5531 & $0.59-$ & 0.012458 & 0.007391 - & $B 12$ & $\mathrm{CONF}$ \\
\hline$* * 0.0145$ & $4.91-$ & 0.009075 & 0.044557 - & $B 15$ & SUC \\
\hline 0.5465 & $0.603-$ & 0.021189 & $0.012784-$ & $B 13$ & FCF \\
\hline 0.2105 & 1.253 & 0.019973 & 0.025028 & $B 14$ & ASI \\
\hline 0.3768 & 0.884 & 0.104566 & 0.092464 & $B 4$ & LCS*CONF \\
\hline$* * 0.0470$ & $5.010-$ & 0.034228 & 0.171486- & $B 11$ & DLCS*ASI \\
\hline$* 0.0568-$ & 4.924 & 0.091476 & 0.450429 - & $B 9$ & DLCS*FCF \\
\hline$* 0.0691$ & $3.861-$ & 0.347248 & $1.340725-$ & $B 10$ & DLCS*SUC \\
\hline$* 0.0975$ & $2.10-$ & 0.097029 & 0.203761 - & $B 8$ & DLCS*CONF \\
\hline$* * * \mathbf{0 . 0 0 0 0}$ & 8.70 & 0.040300 & 0.350911 & $B 7$ & LCS*ASINT \\
\hline 0.1097 & $0.995-$ & 0.108696 & $0.108230-$ & $B 5$ & LCS*FCF \\
\hline 0.1669 & 0.96 & 1.588846 & 1.526554 & B6 & LCS*SUC \\
\hline \multicolumn{6}{|c|}{ 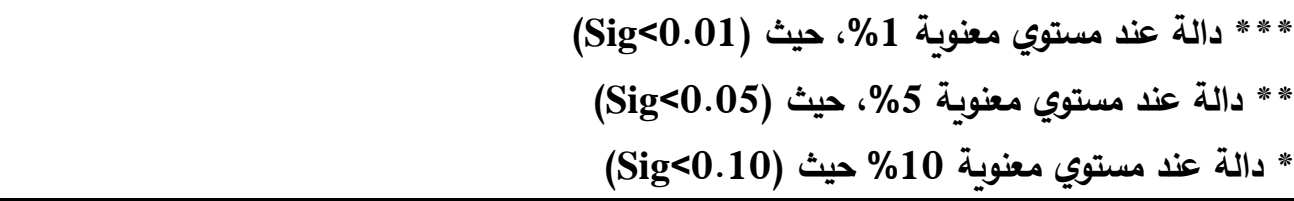 } \\
\hline \multicolumn{3}{|c|}{ معامل التحديد المعل (Adjusted $R^{2}$ \%69.52 } & \multicolumn{3}{|c|}{ معامل التحديد (R2.27=72. } \\
\hline \multicolumn{3}{|c|}{ دلالة اختبار (F) = 0.000** } & \multicolumn{3}{|c|}{ قيمة (F) المحسوبة = 138.7638 } \\
\hline & & $1=$ & & & \\
\hline
\end{tabular}

وبإمعان النظر في النتائج المعروضة بالجدول رقم (12) يمكن ملاحظة معنوية نموذج الإنحدار الخطي بين المتغير التابع "عدم التماثل في سلوك التكاليف" والمتغيرات المفسرة (المستقل، بلهن

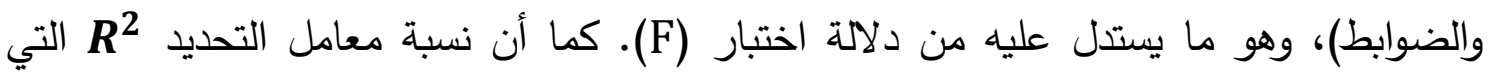


تفسر التباين في قيمة المتغير التابع بلغت 72.27 \%؛ بينما بلغت نسبة معامل التحديد المعدل \%69.52 بلغت Adjusted $\boldsymbol{R}^{2}$

وفيما يتعلق بنتائج اختبار الفرضية الأولي بالبحث الحالي، فإنها تشير إلي وجود علاقة

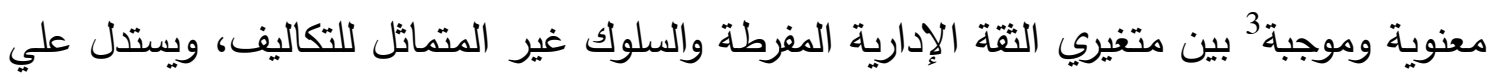
ذللك بالنظر إلي قيمة مستوي الدلالة Sig للمتغير التفاعلي للثقة الإدارية المفرطة مع التغير في المبيعات مضروباً في المتغير الوهمي DLCS*CONF والتي بلغت 0.0975 كما بلغت قيمة

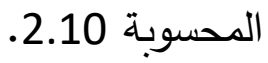
كما تثير النتائج الخاصة بالمتغيرات الضابطة بالنموذج إلي وجود علاقة طردية بين متغير كثافة الأصول (DLCS*ASI) والسلوك غير المتماثل للتكلفة عند مستوي معنوية 5\%، ووجود علاقة طردية بين متغير التدفقات النقدية الحرة (DLCS*FCF) والسلوك غير المتماثل للتكلفة عند مستوي معنوية 5\%، وعدم وجود علاقة بين متغير نجاح المنثأة في زيادة المبيعات والسلوك غير المتماثل للتكلفة.

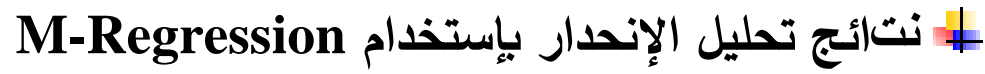

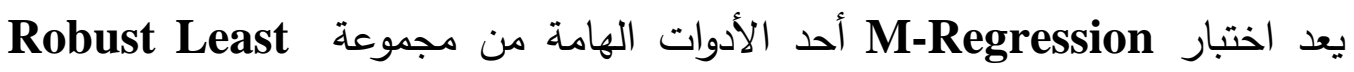
والتي أعدت لتشغيل البيانات التي لا تتتع فيها الأخطاء العشوائية التوزيع الطبيعي Squares (Baltag, 2008)، وبالتالي يمكن استخدام M-Regression في التأكيد علي سلامة النتائج المتوصل إليها بإستخدام نموذج التأثيرات الثابتة، ويعرض الجدول رقم (13) نتائج تحليل الإنحدار بإستخدام إختبار M-Regression: 
جدول رقم (13): نتائج تحليل الإنحدار بإستخدام اختبار M-Regression بين

المتغير المستقل "الثقة الإدارية المفرطة " والمتغير التابع "عدم التماثل في سلوك التكلفة"

\begin{tabular}{|c|c|c|c|c|c|}
\hline \multicolumn{2}{|c|}{ معنوية معاملات الإنحدار } & \multirow{2}{*}{$\begin{array}{c}\text { الخطياري } \\
\text { Robust } \\
\text { Std.Error }\end{array}$} & \multirow{2}{*}{\multicolumn{2}{|c|}{ معاملات الإنحدارم }} & \multirow[t]{2}{*}{ المتغيرات المستقلة } \\
\hline \multirow{2}{*}{$\begin{array}{c}\text { مستوي الدلالة } \\
\text { (Sig) } \\
\text { ***0.003 }\end{array}$} & \multirow{2}{*}{ 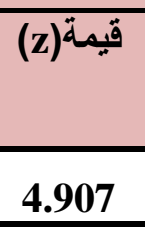 } & & & & \\
\hline & & 0.004972 & 0.0244 & 及0 & ثابت الإنعدار \\
\hline$* * * 0.001$ & 12.45 & 0.098209 & 1.2227 & $\beta 1$ & LCS \\
\hline$* * * 0.000$ & $11.9-$ & 0.00285 & 0.034 - & $\beta 2$ & DUM \\
\hline$* * * 0.000$ & $6.14-$ & 0.143975 & 0.884 - & B3 & DLCS \\
\hline 0.3874 & $0.86-$ & 0.002326 & 0.002 - & $B 12$ & CONF \\
\hline$* * 0.0105$ & $3.34-$ & 0.002395 & 0.008 - & B15 & SUC \\
\hline 0.5805 & 0.55- & 0.0063 & $0.000-$ & $B 13$ & FCF \\
\hline$* * * 0.000$ & 7.80 & 0.001744 & 0.0136 & B14 & ASI \\
\hline 0.8920 & 0.13 & 0.017135 & 0.0023 & $B 4$ & LCS*CONF \\
\hline$* * * 0.000$ & 11.10- & 0.017995 & 0.199 - & $B 11$ & DLCS*ASI \\
\hline$* * * 0.000$ & 13.0 & 0.066046 & $0.860-$ & B9 & DLCS*FCF \\
\hline$* * 0.0410$ & 5.8- & 0.182068 & 1.056- & $B 10$ & DLCS*SUC \\
\hline$* 0.0512$ & $3.06-$ & 0.054248 & 0.166 - & $B 8$ & DLCS*CONF \\
\hline$* * * 0.0000$ & 16.3 & 0.023696 & $\mathbf{0 . 3 9 0 7}$ & B7 & LCS*ASINT \\
\hline 0.3789 & 0.87- & 0.031212 & $0.027-$ & $B 5$ & LCS*FCF \\
\hline 0.3871 & 0.86 & 1.1784 & 1.0191 & B6 & LCS*SUC \\
\hline \multicolumn{6}{|c|}{ 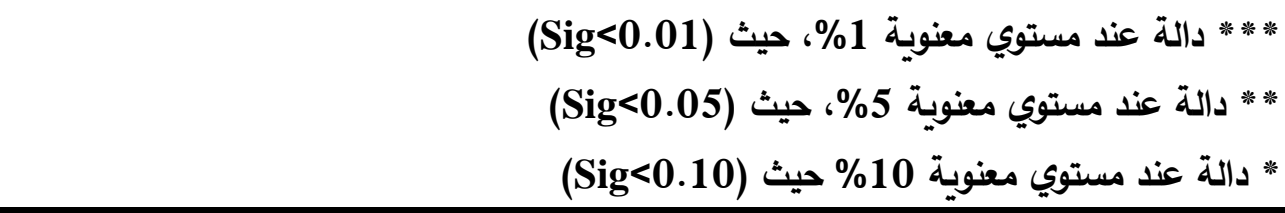 } \\
\hline \multirow{2}{*}{\multicolumn{3}{|c|}{$\begin{array}{c}=\left(\text { Adjusted } R^{2}\right) \text { معامل التحديد المعدل } \\
\text { \%49.10 }\end{array}$}} & \multicolumn{3}{|c|}{ معامل التحديد ( $50.89=\left(R^{2} \%\right.$} \\
\hline & & & \multicolumn{3}{|c|}{ قيمة (Rn) المحسوبة = 10446} \\
\hline \multicolumn{3}{|c|}{ عدد المشاهدات = 954} & \multicolumn{3}{|c|}{ دلالة اختبار (Rn) = 0.000* ** } \\
\hline
\end{tabular}

وبإمعان النظر في النتائج المعروضة بالجدول رقم (13) يمكن ملاحظة معنوية نموذج الإنحدار الخطي بين المتغير التابع "عدم التماثل في سلوك التكاليف" والمتغيرات المفسرة (المستقل، والضوابط)، وهو ما يستدل عليه من دلالة اختبار (Rn). كما أن نسبة معامل التحديد R R التي تفسر التباين في قيمة المتغير التابع بلغت 50.89\% بينما بلغت نسبة معامل التحديد المعدل \%49.10 بلغت Adjusted $\boldsymbol{R}^{2}$ 
وفيما يتعلق بنتائج اختبار الفرضية الأولي بالبحث الحالي، فإنها تثير إلي وجود علاقة

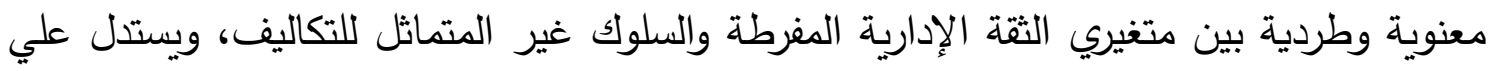

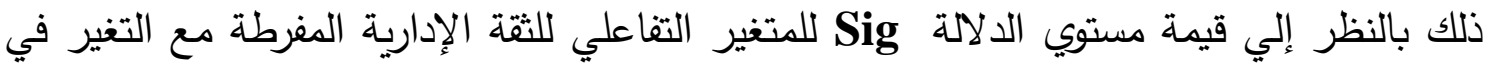
المبيعات مضروباً في المتغير الوهمي DLCS*CONF والتي بلغت المحسوبة 3.06. وبمقارنة النتائج التي تم التوصل إليها بإستخدام M-Regression والمعروضة بالجدول

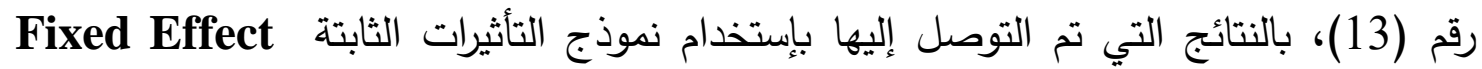

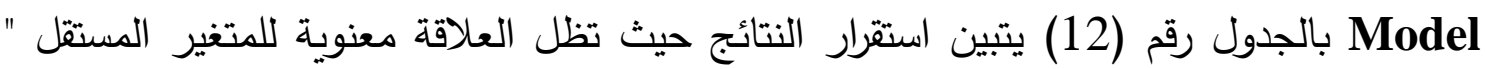
الثقة الإدارية المفرطة" مع المتغير التابع "عدم التماثل في سلوك التكاليف" خلال كلا النموذجين

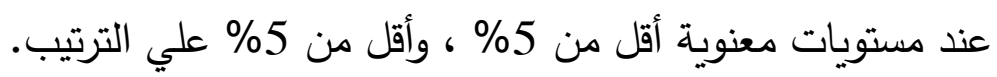
2.3.2.6 تبحث الفرضية الثانية في الدور المنظم لحوكمة الثركات علي طبيعة العلاقة بين الثقة الإدارية الدفرطة والسلوك غير المتماثل للتكلفة من خلال تقسيم عينة الدراسة إلي مجموعتين، الأولي ذات حوكمة قوية، والثانية ذات حوكمة ضعيفة، وتم تقسيم العينة بناءاً علي مؤشر الحوكمة فئه

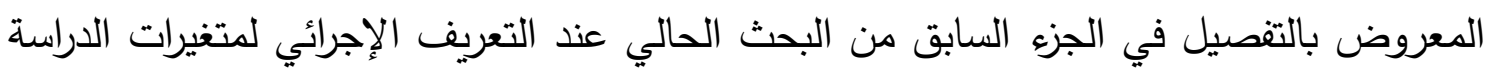

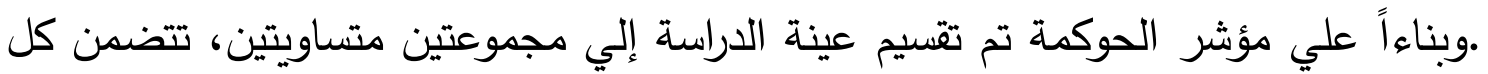
مجموعة عدد 53 شركة بإجمالي مشاهدات 477، ويعرض الجزء التالي النتائج الإحصائية

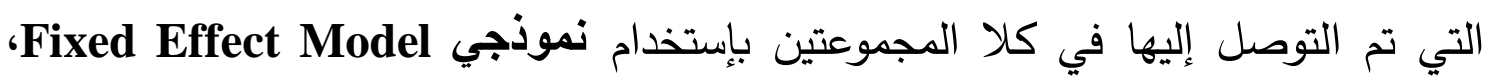
.M-Regression

نتائج تحليل الإنحار علي عينة ذات خصائص حوكمة ضعيفة باستخدام نموذج التأثيرات Fixed Effect Model الثابتة يعرض الجدول رقم (14) نتائج تحليل الإنحدار بإستخدام نموذج التأثيرات الثابتة علي عينة من الشركات ذات خصائص حوكمة ضعيفة 
جدول رقم(14): نتائج تحليل تحليل الإنحار علي عينة ذات خصائص حوكمة ضعيفة باستخدام نموذج التأثيرات الثابتة

\begin{tabular}{|c|c|c|c|c|c|}
\hline \multicolumn{2}{|c|}{ معنويةٌ معاملات الإنحدار } & \multirow{2}{*}{$\begin{array}{c}\text { الخطياري } \\
\text { Robust } \\
\text {.Std.Error }\end{array}$} & \multicolumn{2}{|c|}{ معاملات الإنحدارم } & \multirow[t]{2}{*}{ المتفيرات المستقلة } \\
\hline \multirow{2}{*}{$\begin{array}{c}\text { مستوي الدلالة (Sig) } \\
\text { ***0098 } 0.008\end{array}$} & \multirow{2}{*}{ قيمة) } & & & & \\
\hline & & 0.015789 & 0.0576 & B0 & ثابت الإنحدار \\
\hline ****0.009 & $8.25-$ & 0.117188 & 0.9668 - & $\beta 1$ & LCS \\
\hline$* * * 0.000$ & $7.60-$ & 0.011513 & $0.0875-$ & $\beta 2$ & DUM \\
\hline $0.000 * * *$ & $5.09-$ & 0.009764 & $0.0497-$ & B3 & DLCS \\
\hline 0.4428 & $0.76-$ & 0.009605 & $0.0073-$ & $B 12$ & CONF \\
\hline 0.5901 & $0.53-$ & 0.034717 & $0.0184-$ & $B 15$ & SUC \\
\hline 0.1173 & $1.56-$ & 0.03141 & $0.0490-$ & $B 13$ & FCF \\
\hline$* 0.0676$ & 2.430 & 0.005885 & 0.0143 & $B 14$ & ASI \\
\hline$* * * 0.000$ & 4.623 & 0.037313 & 0.1725 & $B 4$ & LCS*CONF \\
\hline ****0.0009 & $3.35-$ & 0.058299 & $0.1953-$ & $B 11$ & DLCS*ASI \\
\hline **** 0.0088 & $2.05-$ & 0.006293 & $0.0129-$ & B9 & DLCS*FCF \\
\hline${ }^{*} 0.0748$ & $2.62-$ & 0.006565 & $0.0172-$ & $B 10$ & DLCS*SUC \\
\hline **** 0.0095 & 3.615 & 0.021328 & 0.0771 & $B 8$ & DLCS*CONF \\
\hline ***0.000 & 9.004 & 0.035262 & 0.3175 & $B 7$ & LCS*ASINT \\
\hline$* * * 0.0006$ & $4.44-$ & 0.114887 & $0.5101-$ & B5 & LCS*FCF \\
\hline 0.8889 & 0.139 & 0.534532 & 0.0743 & B6 & LCS*SUC \\
\hline & & $\begin{array}{r}(\mathrm{Sig}<0 . \\
(\mathrm{Sig}<0 \\
(\mathrm{Sig}< \\
\end{array}$ & \% \% \% حيث (05) حيث (05. & منوية & 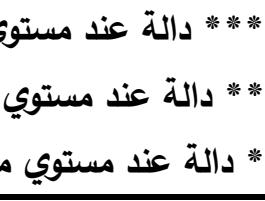 \\
\hline$\% 64.90=$ (Adjust & المعدل ( & معامل التحديد & $\% 66.8$ & $4=\left(R^{2}\right.$ & معامل التصديد \\
\hline ****0.000 & اختبار (F) & נلעلة & 73.145 & $1=$ & قيمة (F) المحس \\
\hline & & كاهدات = & عا & & \\
\hline
\end{tabular}

وبإمعان النظر في النتائج المعروضة بالجدول رقم (14) يمكن ملاحظة معنوية نموذج الإنحدار الخطي بين المتغير التابع "عدم التماثل في سلوك التكاليف" والمتغيرات المفسرة (المستقل، بـان 
والضوابط)، وهو ما يستدل عليه من دلالة اختبار (F) عند مستوي معنوية 1\%. كما أن نسبة

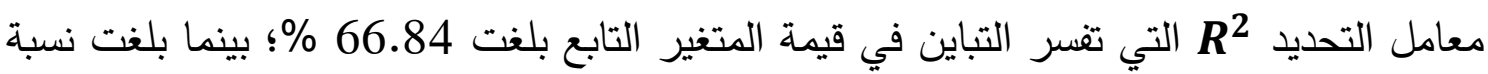
معامل التحديد المعدل Adjusted $\boldsymbol{R}^{2}$ بلغت 64.90\%.

وفيما يتعلق بنتائج اختبار فرضية الثانية بالبحث الحالي، فإنها تثير إلي وجود علاقة معنوية موجبة بين متغيري الثقة الإدارية المفرطة والسلوك غير المتماثل للتكلفة، ويستدل علي ذلك بالنظر إلي قيمة مستوي الدلالة Sig للمتغير التفاعلي للثقة الإدارية المفرطة دع التغير في المبيعات مضروباً في المتغير الوهمي DLCS*CONF والتي بلغت 0.0095 كما بلغت قيمة التهاريه المحسوبة 3.615.

M- نتائج تحليل الإنحدار علي عينة ذات خصائص حوكمة ضعيفة باستخدام .Regression

يعرض الجدول رقم (15) نتائج تحليل الإنحدار بإنتخدام نموذج M-Regression، والتي يمكن

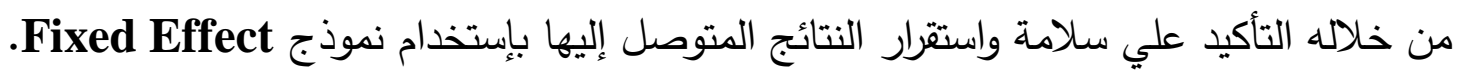
جدول رقم(15): نتائج تحليل تحليل الإنحدار علي عينة ذات خصائص حوكمة ضعيفة

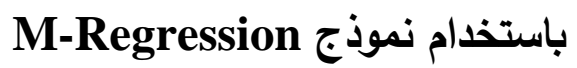

\begin{tabular}{|c|c|c|c|c|c|}
\hline \multicolumn{2}{|c|}{ معنوية معاملات الإنعدار } & \multirow{2}{*}{$\begin{array}{c}\text { المعياري } \\
\text { Robust } \\
\text {.Std.Error } \\
\end{array}$} & \multirow{2}{*}{\multicolumn{2}{|c|}{ معاملات الإنـدارم }} & \multirow[t]{2}{*}{ المتغيرات المستقلة: } \\
\hline مستوي الدلالة (Sig) & قيمة & & & & \\
\hline $08200 * * * *$ & .252 & 0.008044 & 0.0181 & $\beta 0$ & ثابت الإتحدار \\
\hline $00000 . * * *$ & $9.01-$ & 0.088216 & -948370 . & $\beta 1$ & LCS \\
\hline $0.0000 * * *$ & -6.26 & 0.004489 & -0.0281 & $\beta 2$ & DUM \\
\hline$* * * 0.0061$ & -5.51 & 0.129474 & -0.7134 & $B 3$ & DLCS \\
\hline 0.3346 & -0.96 & 0.003958 & -0.0038 & $B 12$ & CONF \\
\hline 0.9793 & -0.02 & 0.015 & -0.0003 & $B 15$ & $\overline{\text { SUC }}$ \\
\hline $0.0423 * *$ & -2.03 & 0.011872 & -0.0241 & $B 13$ & FCF \\
\hline $0.0017 * * *$ & 3.13 & 0.003482 & 0.0109 & $B 14$ & ASI \\
\hline $30000 . * * *$ & .334 & 0.009169 & 0.0397 & $B 4$ & LCS*CONF \\
\hline $0.0000 * * *$ & -7.26 & 0.029325 & -0.2129 & $B 11$ & DLCS*ASI \\
\hline $0.0000 * * *$ & -14.5 & 0.141586 & -2.0530 & B9 & $\overline{\mathrm{DLCS}}{ }^{*} \mathrm{FCF}$ \\
\hline 0.5896 & -0.53 & 1.407358 & -0.7459 & $B 10$ & DLCS*SUC \\
\hline $06300 . * * *$ & -.743 & 0.019866 & 0.0743 & $B 8$ & DLCS*CONF \\
\hline
\end{tabular}

194 


\begin{tabular}{|c|c|c|c|c|c|}
\hline $0.0000 * * *$ & -18.4 & 0.021245 & 0.3909 & B7 & LCS*ASINT \\
\hline $0.0000 * * *$ & -4.34 & 0.059931 & -0.2601 & $B 5$ & LCS*FCF \\
\hline 0.5916 & 0.53 & 1.423611 & 0.754514 & $B 6$ & LCS*SUC \\
\hline \multicolumn{6}{|c|}{ 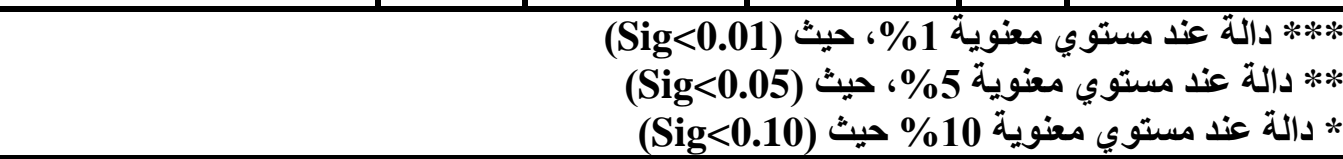 } \\
\hline \multicolumn{3}{|c|}{ معامل التحديد المعدل (Adjusted $R^{2}$ \%0.27 = } & \multicolumn{3}{|c|}{ معامل التحليد (R1.18=(R2) } \\
\hline \multicolumn{3}{|c|}{ 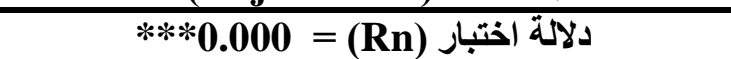 } & \multicolumn{3}{|c|}{ قيمة (Rn) المحسوبة = 5461} \\
\hline \multicolumn{6}{|c|}{ عدد المشاهدات = 477} \\
\hline
\end{tabular}

وبإمعان النظر في النتائج المعروضة بالجدول رقم (15) يمكن ملاحظة معنوية نموذج الإنحدار الخطي بين المتغير التابع "عدم التماثل في سلوك التكاليف" والمتغيرات المفسرة (المستقل،

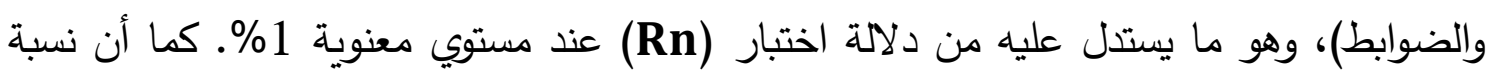

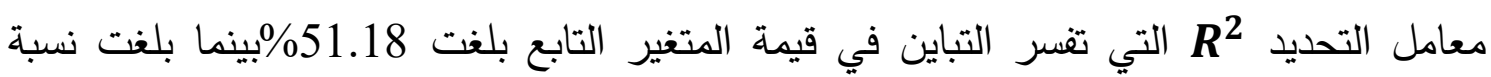

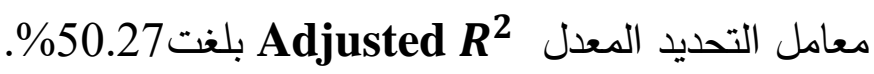
وفيما يتعلق بنتائج اختبار فرضية الثانية بالبحث الحالي، فإنها تشير إلي وجود علاقة معنوية وموجبة بين متغيري الثقة الإدارية المفرطة والسلوك غير المتماثل للتكلفة، ويستدل علي ذللك بالنظر إلي قيمة مستوي الدلالة Sig للمتغير التفاعلي للثقة الإدارية الدفرطة مع التغير في المبيعات مضروباً في المتغير الوهمي DLCS*CONF والتي بلغت 0.0063 عند مستوي معنوية 1\% كما بلغت قيمة $\mathbf{z}$ المحسوبة 3.74.

وبمقارنة النتائج التي تم التوصل إليها بإستخدام M-Regression و المعروضة بالجدول

Fixed Effect رقم (15)، بالنتائج التي تم التوصل إليها بإنتخدام نموذج التأثيرات الثابتة

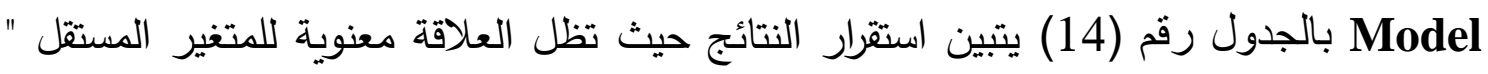
الثقة الإدارية المفرطة" مع المتغير التابع "عدم التماثل في سلوك التكاليف" خلال كلا النموذجين

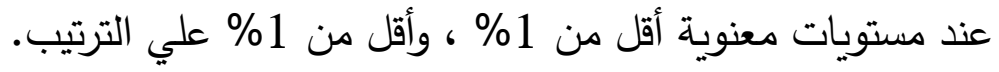

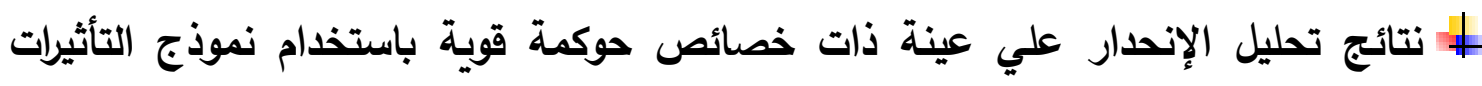

Fixed Effect Model الثابتة 
يعرض الجدول رقم (16) نتائج تحليل الإنحدار بإستخدام نموذج التأثيرات الثابتة علي عينة من الشركات ذات خصائص حوكمة قوية جدول رقم(16): نتائج تحليل تحليل الإنحدار علي عينة ذات خصائص حوكمة قوية باستخدام Fixed Effect Model نموذج التأثيرات الثابتة

\begin{tabular}{|c|c|c|c|c|c|}
\hline \multicolumn{2}{|c|}{ معنوية معاملات الإنحدار } & \multirow{2}{*}{\begin{tabular}{|c|} 
الخطياري \\
Robust \\
المعاً .Std.Error
\end{tabular}} & \multirow{2}{*}{\multicolumn{2}{|c|}{ معاملات الإنحدار }} & \multirow[t]{2}{*}{ المتغيرات المستقلة } \\
\hline مستوي الدلالة (Sig) & قيمةُ (T) & & & & \\
\hline$* * * \mathbf{0 . 0 0 3 7}$ & 2.91 & 0.025326 & $\mathbf{0 . 0 7 3 7}$ & B0 & ثابت الإنحدار \\
\hline$* * \% \mathbf{0 . 0 0 0}$ & $21.3-$ & 0.075704 & $1.6125-$ & $\beta 1$ & LCS \\
\hline$* * * 0.0000$ & $7.74-$ & 0.008915 & $0.069-$ & $\beta 2$ & DUM \\
\hline$* * * 0.000$ & $9.11-$ & 0.063754 & $0.5808-$ & $B 3$ & DLCS \\
\hline 0.7393 & $0.33-$ & 0.008485 & $0.0028-$ & $B 12$ & CONF \\
\hline$* 0.0667$ & $2.83-$ & 0.01576 & $0.0446-$ & $B 15$ & $\overline{\text { SUC }}$ \\
\hline 0.8617 & $\mathbf{0 . 1 7 -}$ & 0.017059 & $0.0029-$ & $B 13$ & FCF \\
\hline *0.0143 & 2.45 & 0.007143 & 0.0175 & B14 & ASI \\
\hline 0.1449 & 0.38 & 0.024474 & 0.0093 & $B 4$ & LCS*CONF \\
\hline$* 0.0693$ & $2.11-$ & 0.275261 & $0.5808-$ & $B 11$ & DLCS*ASI \\
\hline 0.1196 & $0.91-$ & 0.168901 & $\mathbf{0 . 1 5 3 7 -}$ & $B 9$ & DLCS*FCF \\
\hline$* * * 0.0083$ & $3.11-$ & 0.188875 & $0.5874-$ & $B 10$ & DLCS*SUC \\
\hline 0.3312 & 0.97 & 0.081546 & 0.0791 & $B 8$ & DLCS*CONF \\
\hline$* * * \mathbf{0 . 0 0 0 0}$ & 9.58 & 0.040501 & 0.3880 & $B 7$ & LCS*ASINT \\
\hline$* 0.0761$ & $2.23-$ & 0.001166 & $0.0026-$ & $B 5$ & LCS*FCF \\
\hline 0.8678 & 0.166 & 5.133133 & 0.8521 & B6 & LCS*SUC \\
\hline \multicolumn{6}{|c|}{ 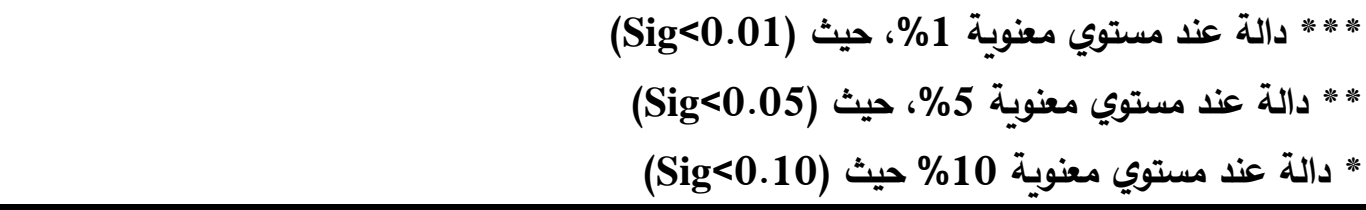 } \\
\hline \multicolumn{3}{|c|}{ معامل التحديد المعدل (Adjusted R $^{2}$ \% } & \multicolumn{3}{|c|}{ معامل التحديد (R3.86=0 } \\
\hline \multicolumn{3}{|c|}{ دلالة اختبار (F) = 0.000 **** } & \multicolumn{3}{|c|}{ قيمة (F) المحسوبة = 101.018} \\
\hline & & & & & \\
\hline
\end{tabular}

وبإمعان النظر في النتائج المعروضة بالجدول رقم (16) يمكن ملاحظة معنوية نموذج

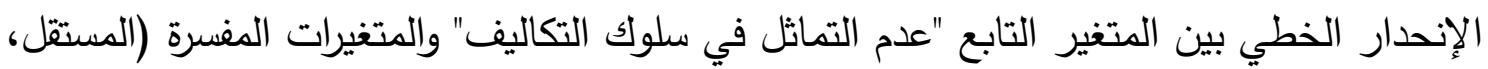


والضوابط) في عينة الثركات ذات الحوكمة القوية، وهو ما يستدل عليه من دلالة اختبار (F) عند

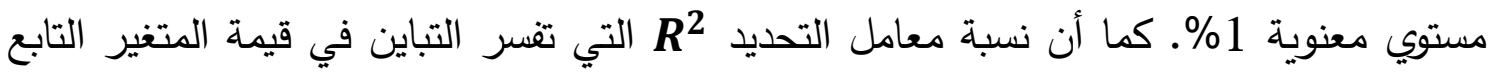
بلغت 73.86\%؛ بينما بلغت نسبة معامل التحديد المعدل Adjusted R $^{2}$ بلغت 71.13\%. وفيما يتعلق بنتائج اختبار فرضية الثانية بالبحث الحالي، فإنها تشير إلي عدم وجود علاقة معنوية بين متغيري الثقة الإدارية المفرطة والسلوك غير المتماثل للتكلفة، ويستدل علي ذلك بالنظر إلي قيمة مستوي الدلالة Sig للمتغير التفاعلي للثقة الإدارية المفرطة مع التغير في المبيعات مضروباً في المتغير الوهمي DLCS*CONF والتي بلغت 0.3312 كما بلغت قيمة

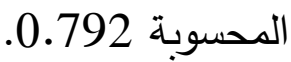

M- نتائج تحليل الإنحار علي عينة ذات خصائص حوكمة قوية باستخدام نموذج

\section{.Regression}

يعرض الجدول رقم (17) نتائج تحليل الإنحدار بإستخدام إختبار M-Regression، والتي يمكن من خلاله التأكيد علي سلامة واستقرار النتائج المتوصل إليها بإستخدام نموذج الإنجات

.Fixed Effect

جدول رقم(17): نتائج تحليل تحليل الإنحدار علي عينة ذات خصائص حوكمة قوية باستخدام

M-Regression نموذج

\begin{tabular}{|c|c|c|c|c|c|}
\hline \multicolumn{2}{|c|}{ معنوية معاملات الإنحدار } & \multirow{2}{*}{$\begin{array}{c}\text { الخطأ المعياري } \\
\text { Robust } \\
\text { Std.Error }\end{array}$} & \multirow{2}{*}{\multicolumn{2}{|c|}{ معاملات الإتـدارم }} & \multirow[t]{2}{*}{ المتغيرات المستقلة } \\
\hline مستوي الدلالة (Sig) & قيمة(z) & & & & \\
\hline $0.0002 * * *$ & 3.73 & 0.011391 & 0.04249 & $\beta 0$ & ثُابت الإنحدار \\
\hline $0.0000 * * *$ & -21.1 & 0.048082 & 1.01453 & $\beta 1$ & LCS \\
\hline $0.0000 * * *$ & -7.88 & 0.004416 & -0.0348 & $\beta 2$ & DUM \\
\hline $0000 . * * *$ & -21.8 & 0.081048 & -54660. & B3 & $\overline{\text { DLCS }}$ \\
\hline 0.2817 & -1.07 & 0.004206 & -0.0045 & $B 12$ & CONF \\
\hline $0.0106 * *$ & -2.55 & 0.010902 & -0.0278 & B15 & $\overline{\text { SUC }}$ \\
\hline 0.4440 & -0.76 & 0.008421 & -0.0064 & B13 & FCF \\
\hline $0.0012 * * *$ & 3.23 & 0.003437 & 0.0111 & $B 14$ & ASI \\
\hline 0.1901 & 0.04 & 2.4325 & 0.0973 & $B 4$ & LCS*CONF \\
\hline $0.0473 * *$ & -2.34 & 0.004188 & -0.0098 & B11 & DLCS*ASI \\
\hline
\end{tabular}




\begin{tabular}{|c|c|c|c|c|c|}
\hline 09510.* & -760. & 1.262687 & -0.8460 & $B 9$ & DLCS*FCF \\
\hline $0.0303 * *$ & -2.16 & 0.035046 & -0.0757 & $B 10$ & DLCS*SUC \\
\hline 22170. & 99.0 & 0.147778 & 0.1463 & $B 8$ & DLCS*CONF \\
\hline $0.0000 * *$ & 14.1 & 0.017163 & 0.2420 & $B 7$ & LCS*ASINT \\
\hline $0.0076 * * *$ & -2.66 & 0.043233 & -0.1150 & $B 5$ & LCS*FCF \\
\hline $1110.0 * *$ & 3.27 & 0.05318 & 0.1739 & B6 & LCS*SUC \\
\hline \multicolumn{6}{|c|}{ 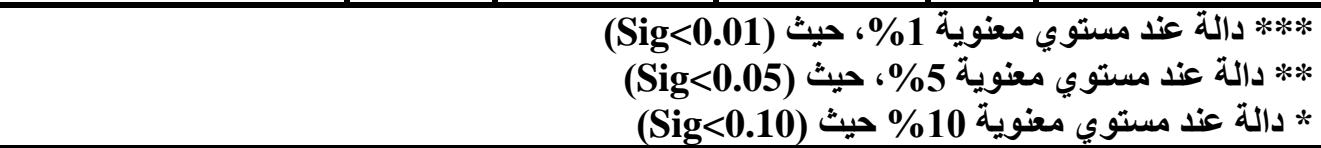 } \\
\hline \multicolumn{3}{|c|}{ معامل التحديد المعدل (Adjusted $R^{2}$ \%51.11 = } & \multicolumn{3}{|c|}{ معامل التحديد (R2.51=(R2) } \\
\hline \multicolumn{3}{|c|}{ 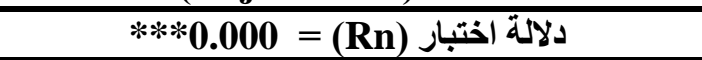 } & \multicolumn{3}{|c|}{ قيمة (Rn) المحسوبة = 6087} \\
\hline
\end{tabular}

وبإمعان النظر في النتائج المعروضة بالجدول رقم (17) يمكن ملاحظة معنوية نموذج الإنحدار الخطي بين المتغير التابع "عدم التماثل في سلوك التكاليف" والمتغيرات المفسرة (المستقل،

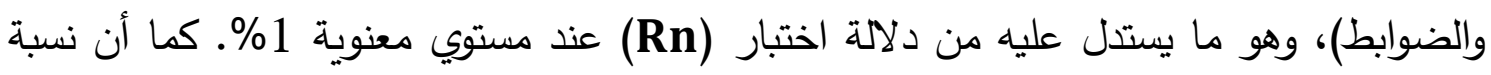

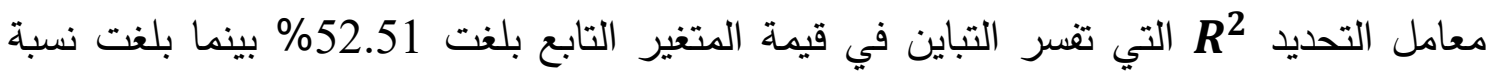

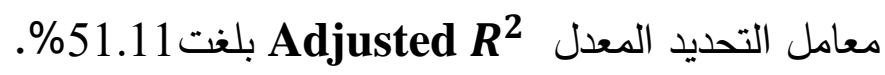

وفيما يتعلق بنتائج اختبار فرضية الثانية بالبحث الحالي، فإنها تثير إلي عدم علاقة معنوية بين متغيري الثقة الإدارية المفرطة والسلوك غير المتماثل للتكلفة، ويستدل علي ذلك بالك بالنظر إلي قيمة مستوي الدلالة Sig للمتغير التفاعلي للثقة الإدارية المفرطة مع التغير في التئيل المبيعات

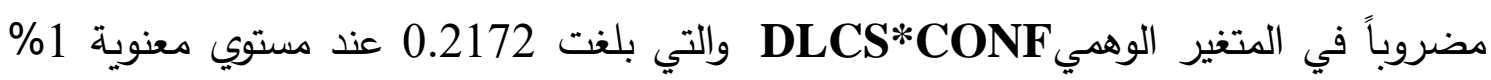
كما بلغت قيمة z المحسوبة 0.99.

وبمقارنة النتائج التي تم التوصل إليها بإستخدام M-Regression والمعروضة بالجدول

Fixed Effect رقم (17)، بالنتائج التي تم التوصل إليها بإستخدام نموذج التأثيرات الثابتة باتئة Model

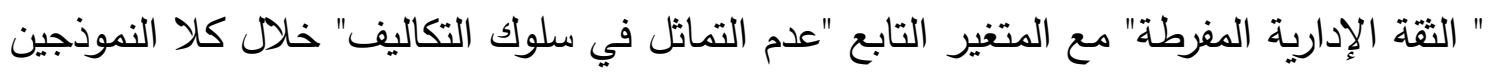


ويستعرض الجدول رقم (18) مقارنة بين نتائج النموذج الرئيسي للدراسة ونتائج تقسيم

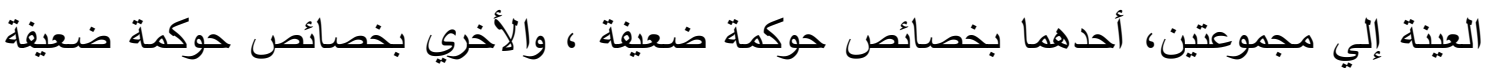

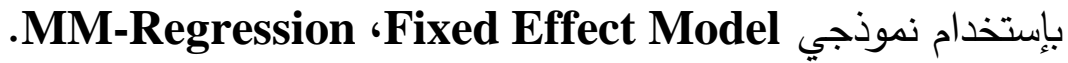
جدول رقم (18): مقارنة نتائج الدراسة علي مستوي العينة الكلية ، وعلي مستوي العينة الكقسمة وبإستخدام نموذجي MM-Regression،Fixed Effect Model.

\begin{tabular}{|c|c|c|c|}
\hline العينة بخصة قويائص & حوكمة ضائصنة & بالكامل & ونوع الإختبار \\
\hline & & & $\begin{array}{c}\text { Fixed Effect } \\
\text { Model }\end{array}$ \\
\hline 0.97 & $* * * 0.0095$ & $* 0.0975$ & SIG \\
\hline 0.3312 & 3.615 & 2.10 & $\mathbf{T}$ \\
\hline & & & MM-Regression \\
\hline 0.2172 & $* * * 0.0095$ & $* 0.0512$ & SIG \\
\hline 0.99 & 3.74 & 3.06 & $\mathbf{Z}$ \\
\hline باية 1\%، ح10 & 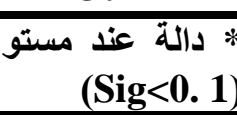 & \multicolumn{2}{|c|}{ 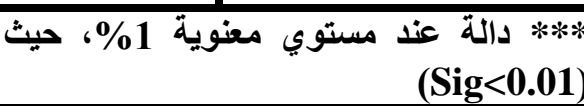 } \\
\hline
\end{tabular}

4.2.6 عرض نتائج فرضيات البحث

أظهرت نتائج تحليل الإنحدار علي مستوي العينة ككل وجود علاقة معنوية موجبة بين الثقة الإدارية الدفرطة والسلوك غير المتماثل للتكلفة وبالتالي لا يمكن رفض الفرضية

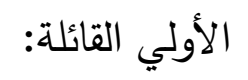

"يوجد علاقة معنوية موجبة بين الثقة الإدارية المفرطة والمسلوك غير المتماثل للتكلفة ".

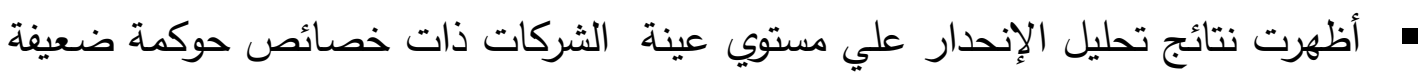
وجود علاقة معنوية موجبة بين الثقة الإدارية المفرطة والسلوك غير المتماثل للتكلفة ؛

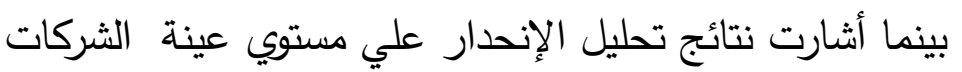
ذات خصائص حوكمة قوية عدم وجود علاقة بين الثقة الإدارية المفرطة والسلوك غير المتماثل للتكلفة وبالتالي لا يمكن رفض التهائ الفرضية الثانية القائلة:

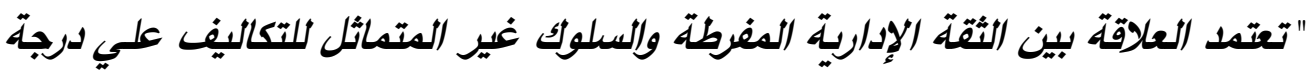
حوكمة الشركات" 
ويعرض جدول رقم (19) ملخص لنتائج اختبار فرضيات الدراسة

جدول رقم (19): ملخص نتائج اختبارات فرضيات الدراسة

\begin{tabular}{|c|c|c|c|}
\hline نتيجة اختبار & العلاقات & متغير ات الدر اسة & الفرضيات \\
\hline لا لا يمكن & + & * الثقة الإدارية المغرطة & الأولي \\
\hline لا يمكن & + & * الثقة الإدارية المفرطة & القوية والضعيفة كمتغير منظم للعلاقة) \\
\hline
\end{tabular}

7. 1.7

1.7

يتركز اهتمام هذه الدراسة في التعرف علي طبيعة العلاقة الثقة الإدارية المفرطة كمتغير مستقل، والسلوك غير المتماثل للتكاليف كمتغير تابع، وقد اتضح من إجراء الإختبار النتائج

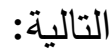

• تثير نتائج الدراسة الحالية إلي وجود علاقة معنوية وموجبة بين الثقة الإدارية الدفرطة والسلوك غير الدتعاثل للتكاليف، وتتفق النتائج المتوصل إليها مع النتائج

المتوصل إليها في دراسات : Chen et al., 2013 ؛ (Hur et al., 2019؛Chen et al., 2018؛ Liang \& Mo, 2017 تبرير ذلك بأن الثقة الإدارية المفرطة تدفع المدير إلي المبالغة في توقعات حجم الطلب المستقبلي، وتوليد الثعور لديه بالقدرة علي السيطرة علي كل الآثار والنتائج المستقبلية، وبالتالي ومع إنخفاض حجم الطلب يميل المديرون مغرطي الثقة إلي الإحتفاظ بموارد غير مستغلة لفترات زمنية معينة علي امل توقع تحسن ملحوظ خلال الفترات القادمة، الأمر الذي يؤدي لحدوث اختلالات في تماثيلية هيكل

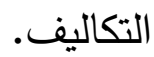


تثير نتائج الدراسة الحالية إلي أن حوكمة الثركات تلعب دوراً منظماً لطبيعة العلاقة بين الثقة الإدارية المفرطة والسلوك غير المتماثل للتكلفة، حيث تظهر النتائج وجود ارتباط معنوي موجب بين الثتة الإدارية المفرطة والسلوك غير المتماثل للتكلفة في ظل عينة حوكمة الثركات الضعيفة، ولا توجد علاقة بين الثقة الإدارية المفرطة والسلوك غير المتماثل للتكلفة في ظل عينة حوكمة الثركات الضعيفة، ويمكن تبرير ذلك بفاعلية آليات الحوكمة في تقويم التصرفات المختلفة للمدير التنفيذي والحد من القرارات الإدارية التي لم تنطوي علي دراسة كافية بخصوص الآثار والنتائج المترتبة عليها(Malekvar\& Abdoli, 2015)؛ كما قد تساهم الحوكمة القوية في إعادة تفكير المدير التتفيذي في القرارات الإستثمارية لفترة أطول بدلأ من التعجيل بالقرارات غير المدروسة، وبالتالي فان اقبال المدير علي اتخاذ قرارات غير مدروس وعشوائية منبعها الثقة المفرطة في قدراته وخبراته سيكون محدود، وبطبيعة الحال فإن المديرين بشكل عام يسعون لتحسين الصورة الذهنية عن أدائهم، وبالتالي فإن الخضوع لآليات الحوكمة الرقابية سيكون عامل فعال في الحد من الآثار السلبية لثقة الإدارية

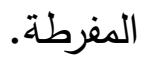

في ضوء ما توصل إليه البحث الحالي من نتائج، يري الباحثان أن هناك العديد من المجالات التي

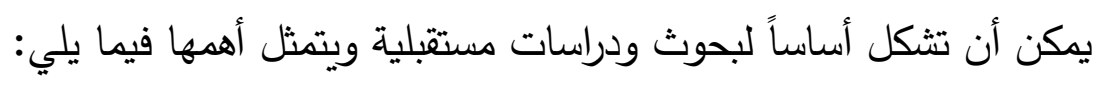

(1) إعادة اختبار العلاقة بين الثقة الإدارية المفرطة والسلوك غير المتماثل للتكلفة علي

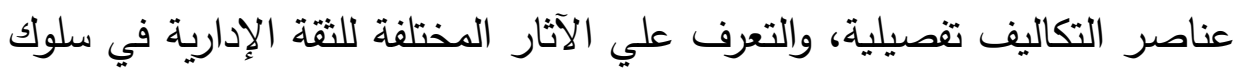

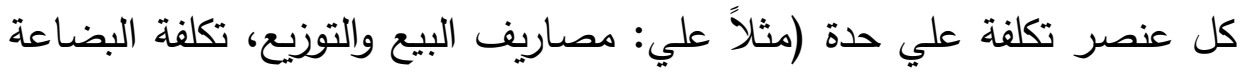

$$
\text { المباعة، مصاريف الأجور ). }
$$

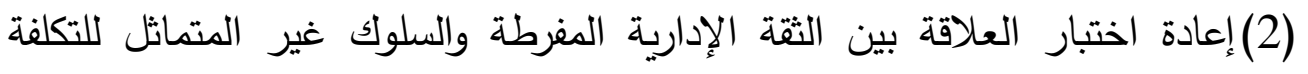
بإستخدام أسلوب الحدث، بمعني اختبار العلاقة علي عينة من الشركات خلال 
الفترة قبل عام 2007 مقارنة بعينة من الشركات بعد عام 2007، حيث يعتبر

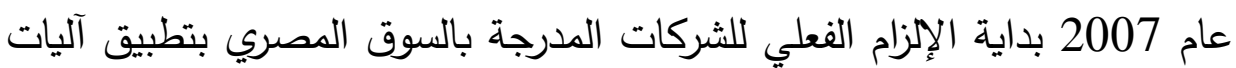

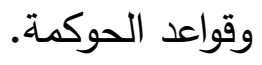

(3) إعادة اختبار العلاقة بين الثقة الإدارية المفرطة والسلوك غير المتماتل للتكلفة بعد

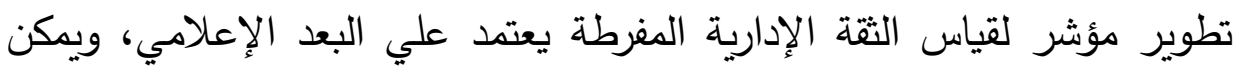
الإستعانة في ذلك بأداوت Google Trend. (4) اختبار أثر الملكية الإدارية علي طبيعة العلاقة بين الثقة الإدارية المفرطة والسلوك غير المتماثل للتكلفة (5)اختبار أثر الملكية الحكومية علي طبيعة العلاقة بين الثقة الإدارية المفرطة والسلوك غير المتماثل للتكلفة (6)اختبار أثر الملكية المؤسسية علي طبيعة العلاقة بين الثقة الإدارية المفرطة والسلوك غير المتماثل للتكلفة.

\section{أولاً: المراجع العربية}

أبو سالم، السيد سالم محمد، 2017، " التأثيرات المباشرة والوسيطة بين حوكمة الثركات، جودة الأرباح، والأداء المالي"، رسالة دكتوراه غير منشورة، كلية التجارة، جامعة الزقازيق.

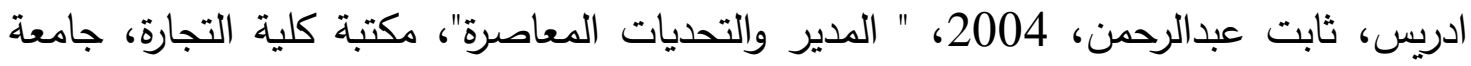

$$
\text { المنوفية. }
$$

الجبوري، مهدي عطية، 2014، " التمويل السلوكي ودوره في القرارات المالية"، مجلة العلوم الانسانية، جامعة بابل.

عفيفي، هلال عبد الفتاح، 2008، "العلاقة بين تطبيق حوكمة الثركات ومستوي الإفصاح بابل

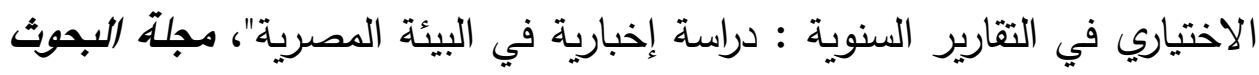

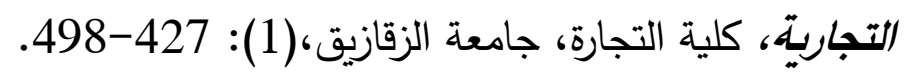

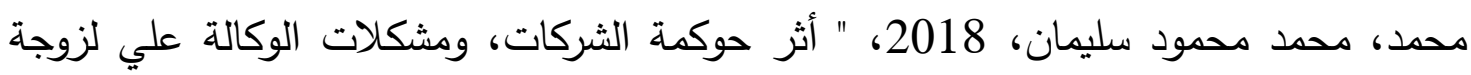

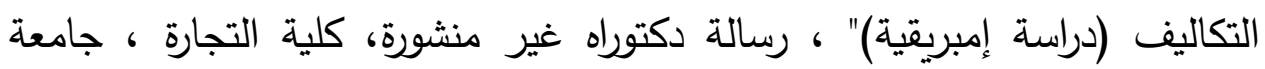
الزقازيق. 
مندور، محد محمد محمد ابراهيم، 2017، " أثر الخطر المالي واتجاه تغير مبيعات الفترة

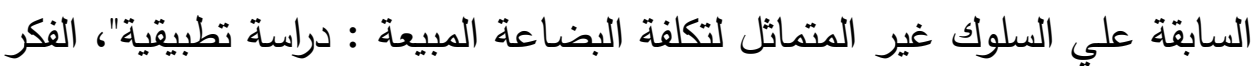

$$
\text { المحاسبي، } 21 \text { (1) : 567-622. }
$$

منطاش، عبد الحميد عبد المنعم عبد الحميد، 2015، " قياس انعكاس التكلفة الثنائية الاتجاه علي دقة مخرجات نظام المحاسبة الإدارية"، رسالة دكتوراه غير منشورة، كلية

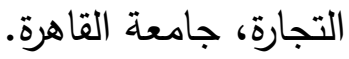

يوسف، أبوبكر محمد أحمد، 2017، "المراجعة الإدارية وتتييم الأداء الإداري"، كلية التجارة، جامعة الزقازيق ثانياً: المراجع الأجنبية

Abdel Aziz, A, M., 2014, " Testing the stickiness behavior of selling, general and administrative expenses in Egyptian corporation: An empirical study ", Un Published Master thesis, Faculty of commerce, zagazig university

Ackert, L. F., and Deaves, R.,2010, "Behavioural finance: psychology, decision making, and markets", South-Western Cengage Learning, Mason.

Ahmed, A. S., and Duellman, S., 2013," Managerial overconfidence and accounting conservatism", Journal of Accounting Research, 51(1): 1-30.

Anderson, M. C., and Banker, R, D., and Janakiraman, S, N., 2003," Are Selling, General, and Administrative Costs "Sticky"?", Journal of Accounting Research, 41 (1): 47-63.

Andriosopoulos, D., Andriosopoulos, k., Hoque, T., 2013, "Information disclosure, CEO overconfidence, and share buyback completion rates", Journal of Banking \& Finance, 37(12) : 5486-5499.

Banker, R, D., Byzalov, D., Ciftci, M., and Mashruwala, R., 2014,"The Moderating Effect of Prior Sales Changes on Asymmetric Cost Behavior", Journal of Management Accounting Research, 26(2).

Banker,R., B, Jin., and M, Mehta., 2013, " CEO Compensation and Cost Structure ", Available at: 
https://www.researchgate.net/publication/256031815 Impact of CEO Compensat ion_Structure_on_Cost_Stickiness

Barone-Adesi, G., Mancini, L., and Shefrin, H., 2012, "A Tale of two investors: Estimating risk aversion, optimism and overconfidence", (Working Paper)

Ben-david, I., Graham, J, R., and Harvey, C. R, 2007, "Managerial Overconfidence and Corporate Policies (No, W13711), Nation Bureau of Economic Research.

Ben-David, I., Graham, J. R., and Harvey, C. R., 2013, "Managerial miscalibration", The Quarterly Journal of Economics, 128(4): 1547-1584.

Berry-Stölzle, T. R., Eastman, E. M., and Xu, J., 2018, "CEO overconfidence and earnings management: Evidence from property-liability insurers' loss reserves", North American Actuarial Journal, 22(3): 380-404.

Brown, R., and Sarma, N.,2007, "CEO overconfidence, CEO dominance and corporate acquisitions", Journal of Economics and Business, 59(5): 358-379

Bruggen, A., and Jense, Z, 2014, " SG\&A Cost Stickiness and Equitybased Executive Compenstation: does Empire Building Matter?", Spinger-Verlag Berlin Heidelberg, 25: 169-192.

Campbell, T. C., Gallmeyer, M., Johnson, S. A., Rutherford, J., and Stanley, B. W., 2011, "CEO optimism and forced turnover", Journal of Financial Economics, 101(3): 695-712.

Chang, S. L., Hwang, L. J., Li, C. A., and Jhou, C. T. , 2018, "Managerial overconfidence and earnings management", International Journal of Organizational Innovation (Online), 10(3): 189-205.

Chang, S., and Hsu, F., 2017, "The Impact of Governance Mechanism and Managerial Overconfidence on the Value of Cash Holdings", International Journal of Economics and Financial Issues, 7(5), 517-529.

Chatterjee, A., Hambrick, D, C., 2007, "It's All about Me: Narcissistic Chief Executive Officers and Their Effects on Company Strategy 
and Performance", Administrative Science Quarterly, 52(3) : 351-386.

Chen, C, X., Gores, T., Nasev, J., Ching and Wu, S., 2018, "CEOs versus CFOs: Managerial Overconfidence and Cost Behavior", AAA 2019 Management Accounting Section (MAS) Meeting. Available at: SSRN: https://ssrn.com/abstract=3233106 or http://dx.doi.org/10 $.2139 /$ ssrn.3233106

Chen, C., X., Gores, T., and Nasev, J., 2013," Managerial Overconfidence and Cost Stickiness, Available at: SSRN: https://ssrn.com/abstract=2208622 or http://dx.doi.org/10.2139/ssrn.2208622

Chen, J.V., Kama, I., and Lehavy, R., 2017, "The Tone of Management Forward Looking Statements and Asymmetric Cost Behavior" Review of Accounting Studies, Available at SSRN: $\underline{\text { https://ssrn.com/abstract=2684164. }}$

Chen, S., Lai, S., Liu, C., and Mcvay, S., 2014," Overconfident Managers and Internal Controls", SSRN Electronic Journal Available at: SSRN: https://ssrn.com/abstract=2510137

DeLong, J. B., Shleifer, A., Summers, L. H., and Waldmann, R. J., 1990, "Noise trader risk in financial markets". Journal of Political Economy, 98(4): 703-738.

Doukas, j, a., and Petmezas, D., 2007,"Acquisitions, Overconfident Managers and Self-attribution Bias", European Financial Manament, 13(3): 531-577.

Duellman, S., Hurwitz, H, and Sun, Y, 2015 "Managerial overconfidence and audit fees", Journal of Contemporary Accounting \& Economics, 11(2) : 148-165.

Fairchild, R., 2009, "Managerial overconfidence, moral hazard problems, and excessive life cycle debt sensitivity", Investment Management and Financial Innovations, 6(3): 35-42.

Ferreira, M. P., 2017, "Overconfidence in Finance: Overview and Trends", In Handbook of Investors' Behavior During Financial Crises (pp. 101-112). Academic Press. 
Gervais, S., Heaton, J. B., and Odean, T., 2011, "Overconfidence, compensation contracts, and capital budgeting", The Journal of Finance, 66(5): 1735-1777.

Goel, A. M., and Thakor, A. V., 2008, "Overconfidence, CEO selection, and corporate governance", The Journal of Finance, 63(6): 27372784.

Habib, A., Hossain, M. and Cahan, S., 2012, "Managerial overconfidence, earnings management and the Global Financial Crisis. In S. Cahan (Ed.)" , Accounting and Finance Association of Australia and New Zealand (AFAANZ) 2012, (pp. 89). Melbourne, Australia, WileyBlackwell Publishing Asia.

Hasanikolavani, Z., and Mahfoozi, G. , 2015, "Investigating the relation between managerial overconfidence and unconditional conservatism in accepted companies in Tehran's stock exchange", International Journal of Review in Life Sciences, 5(7): 128-133.

Hayward, M, L, A., and Hambrick, D, C., 1997," Explaining the premiums paid for large acquisitions: Evidence of CEO hubris", Administrative Science Quarterly, 42(1), 103-127

Hilary, G., and Hsu, C., 2011, "Endogenous Overconfidence in Managerial Forecasts", Journal of Accounting and Economics, 51(3):300-313.

Hirshleifer, D., Low, A., and Teoh, S. H., 2012, "Are overconfident CEOs better innovators?", The Journal of Finance, 67(4), 14571498.

Hoechle, D. , 2007, " Robust standard errors for panel regressions with cross-sectional dependence" Stata Journal, 7(3): 281-312.

Holzhacker, M., Krishnan, R., and Mahlendorf, M. , 2015, "The impact of changes in regulation on cost behavior", Contemporary Accounting Research, 32(2), 534-566.

Hribar, P., and Yang, H, I., 2016, "CEO Overconfidence and Management Forecasting", Contemporary Accounting Research, 33 (1): 204-227. 
Hsu, C., Novoselov, k., and Wang, R., 2017, “ Does Accounting Conservatism Mitigate the Shortcomings of CEO Overconfidence?", The Accounting Review: 92(6): 77-101.

Hur, K., Kim, D., and Cheung, J., 2019, "Managerial Overconfidence and Cost Behavior of R\&D Expenditures", Sustainability. 11. 4878. 10.3390/su11184878

Hwang, K., Cha, M., and Yeo, Y., 2015, " Does managerial overconfidence influence on financial reporting?: The relationship between overinvestment and conditional conservatism", Review of Integrative Business \& Economics Research, 4(1): 273-298.

Kim, H. J. 2016, " The impact of managerial overconfidence and ability on auditor going-concern decisions and auditor termination", working paper. Retrieved from: http://w.batteninstitute.com/uploadedFiles/Kim.pdf.

Kuang, Y., Mohan, A., and Qin, B., 2015, "CEO Overconfidence and Cost Stickiness", (2015). Management Control \& Accounting (2): 26-32.

Langer, E. J., 1975, “ The illusion of control”, Journal of Personality \& Social Psychology, 32(2), 311-328.

Lee, J, 2016, "CEO Overconfidence And The Effectiveness Of Internal Control Over Financial Reporting", The Journal of Applied Business Research,32(1).

Liang, T., and Mo, X., 2017, "Research on the Relationship between Managerial Overconfidence and Corporate $R$ \& D Investment in the Context of Financing Constraints", Open Journal of Business and Management, 5(01):22-33.

Lin, Y., Hu, S., and Chen, M., 2005, "Managerial optimism and corporate investment: Some empirical evidence from Taiwan," Pacific-Basin Finance Journal 13(5), 523-546.

Loughran, T., and McDonald, B., 2011, "When is a liability not a liability? Textual analysis, dictionaries, and 10-Ks", The Journal of Finance, 66 (1): 35-65 
Ma, N. 2008, "Overconfidence - its theory and implications in dispute resolution", ADR Bulletin, 10(4), Article 4. Retrieved from: http://epublications.bond.edu.au/adr/vol10/iss4/4.

Malekvar, H., and Abdoli, M., 2015, " Relationship between Costs Stickiness and Corporate Governance" Bulletin of The Georgian National Academy of Sciences, 9(2): 97-137.

Malmendier, U., and Tate. G., 2008, "Who makes acquisitions? CEO overconfidence and the market's reaction", Journal of Financial Economics 89 (1):20-43.

Margolin, M., 2012, “ Managerial Overconfidence and EducationInsight from Dual Process Theory, Master thesis, University of Mannheim.

McLean, B., and Elkind, P., 2003 "Smartest Guys in the Room: The Amazing Rise and Scandalous Fall of Enron", Penguin Group:New York, NY, USA.

Minggui, Y., Xinping, X., and Zhensong, Z.,2006, “ The relationship between managers' overconfidence and enterprises' radical behavior in incurring debts", Management World, 8, 358-379.

Mitra, S., Jaggi, B., and Al-hayal, T., 2019, "Managerial overconfidence, ability, firm-governance and audit fees", Review of Quantitative Finance and Accounting, 52(3): 841-870.

Moore, D. A., and Schatz, D., 2017, "The three faces of overconfidence", Social and Personality Psychology Compass, 11(8), e12331.

Pallier, G., Wilkinson, R., Danthiir, V., Kleitman, S., Knezevic, G., Stankov, L., and Roberts, R. D., 2002, "The role of individual differences in the accuracy of confidence judgments", Journal of General Psychology, 129(3), 257-299.

Paredes, T. A, 2005, “ Too much pay, too much deference: Behavioral corporate finance, CEOs, and corporate governance", Florida State University Law Review, 32(2): 673-762.

Prosad, J., Kapoor, S., 2015, "Theory of Behavioral Finance", IGI Global book series Advances in Finance, Accounting, and Economics (AFAE) (ISSN: 2327-5677; eISSN: 2327-5685) 
Ramsheh, M., and Molanzari, M., 2014, "Managerial overconfidence and accounting conservatism", Journal of Accounting Knowledge, 5(16): 55-79.

Rawson, C.,2019, "Overconfidence and Proprietary Investment Disclosure" Available at SSRN: https://ssrn.com/abstract=3215395

Russo, J. E., and Schoemaker, P. J., 1992, " Managing overconfidence", Sloan Management Review, 33(2): 7-17.

Schrand, C, M., and Zechman, S, L., 2012, "Executive overconfidence and the slippery slope to financial misreporting" Journal of Accounting and Economics, 53(1): 311-329

Sharto, t., 2011, "The optimism bias", Current Biology, 12(23) : 941945

Weiss, D., 2010, " Cost behavior and analysts' earnings forecasts", the Accounting Review, 85(4): 1441-1471.

zaher, A, M., 2019, "Earnings Management, Accounting Conservatism and Debt Financing: Does Managerial Overconfidence Matter", Bh.D thesis, Faculty of commerce, zagazig university. 


\section{ملحق رقم (1) - مان}

\begin{tabular}{|c|c|c|c|}
\hline القطاع والشركات & r & القطاع والشركات & r \\
\hline قطاع الموارد الأسساسية & & \multicolumn{2}{|l|}{ قطاع الأغذية والمشروبات } \\
\hline قطاع الموارد الأساسبة & 23 & الوطنية لمنتجات الذرة & 1 \\
\hline اسيك للتعدين - اسكوم & 24 & النصر لتصنيع الحاصلات الزراعية & 2 \\
\hline العز الاخيلة للصلب - الاسكندرية & 25 & مطاحن ومخابز الاسكندرية & 3 \\
\hline مصر للالومنيوم & 26 & المصرية لصناعة النشا والجلوكوز & 4 \\
\hline مصر الوطنية للصلب - عتاقة & 27 & مطاحن مصر الوسطي & 5 \\
\hline الورق للشرق الاوسط - سيمو & 28 & الالتا للسكر & 6 \\
\hline العامة لصناعة الورق - راكتا & 29 & المنصورة للاواجن & 7 \\
\hline حديد عز & 30 & القاهرة للاواجن & 8 \\
\hline الحديد والصلب المصريـة & 31 & المصرية للاواجن & 9 \\
\hline الالومنيوم العربية & 32 & الزيوت المستخلصة ومنتجاتها & 10 \\
\hline \multicolumn{2}{|c|}{ قطاع الخدمات والمنتجات الصناعية والسيارات } & مطاحن شرق الدالتا & 11 \\
\hline الثرق الأوسط لصناعة الزجاج & 33 & مطاحن مصر العليا & 12 \\
\hline الكابلات الكهربائية المصرية & 34 & مطاحن وسط وغرب الدلتا & 13 \\
\hline المصرية لخدمات النقل (ايجيترانس) & 35 & القاهرة للزيوت والصابون & 14 \\
\hline الثروق الحديثة للطباعة و التغليف & 36 & العربية لمنتجات الألبان & 15 \\
\hline الاهرام للطباعة و التظليف & 37 & \multicolumn{2}{|c|}{ قطاع الكيماويات } \\
\hline يونيفرسال لصناعة مواد التعبئة والتفليف & 38 & سيدى كرير للبتروكيماويات & 16 \\
\hline دلتا للطباعة والتغليف & 39 & مصر لصناعة الكيماويات & 17 \\
\hline الصناعات الهندسية المعمارية- ايكون & 40 & المالية و الصناعية المصرية & 18 \\
\hline العربية للصناعات الهندسية & 41 & ابوقير للاسمدة والصناعات الكيماوية & 19 \\
\hline النصر لصناعة المحولات - الماكو & 42 & الصناعات الكيماوية المصرية - كيما & 20 \\
\hline الاسكندرية لتداول الحاويات والبضائع & 43 & كفر الزيات للمبيدات والكيماويات & 21 \\
\hline العربية المتحدة للشحن والتفريغ & 44 & سماد مصر (ايجيفرت) & 22 \\
\hline
\end{tabular}




\begin{tabular}{|c|c|c|c|}
\hline القطاع والشركات & s & القطاع و الشركات & p \\
\hline السويس للاسمنت & 66 & \multicolumn{2}{|l|}{ قطاع الرعاية الصحية والأدوية } \\
\hline القومية للاسمنت & 67 & المصرية الدولية للصناعات الدوائية & 45 \\
\hline اسمنت سيناء & 68 & ممفيس للادوية والصناعات الكيماوية & 46 \\
\hline جنوب الوادى للاسمنت & 69 & النيل للادوية والصناعات الكيماوية & 47 \\
\hline الحديثة للمواد العازلة & 70 & العزبية للادوية والصناعات الكيماوية & 48 \\
\hline دلتا للانشاء والتعمير & 71 & القاهرة للادوية والصناعات الكيماوية & 49 \\
\hline شركة النصر للأعمال المدنية & 72 & مستثفى النزهه الدولي & 50 \\
\hline الجيزة العامة للمقاولات والاستثمار & 73 & الاسكندرية للخدمات الطبية & 51 \\
\hline الصعيد العامة للمقاولات والاستثمار & 74 & مينا فارم للأدوية و الصناعات الكيماوية & 52 \\
\hline المصرية لتطوير صناعة البناء & 75 & جلاكسو سميثكلاين & 53 \\
\hline العربية للمحابس & 76 & الاسكندرية للادوية والصناعات الكيماوية & 54 \\
\hline ليسيكو مصر & 77 & 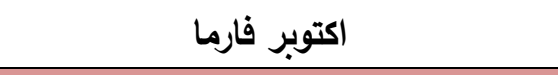 & 55 \\
\hline مصر بنى سويف للاسمنت & 78 & \multicolumn{2}{|l|}{ قطاع المنتجات المنزلية والشخصية } \\
\hline اسمنت بورتلاند طرة المصرية & 79 & العربية لحليج الأقطان & 56 \\
\hline مصر للاسمنت - قنا & 80 & دايس للملابس الجاهزة & 57 \\
\hline \multicolumn{2}{|l|}{ قطاع العقارات } & النيل لحليج الاقطان & 58 \\
\hline المصريين للاسكان والتنمية والتعمير & 81 & النصر للملابس والمنسوجات - كابو & 59 \\
\hline السادس من اكتوبر للتنميه & 82 & النساجون الشرقيون للسجاد & 60 \\
\hline الثمس للاسكان والتعمير & 83 & العامة لمنتجات الخزف والصيني & 61 \\
\hline التعمير والاستشارات الهندسية & 84 & العزبيه وبولفارا للغزل والنسيج & 62 \\
\hline القاهرة للاسكان والتعمير & 85 & الاسكندريـة للفزل وإلنسيج (سبينالكس) & 63 \\
\hline المتحدة للاسكان والتعمير & 86 & جولان تكس للاصواف & 64 \\
\hline مصر الجديدة للاسكان والتعمير & 88 & \multicolumn{2}{|l|}{ قطاع التشييد ومواد البناء } \\
\hline مينا للاستثمار السياحي والعقاري & 89 & روبكس العالميه لتصنيع البلاستيك & 65 \\
\hline
\end{tabular}


الثقة الإدارية والسلوك غير المتماثل

د. محمد سليمان ، د. أحمد بغدادى

\begin{tabular}{|c|c|c|c|}
\hline القطاع والثركات & p & القطاع والثركات & p \\
\hline \multicolumn{2}{|l|}{ قطاع الإعلام والإتصالات والتكنولوجيا } & زهراء المعادي للاستثمار والتعمير & 90 \\
\hline قناة السويس لتوطين التكنولوجيا & 103 & الخليجية الكندية للاستثمار العقاري & 91 \\
\hline راية القابضة للأستثمارات المالية & 104 & مدينة نصر للاسكان والتعمير & 92 \\
\hline \multicolumn{2}{|l|}{ قطاع الغاز والبترول } & العربية لاستصلاح الاراضي & 93 \\
\hline الاسكندرية للزيوت المعدنية & 105 & العالمية للاستثمار والتنمية & 94 \\
\hline مجموعة جى ـ أم ـ سلى للاستثمارات الصناعية & 106 & \multicolumn{2}{|l|}{ قطاع السياحة والترفيه } \\
\hline & & رواد مصر للاستثمار السياحى & 95 \\
\hline & & رواد السياحة - رواد & 96 \\
\hline & & رمكو لانثاء القرى السياحيه & 97 \\
\hline & & بيراميزا للفنادق والقرى السياحية & 98 \\
\hline & & اوراسكوم للتنمية مصر & 99 \\
\hline & & المصرية للمنتجعات السياحية & 100 \\
\hline & & مصر للفنادق & 101 \\
\hline & & عبر المحيطات للسياحه & 102 \\
\hline
\end{tabular}

